Portland State University

PDXScholar

Dissertations and Theses

Dissertations and Theses

Summer 9-9-2019

\title{
Manufacturing in Place: Industrial Preservation in the US
}

Jamaal William Green

Portland State University

Follow this and additional works at: https://pdxscholar.library.pdx.edu/open_access_etds

Part of the Urban Studies Commons

Let us know how access to this document benefits you.

Recommended Citation

Green, Jamaal William, "Manufacturing in Place: Industrial Preservation in the US" (2019). Dissertations and Theses. Paper 5138.

https://doi.org/10.15760/etd.7017

This Dissertation is brought to you for free and open access. It has been accepted for inclusion in Dissertations and Theses by an authorized administrator of PDXScholar. Please contact us if we can make this document more accessible: pdxscholar@pdx.edu. 
Manufacturing in Place: Industrial Preservation in the US

\author{
by \\ Jamaal William Green
}

A dissertation submitted in partial fulfillment of the requirements for the degree of

\author{
Doctor of Philosophy \\ in \\ Urban Studies
}

\title{
Dissertation Committee: \\ Gregory Schrock, Chair \\ Lisa K. Bates \\ Megan Horst \\ Julius McGee
}

Portland State University

2019 
Abstract

In the face of growing economic inequality and population growth, several large cities in the US have started to proactively protect vital industrial lands from conversion to nonindustrial uses. These new policies signal a potentially dramatic shift in both land-use and economic development practices.

In the first essay of this dissertation I present a typology of existing industrial land protective policies after reviewing the comprehensive plans and zoning codes of the United States’ fifty largest cities. I identify 11 cities with protective policies and highlight the variance of these policies by offering a simple two part typology based upon a city's use of increased usage restrictions or greater process requirements for conversion of protected parcels.

The second essay present results of a survey I administered to planners exploring the varied ways that planners understand the pressures facing industrial land in their cities and the political contexts they operate within regarding industrial land policy in their respective cities. I find that planners are generally supportive of industrial land protective policies but are ambivalent about the long term viability of industrial labor in cities and face political pressure to convert industrial land to non-industrial uses.

The final essay presents an evaluation of protective land policies. I estimate a propensity score model measuring the change in manufacturing and broader 'industrial' employment a the census tract level between 2009 and 2015 using LEHD LODES workplace association data. I estimate the propensity score model using a gradient boosted model and 
ultimately find a null effect of protective policies on manufacturing and 'industrial' job growth. 
Table of Contents

Abstract...............................................................

List of Tables.............................................................

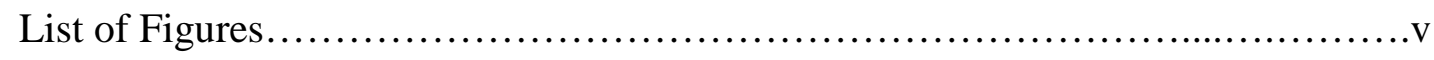

Introduction...........................................................1

Zoning for Jobs-Industrial Land: Preservation in the Nation’s Largest Cities ........10

Planners and Industrial Land: Ongoing Dilemmas and Contradictions.............45

Keeping Space for Jobs: Evaluating Industrial Land Protection Policies............88

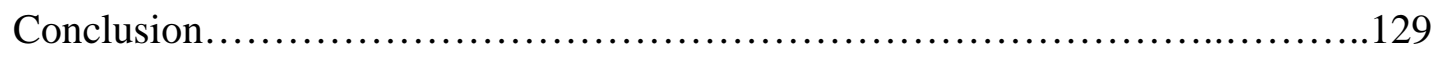


List of Tables

Zoning for Jobs-Industrial Land

Table 1: Cities with Industrial Land Preservation Policies. ...

$\underline{\text { Planners and Industrial Land: Ongoing Dilemmas and Contradictions }}$

Table 1: A Majority of respondents report their cities have industrial land

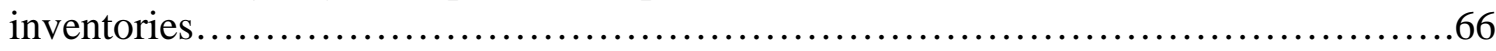

Table 2: Respondents in both types of cities are planning for industrial land..............79

Table 3: Industrial Land Supply Contingency Table.................................80

Table 4: Land Inventory and Protective Policy Contingency Table......................80

Table 5: Greater industrial/manufacturing strategies are found in about half of cities....81

Keeping Space for Jobs: Evaluating Industrial Land Protection Policies

Table 1: Cities with ILP Policies (excludes Chicago and Portland)....................103

Table 2: Independent variables for propensity score model._.......................110

Table 3: Mean Values for Independent Variables..................................112

Table 4: Relative Variable Influence for Manufacturing Employment ATE Propensity

Score Models.............................................................113

Table 5: Relative Variable Influence for Manufacturing Employment ATT Propensity

Score Models............................................................. 113

Table 6: Relative Variable Influence for Industrial Employment ATE Propensity Score

Models...............................................................114

Table 7: Relative Variable Influence for Industrial Employment ATT Propensity Score

Models.................................................................... 114

Table 8: Effect of ILPs on Manufacturing and Industrial Employment Change, 2009-

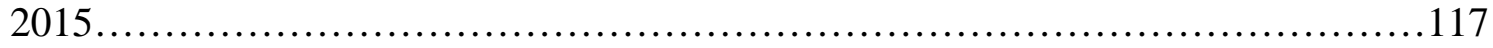


List of Figures

Zoning for Jobs-Industrial Land

Figure 1: Cities with Industrial Land Preservation Policies..........................17

Figure 2: Cities Use a Combination of Use Restrictions and Additional Process

Requirements............................................................. 20

Figure 3: MIZOD Coverage in Baltimore....................................36

Figure 4: Portland Industrial Sanctuary Coverage..................................37

$\underline{\text { Planners and Industrial Land: Ongoing Dilemmas and Contradictions }}$

Figure 1: Survey Respondent Cities..........................................61

Figure 2: Respondents are Primarily from Planning Departments....................62

Figure 3: Planners believe their cities have adequate industrial land supplies...........65

Figure 4: Respondents reported their cities performed inventories primarily since

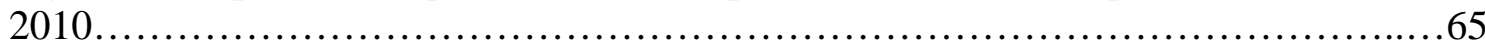

Figure 5: Urban manufacturing is an important part of cities' economic development

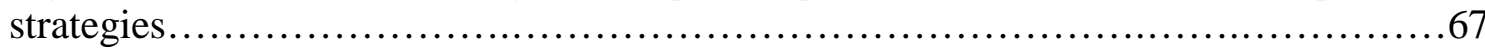

Figure 6: Respondents report industrial land preservation matters for urban manufacturing strategies................................................68

Figure 7: Respondents largely agree that planning officials think industrial land preservation is important..

Figure 8: Respondents report planning officials in their city think manufacturing will continue to lose jobs.

Figure 9: Respondents see urban/industrial employment as key source of traded goods

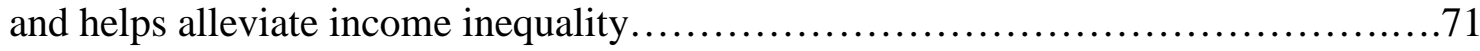

Figure 10: Respondents largely agree that manufacturing/industrial jobs are sustainable.

Figure 11: Economic Development and Redevelopment Agencies are responsible for

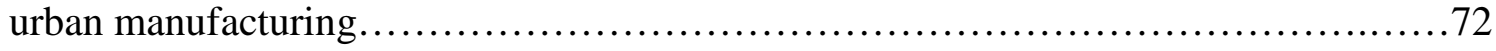

Figure 12: Respondents report planners face political pressure to convert..............73

Figure 13: Some community groups are organized to protect industrial land...........74 
Keeping Space for Jobs: Evaluating Industrial Land Protection Policies

Figure 1: Change in manufacturing employment for the nation's largest cities..............96

Figure 2: Most Large US Cities had at least 25,000 manufacturing jobs................98

Figure 3: Wichita and San Jose lead large cities in the percentage share of jobs in

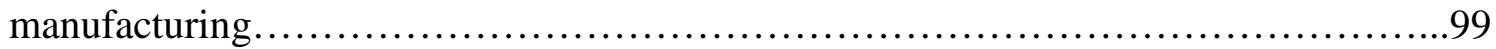

Figure 4: 'Industrial' employment is growing in nearly a quarter of large US cities.....100

Figure 5: Industrial Job Share of Total Employment, 2015.........................101

Figure 6: Variable Balance for Manufacturing Models..............................118

Figure 7: Variable Balance for 'Industrial’ Models..................................119

\section{Supplemental Figures}

Figure 8: Population Density Distribution..................................121

Figure 9: Vacant Units by Protection Policy.......................................121

Figure 10: Renter Occupied Units by Protection Policy............................122

Figure 11: Logged Jobs-to-Population Ration by Protection Policy...................122

Figure 12: Manufacturing Employment Share by Protection Policy.................123

Figure 13: Industrial Employment share by Protection Policy $. . . \ldots \ldots \ldots \ldots \ldots \ldots \ldots \ldots . . . \ldots \ldots$

Figure 14: FIRE Employment Share by Protection Policy..........................124

Figure 15: Retail Employment share by Protection Policy.........................124

Figure 16: Road Network Density by Protection Policy ...........................125

Figure 17: Distance to City Center by Protection Policy............................125 
Introduction

The US is nearly a decade into an urban revival characterized by the return of predominately white middle class residents to central cities. Combined with a strong national economy, growing cities have burgeoning populations, relatively low unemployment rates and growing political and cultural salience. But the distribution of the benefits of this re-urbanization of the population is uneven.

Urban economies today are stronger than they have been in decades and traditionally marginalized groups, such as African-Americans, have record low unemployment rates (Fox 2018). But still income and wealth inequality remain stubbornly high between an increasingly affluent, highly educated service class and workers whose jobs are built around serving them. One reason for this stubborn inequality in the face of general economic growth is the hollowing out of traditionally middle waged jobs throughout the country, but especially our cities. In a recent working paper, David Autor (2019) connects the falling real wages of non-college educated workers in urban areas to the loss of skilled jobs available to non-college educated workers.

Beyond the observation that job polarization exists, Autor observes that polarization is relatively more intense in urban areas due to greater industrial restructuring over the past four decades. Namely, the exit of manufacturing/production industries out of central cities and the growing clustering of knowledge-intensive firms within urban areas. This pattern combined with the dramatic drops in unionized firms, the rise of precarious work and job loss to globalized competition results in cities that no longer offer the traditional wage 
premiums less educated workers enjoyed in the past (Kalleberg 2011; Mouw and Kalleberg 2010; Doussard and Schrock 2012).

A central concern for economic development planners, then, is what policy options are available to address this deepening wage inequality. One straightforward approach is to mandate higher wages at the bottom of the labor market through mandating increased minimum wages. Some cities have done this through passing living wage ordinances and advocating for increased minimum wages at the state level, but both of these options are political fraught. Therefore, cities that are not able or are unwilling to engage in direct labor interventions but are still concerned about rising wage inequality and falling opportunity for their residents must look at industrial policy- particularly industrial retention policy.

But one could reasonably ask why the focus on manufacturing/industrial jobs at all? Do we not live in a "post-industrial" economy, especially in our cities? The answers to these questions offer some mixed conclusions, but one thing is clear. Manufacturing and industrial work has not disappeared from the US, as a whole, and has also not disappeared from our large central cities. In fact, one could argue that the modest recovery in manufacturing/industrial employment seen in the past decade, and the future of more advanced industrial operations is decidedly urban. In a series on the "renaissance" of manufacturing in the US in the early 2010s, the New York Times profiled a variety of manufacturing plants that were flourishing in the immediate aftermath of the great recession. One piece focused on a textile manufacturing operation in Minneapolis suffering from an acute worker shortage that was actively involved in both private and 
public training programs (Clifford 2013a). Similar articles at the time noted that specific industries, particularly in energy were seeding contemporary manufacturing and industrial booms while other articles highlighted the role of equalized labor costs, supply chain costs and intellectual property protection as major reasons for firms to relocate production back to the US (“America’s New Manufacturing Boomtowns,” n.d.; Clifford 2013b).

Beyond reshoring, academic researchers in regional studies, geography and business have explored the ways that contemporary advanced manufacturing benefits from locating in urban areas. Van Winden et al (2010) note that advanced manufacturing that requires quick prototyping, a mix of traditional fabrication with more advanced design and research skills, necessarily requires that firms locate in urban areas to take advantage of their naturally thick labor markets and agglomeration benefits. More recent work in economic development and regional studies tie healthy manufacturing employment and ecosystems to greater regional economic resilience and innovation (Doussard, Schrock, and Lester 2016; Lowe and Wolf-Powers 2017). These studies all point towards greater generalized benefits of manufacturing for regional growth and development and offer compelling reasons for working to keep and grow industrial work in our cities and metropolitan regions.

In addition to questions of re-shoring and the role of manufacturing/industrial work to regional innovation, another reason to focus on manufacturing/industrial work is that these jobs remain better, in terms of quality, for workers lacking advanced degrees. A 2015 report from the Economics and Statistics Administration, using 2013 data from ten different federal data sources, finds that manufacturing jobs maintain a pay premium over 
equivalent jobs in the rest of the private sector (Nicholson and Powers 2015). The size of the premium ranges widely from $12-32 \%$ depending on the definition of worker and job type, but a premium persists across all combinations. For policymakers and researchers concerned about income inequality and access to greater benefits, industrial jobs remain a prime target for improving the prospects of workers.

Even with these stylized facts and favorable trends, critics may still contend that manufacturing/industrial work is dying and is inherently incompatible with contemporary cities in the US. Employment numbers belie this convention wisdom though. Calculating the change in manufacturing, and broader, industrial employment for some of the largest cities in the US from 2004-2015, I find that many cities are indeed losing manufacturing employment but a minority have seen robust manufacturing employment growth and a plurality of cities have had robust industrial job growth beyond manufacturing. In fact, if you track broader "industrial” sectors, including agricultural, mining, utilities, wholesale trade and transportation industries, 21 of the 47 cities in my sample had greater industrial employment in 2015 than they had in 2004. These results point towards some existing complications in how we understand manufacturing/industrial employment, generally, but especially for cities. First, manufacturing has indeed dropped in many cities, but focusing only on manufacturing blinds policymakers to the many different users of industrial lands and additional sources of productivity and work. Second, industrial work is growing in many cities and it is unclear whether planners and policymakers are truly aware of the durability of these industries. 
Industrial retention through land use policy is the subject of this dissertation. Urban labor markets are becoming more unequal even as urban areas grow and one consequence of this growth that accelerates the kind of occupational polarization that economists, sociologists and geographers have tracked for years now. But a major gap in the explanations regarding job polarization in cities is the role of land use policy in accelerating deindustrialization. Recent economic development research has highlighted the role that cities play in chasing out industrial firms by encouraging the development of industrial buildings to nonindustrial uses, particularly residential uses (Leigh and Hoelzel 2012; Curran 2010; Lester, Kaza, and Kirk 2013; Chapple 2014). The basic conclusions of these papers is that there is a significant endogenous component of urban deindustrialization that has been ignored and that local policy decisions have very real labor market repercussions.

In recent years, a handful of large cities in the US have passed industrial land protection policies for the express purpose of keeping family wage jobs in their cities. Whether through passing new zoning ordinances or setting policy in their comprehensive plans these cities are part of a novel experiment at the intersection of land use and economic development policy for the purpose of industrial retention. But, to date, the details regarding scope of these policies, the effect these policies have on planning practice and their ultimate effectiveness in protecting industrial jobs have been unanswered. It is these three issues that this dissertation will explore in the following essays.

In my first essay, “Zoning for Jobs- Industrial Land Preservation Policy in the Nation’s Largest Cities”, I track the adoption of industrial land protection policies in the US's 
largest cities. In order to do so I conducted a content analysis of the zoning codes and comprehensive plans of the fifty largest cities in the US. I present a simple typology of the protective policies separated into increased use restrictions or greater process requirements. I then use this typology to highlight the different approaches each city uses to implement their respective policies.

The second essay will cover how planners understand the industrial land situations in their cities and what that ultimately means for planning practice. Scholars such as Wolf-Powers (2005) and Curran (2005) have highlighted how individual planners’ perceptions of the viability of industrial work in the future influences their decisions regarding industrial land management. Succinctly, if planners perceive that industrial work is obsolete or dying, then they will support land use decisions to displace existing industrial users even if those users, and their respective districts, are healthy. In order to gain a better understanding of how planners perceive the value of industrial land in their cities my second essay presents the results of a survey of planners in the nation's largest cities. In the survey planners provide insight into how they personally view industrial land, the extent of the industrial land pressures in their cities and the greater political context they work within with respect to making decisions regarding industrial land conversion.

Ultimately, this essay highlights the multiple dilemmas planners face regarding industrial land decisions as they are connected to potentially conflicting goals regarding real-estate development, local labor market change and greater economic development.

The final essay is an evaluation of the jobs impact of these new protective policies. Using the Longitudinal Household-Employer Dynamics Workplace Association File (LEHD 
WAC) dataset collected with an R package I wrote, I present the broad changes in manufacturing and greater industrial employment in the nations 45 largest cities from 2005 to 2015. I use a quasi-experimental method, propensity score weighting using gradient boosted score modeling, to estimate the causal effect of industrial land protective policies on manufacturing and industrial job change between 2009 and 2015 (Rosenbaum and Rubin 1983; Ridgeway et al. 2017).

Industrial land may seem an obscure subject of study, but questions regarding industrial land management play a major role in how cities’ labor markets have changed over time, represent a potential bridge between the traditionally separate economic development and is an area where progressive economic development planners can test industrial retention policies at the urban scale. I deliberately focus upon large cities in this dissertation for a variety of reasons. First, they are major employment centers in their respective states with diverse economies. Smaller suburbs or rural areas may tend to be dominated by single industries or, in extreme cases, single firms that make analysis more difficult. Second, it is in these large cities where we find the most dramatic re-urbanization of people and businesses that seed the conversion of industrial lands to non-industrial uses over time. It is taken as common knowledge that industrial employment that has remained in the US has often moved to more rural areas, but large cities still have rich industrial ecosystems that are under active threat. And finally, these are the places that are experimenting with the kinds of protective policies I am interested in. These policies require relatively sophisticated and well supported planning staffs that are not normally found in smaller areas. Focusing on large city industrial land policy, then, allows planners to examine 
greater issues of economic restructuring, planning practice and inequality in a unique way

that cannot be duplicated easily in other areas.

\section{References}

“America’s New Manufacturing Boomtowns.” n.d. Forbes.

http://www.forbes.com/sites/joelkotkin/20 manufacturing-boomtowns/.

Autor, David. 2019. “Work of the Past, Work of the Future.” w25588. Cambridge, MA:

National Bureau of Economic Research. doi:10.3386/w25588.

Chapple, Karen. 2014. “The Highest and Best Use? Urban Industrial Land and Job Creation.” Economic Development Quarterly, August, 0891242413517134.

doi:10.1177/0891242413517134.

Clifford, Stephanie. 2013a. “A Wave of Sewing Jobs as Orders Pile up at U.S.

Factories.” The New York Times, September.

— 2013b. "U.S. Textile Plants Return, with Floors Largely Empty of People.” The New York Times, September.

Curran, Winifred. 2010. "In Defense of Old Industrial Spaces: Manufacturing, Creativity and Innovation in Williamsburg, Brooklyn.” International Journal of Urban and Regional Research 34 (4): 871-85. doi:10.1111/j.14682427.2010.00915.x.

Curran, Winifred, and Susan Hanson. 2005. "Getting Globalized: Urban Policy and Industrial Displacement in Williamsburg, Brooklyn.” Urban Geography 26

(6): 461-82. doi:10.2747/0272-3638.26.6.461.

Doussard, Marc, and Greg Schrock. 2012. “Post-Industrial Restructuring?” Progressive Planning, no. 190: 40-42.

Doussard, Marc, Greg Schrock, and T. William Lester. 2016. "Did US Regions with Manufacturing Design Generate More Production Jobs in the 2000s? New Evidence on Innovation and Regional Development." Urban Studies, September, 0042098016663835. doi:10.1177/0042098016663835.

Fox, Justin. 2018. “Black Unemployment Is at an All-Time Low, but ...” May.

Kalleberg, Arne L. 2011. Good Jobs, Bad Jobs: The Rise of Polarized and Precarious Employment Systems in the United States, 1970s-2000s. Russell Sage Foundation.

Leigh, Nancey Green, and Nathanael Z. Hoelzel. 2012. “Smart Growth’s Blind Side: Sustainable Cities Need Productive Urban Industrial Land.” Journal of the American Planning Association 78 (1): 87-103. doi:10.1080/01944363.2011.645274.

Lester, Thomas W., Nikhil Kaza, and Sarah Kirk. 2013. "Making Room for Manufacturing: Understanding Industrial Land Conversion in Cities.” Journal of the American Planning Association 79 (4): 295-313. doi:10.1080/01944363.2014.915369. 
Lowe, Nichola J., and Laura Wolf-Powers. 2017. "Who Works in a Working Region? Inclusive Innovation in the New Manufacturing Economy.” Regional Studies, January, 1-13. doi:10.1080/00343404.2016.1263386.

Mouw, Ted, and Arne L. Kalleberg. 2010. "Occupations and the Structure of Wage Inequality in the United States, 1980s to 2000s.” American Sociological Review 75 (3): 402-31. doi:10.1177/0003122410363564.

Nicholson, Jessica R., and Regina Powers. 2015. “The Pay Premium for Manufacturing Workers as Measured by Federal Statistics.” ESA Issue Brief 0515. Washington DC: US Department of Commerce, Economics and Statistics Administration.

Ridgeway, Greg, Dan McCaffrey, Andrew R. Morral, Beth Ann Griffin, and Lane Burgette. 2017. "Twang: Toolkit for Weighting and Analysis of Nonequivalent Groups.”

Rosenbaum, Paul R., and Donald B. Rubin. 1983. "The Central Role of the Propensity Score in Observational Studies for Causal Effects.” Biometrika 70 (1): 41-55. doi:10.1093/biomet/70.1.41.

Van Winden, Willem, Leo Van den Berg, Luis Carvalho, and Erwin Van Tuijl. 2010. Manufacturing in the New Urban Economy. Vol. 42. Taylor \& Francis US.

Wolf-Powers, Laura. 2005. “Up-Zoning New York City’s Mixed-Use Neighborhoods Property-Led Economic Development and the Anatomy of a Planning Dilemma.” Journal of Planning Education and Research 24 (4): 379-93. doi:10.1177/0739456X04270125. 
Zoning for Jobs-Industrial Land: Preservation in the Nation’s Largest Cities Introduction

Several of the nation's largest cities are engaging in a new set of land-use policies designed to protect industrial land from conversion and encroachment. These policies signal a growing realization of the strategic importance of industrial land reserves and a rejection of the conventional wisdom and economic dictate that land should always be allotted to its "highest and best use". A central conflict in many cities concerns the future uses of industrially zoned land (particularly more centrally located industrial districts that are most attractive to residential and commercial developers). The arguments for conversion range from economic efficiency claims (land should be allowed to develop to its highest use), environmental (industrial activities do not belong in cities because they are polluting) or strategic concerning past and current de-industrialization (Rast 2001; N. G. Leigh and Hoelzel 2012; Wolf-Powers 2005; Lester, Kaza, and Kirk 2013; Jonas, Gibbs, and While 2011). In response to this research, and a growing realization by practicing planners that the loss of industrial land is a crisis in many cities, the American Planning Association recently released a policy guide offering instructions for cities that wish to grow their industrial workforce (N. Leigh et al. 2014). A consistent message in these studies is that industrial land should be protected and that cities should pass additional protections in order to guarantee such lands will be used for jobs production in the future. While these studies highlight the problem of industrial land conversion and offer guidance to address 
it, no one study has yet done a more systematic survey of already-existing industrial land preservation policies.

In this study, I review the industrial land-use policies of the nation's fifty largest cities (according to their total populations in 2012) in order to see to what extent industry preservation policy is actually used.

I find eleven of the nation's fifty largest cities have some form of industrial land preservation policy (ILP). Cities with protective policies largely use two different strategies for protection- increased use restrictions and/or a more burdensome review process.

The paper continues first with a background section exploring the politicaleconomic context that encourages cities to convert industrial land, planning's response, or lack thereof, to shrinking industrial land bases, and the importance of industrial land in urban economic development. Next a methodology section describes my identification strategy and a description of the data sources used. The results section offers a brief description of each city's industrial preservation policy classifying each one on the based upon their adding new use restrictions and/or intensifying the process necessary to convert parcels from non-industrial uses.

\section{Background}

A central motivation for this paper and the greater issue of industrial land conversion why do cities convert scarce industrial land at all? The planning and urban affairs literature 
offer the following explanations: first, the current political-economy of cities encourages industrial land conversion; second, a change in the mode of planning from a more strategic to entrepreneurial approach; and planning policy priorities actively encourage conversion. Recent planning research, though, has started to focus upon questions of the role of industrial land in local labor market change and city-regional business dynamics and finds that industrial land is more important to local economic development than commonly assumed.

\section{Local Politics and City-led De-industrialization}

The conversion of industrial land in many cities is a direct application of a more entrepreneurial planning approach that prioritizes immediate fiscal concerns over alternative strategic outcomes such as increasing employment or bolstering local innovation. Harvey (1989) broadly describes this entrepreneurial shift as a response to the collapse of cities’ finances throughout the 1970s and early 1980s. In response to the fiscal collapse of many large cities in the 1970s, the federal government also curtailed or eliminated funding and programs for many cities. As a response, cities took on a more entrepreneurial set of strategies where economic growth and the bolstering of property tax rolls became paramount. In the US, city governments primary strategies, then, were real estate development. This focus lead to a greater focus on individual projects and a concomitant abandonment of more comprehensive or strategic approaches to development. 
In a series of articles covering both US and UK cities, Susan Fainstein offers a closer analysis of the entrepreneurial turn Harvey describes. One example, a 1987 piece, Fainstein and Fainstein highlight how the hard economic restructuring of the late 70s and early 1980s encouraged the city to undergo massive redevelopment schemes (N. I. Fainstein and Fainstein 1987). But while the city faced intense economic pressures, the redevelopment projects the city pushed were largely divorced from greater strategic considerations, including but not limited to: concerns over commercial or residential gentrification of low income and working class neighborhoods; and the health of local manufacturers who feared increasing residential and commercial encroachment. The projects were not only singularly focused on maximizing real estate returns and accommodating a service-based economy, but the city institutions tasked with carrying them out were city and state development corporations lead by private development groups. In those cases, land use planners, and the traditional planning bodies, were systematically excluded.

The ultimate result, for industrial users, at least, is that US cities aggressively convert industrial lands for non-industrial uses even if those lands are already occupied and have healthy industrial firms. This happens because of cities' focus on maximizing real estate returns but also due to legitimate concerns about the future economic structure of cities. Wolf-Powers (2005) highlights this dilemma by showing how planners' beliefs about a neighborhood's future economic structure can encourage the actively destroy the existing economic structure. Curran’s (2010; 2007; 2004) pieces on gentrification in Brooklyn offer a parallel view of how visions of a service-based economy and amenity-driven real 
estate strategy further exacerbate economic restructuring and show that such restructuring is not totally exogenous but also encouraged by local policy.

\section{$\underline{\text { Smart Growth and Industrial Development }}$}

Beyond their political-economic context cities are also encouraged to convert industrial land by policy consensus. The predominate planning policy approach of the past thirty years- Smart Growth- recommends a land-use policy that is, at best, indifferent to industrial land provision and, at worst, actively encourages cities to dispose of their industrial land due to assumed obsolescence and environmental concerns. Leigh and Hoelzel (2012) review Smart Growth manuals and policies across the country and find that Smart Growth policies largely frame industrial land as a drag on local economies and sources of environmental contamination. In response, they note the myriad uses industrial land has in addition to local fiscal priorities and private sector employment including, but not limited to: space for public vehicles and infrastructure such as transit agency garages; limiting further job sprawl and spatial mismatch between workers and job locations; and creating more resilient, innovative local economies by having a true mix of industries present in our cities (N. G. Leigh and Hoelzel 2012).

Leigh and Hoelzel highlight an emerging policy concern for cities now aware of impending industrial land shortages and a lack of widely accepted policy guidance that more explicitly links land-use with strategic economic concerns that respect the whole labor market. The American Planning Association has stepped into the conceptual and policy gap here offering a guide, published by Leigh and others, called Sustainable 
Industrial Development that frames industrial land as a strategic asset that must be managed if cities are to maintain operations as well as provide space for economic growth and development (N. Leigh et al. 2014). The argument for better management of industrial lands is made even more forcefully in 2012 Transportation Research Board report on the vulnerable freight infrastructure in our city-regions. In a review, the study group found that freight planning in the US failed due to a combination of the following reasons:

- The federal government has a scattered approach to freight planning with responsibility spread over multiple agencies;

- Local and regional governments primarily responsible for land use did not include freight related matters in comprehensive plans nor did they have freight-specific zoning regulations;

- Local authorities lacked basic freight information that would allow them to informatively plan for freight users in the first place;

- Freight stakeholders typically did not participate in local or regional planning projects;

- Local jurisdictions have financial incentive to rezone freight areas for more intensive uses (Transportation Research Board and National Cooperative Freight Research Program 2012, 28-29).

The ultimate result of the improper, or lack of, management of industrial lands in cities could have long term repercussions to greater regional, or even national, economic competitiveness and prosperity. Cities, then, must have a better understanding of the value of their different land uses, particularly industrial lands.

Methodology and Data

This study is a content and descriptive analysis of land-use policies (both zoning codes and comprehensive plans) of the US's fifty largest cities, by population, in 2012 according 
to the US Census Bureau. I collected policies from each city by perusing their latest zoning codes, comprehensive plans and economic development websites. I decided upon identifying separate and distinct policies as recent studies show that cities that do adopt industrial preservation policies often designate protected districts as opposed to increasing protections on all existing manufacturing land (N. G. Leigh and Hoelzel 2012; N. Leigh et al. 2014). Secondly, Green-Leigh and Hoelzel (2012) highlight the importance of discourse surrounding industrial land and moving from a deficit or nuisance frame to one of an asset. I coded potential industrial preservation policies on two criteria, the first functional and the second more discursive:

1. The code is distinct and protective- The code is new/novel in addition to the standard manufacturing zones and lists a stronger set of protections or limitations on uses of the land than is found in the standard codes

2. Industrial Land is an asset- The code does not frame industrial land as a nuisance but as an asset that is important for the local economy/job base. Though not used to identify codes, I also marked what kinds of additional restrictions were required (residential, commercial, retail, restaurants, healthcare sites, day cares, primary/secondary educational institutions, and public buildings).

Additionally, in cities where I identified ILP policies, I attempted to code whether or not the listed policy required additional review compared to the standard zoning code and at what levels that review is made. For example, applications for rezoning protected industrial lands in Minneapolis trigger a comprehensive plan amendment process that requires both city and regional review.

An archetypal example of the kind of policy language I looked is the stated purpose of Chicago’s Planned Manufacturing District ordinance (City of Chicago 1988): 
" 17-6-0401-A Purpose. The "PMD”, planned manufacturing district zoning classification is intended to:

1. foster the city's industrial base; 2 . maintain the city's diversified economy for the general welfare of its citizens; 3. strengthen existing manufacturing areas that are suitable in size, location and character and which the City Council deems may benefit from designation as a PMD; 4. encourage industrial investment, modernization, and expansion by providing for stable and predictable industrial environments; and 5. help plan and direct programs and initiatives to promote growth and development of the city's industrial employment base."

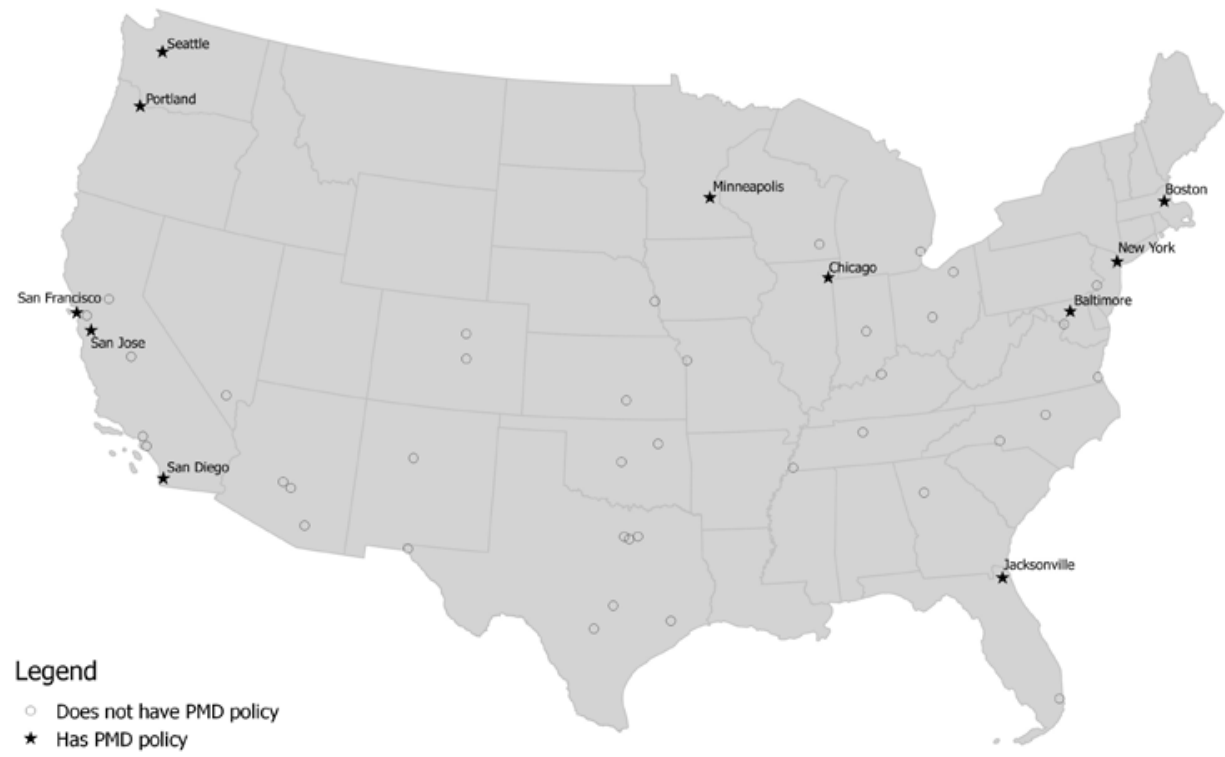

Figure 1: Cities with Industrial Land Preservation Policies

Chicago’s PMD ordinance demonstrates the asset-based view of industrial land well as well as explicitly linking the preservation of industrial land with zoning to greater planning priorities. In terms of use, PMD review requires prospective developers to estimate the 
impact on surrounding industrial users explicitly in filing for a rezoning as part of the review. This extra layer of review and impact assessment act as an effective barrier to industrial parcel conversion.

In order to better organize the identified policies I categorized them into two groups: usebased and process-based. As mentioned above, policies can draw on some combination of greater use restrictions, more burdensome process or some combination therein. This broad differentiation allows me to offer a taxonomy of industrial preservation policies.

Results

Industrial land preservation zoning is more common across the nation's largest cities than many would assume based on the coding criteria. Eleven of the nation's largest cities have some variant of industrial preservation/conservation zoning. These eleven cities held eighteen million people in 2012, and while they are geographically dispersed, industrial preservation zoning is concentrated in West Coast cities from San Diego to Seattle. While diverse, some common features of these cities are not only historical, but current dependence on industrial employment, and a mix of growth management issues. Cities such as San Francisco, San Diego or New York have famously expensive real estate markets and relatively consistent population growth that exacerbate already tight housing markets. Conversely, a city like Baltimore stands in contrast as its population growth has been relatively flat to falling, but it does have very specific speculative real estate pressure on harbor land. As a result, Baltimore business interests acted early to protect one of the valorized places in a largely declining city. 
Table 1: Cities with Industrial Land Preservation Policies

\begin{tabular}{lllr}
\hline City & State & Population 2012 & Policy Passed \\
\hline New York & NY & $8,199,221$ & 2005 \\
Chicago & IL & $2,714,856$ & 1988 \\
San Diego & CA & $1,338,348$ & 2008 \\
Jacksonville & FL & 836,507 & 2007 \\
San Francisco & CA & 825,863 & 2008 \\
Boston & MA & 636,479 & 1978 \\
Seattle & WA & 634,535 & 2002 \\
Baltimore & MD & 621,342 & 2004 \\
Portland & OR & 603,106 & 1988 \\
San Jose & CA & 982,765 & 2007 \\
Minneapolis & MN & 392,880 & 2009 \\
\hline
\end{tabular}

\section{$\underline{\text { Code Differences }}$}

While each city has their own unique implementation of protective codes their variation can be divided into two broad categories: increased use restrictions and more burdensome process rules. Use rules refer to the actual allowed uses listed by the city within the zones of interest. For example, Chicago's 


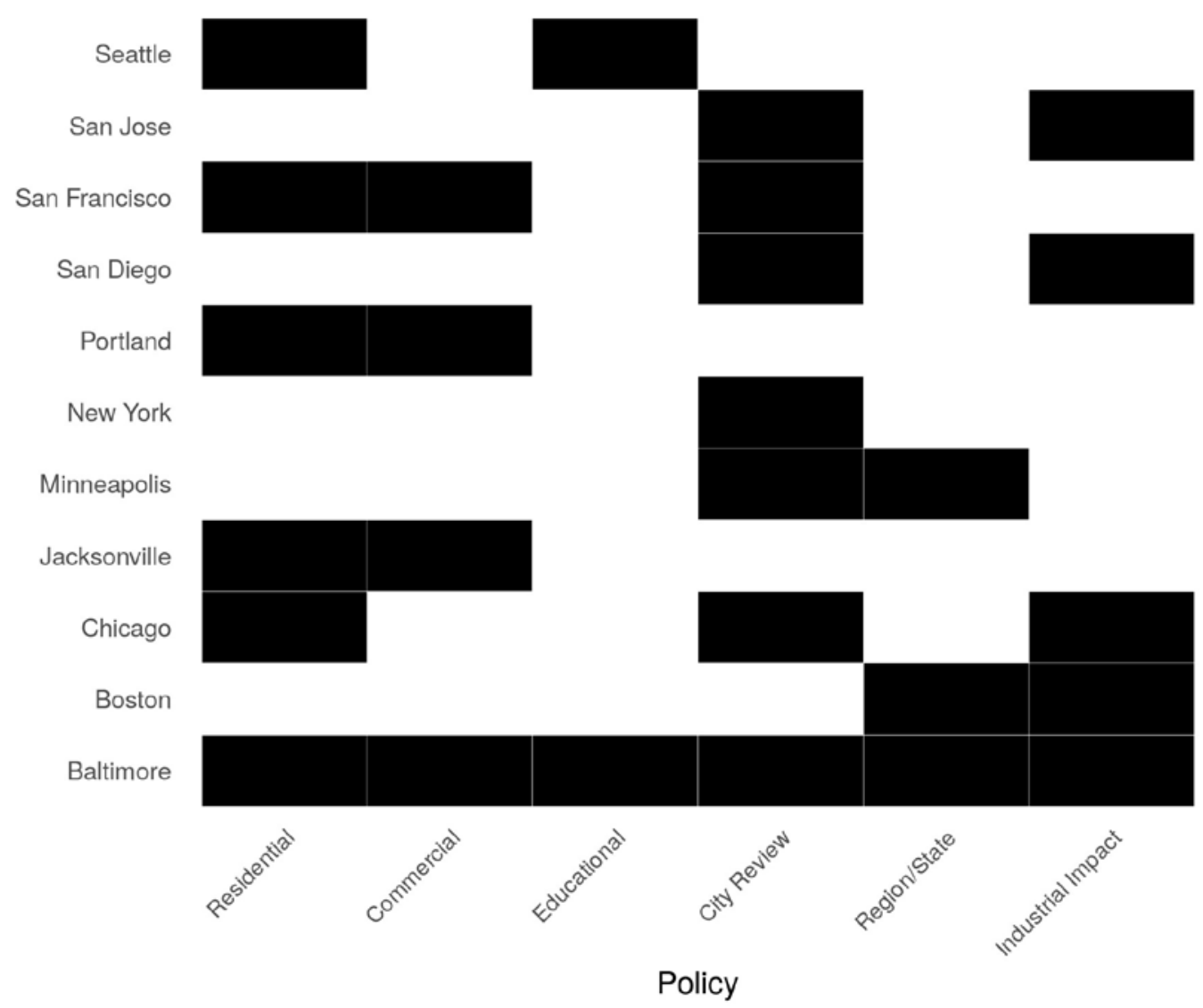

Figure 2: Cities Use a Combination of Use Restrictions and Additional Process Requirements

Planned Manufacturing Districts (PMDs) have a blanket ban on residential uses, whereas the city's other industrially zoned districts may allow some forms of residential development on a conditional basis. Process rules refer to the necessary steps a developer or property owner must take in applying for a re-zoning in a protected area. Again using Chicago as an example, for prospective re-zonings of buildings within PMDs the city's Zoning Board of Appeals are supposed to take multiple potential impacts into account such as the impact on neighboring industrial users, the current neighborhood job market, and potential local real estate impacts. In this sense, Chicago's PMDs use a combination of both increased use restrictions and multiple additional process requirements. 
The following sections provide a description of each city's policy followed by a more general exploration of the shared and distinctive features of protective policies.

\section{Chicago}

Chicago is probably the archetypal case of industrial land protection in the US. As mentioned above, the city has both stronger use restrictions compared to the city's standard industrial districts, as well as, additional process requirements. Chicago’s PMDs are very restrictive in terms of appropriate uses compared to standard industrial zones in the city. Residential development is banned outright and PMDs, generally, do not allow outdoor agricultural uses or consumer financing establishments. Additional use restrictions exist for particular PMDs are spelled out in their supplemental use regulations. One example of this is that light equipment sales (boats and motorcycles) is prohibited in ten PMDs and allowed, to varied extents, in the other five.

In terms of process, the city's Zoning Board of Appeals must answer a series of questions regarding the potential impact of a rezoning including, but not necessarily limited to: current industrial uses adjacent to the site and the potential for nuisance complaints if a rezoning is approved; the current job market in the district and potential jobs impact of the new development, the kinds of jobs currently available in the district; the potential effects of the redevelopment on surrounding property values; traffic impacts; and whether there have been past attempts to market the property to an industrial user. Additionally, the PMD process subverts Chicago's aldermanic privilege rules removing a major potential barrier to local industrial protection. 


\section{San Diego}

San Diego’s Prime Industrial Lands (PILs) are identified in its latest comprehensive plan, are managed at the community planning level, and depends primarily upon process rules to protect industrial lands. PILs are areas that were already zoned for industrial use and were identified by the city and the responsible planning areas as holding especially vital land and are targeted for protection and expansion of industrial uses. Of particular concern for planners when initially deciding on PILs were identifying locations of strategic importance to the city's large, and growing, logistics and transport industries. For all proposed developments San Diego requires a lengthy set of impact statements, including but not limited to: traffic; environmental; and health impact studies. Proposed developments in a PIL require an additional impact statement concerning the impact of the development on the availability of prime industrial land supply and as well as the overall industrial employment viability of the PIL were the development approved. Once those impact statements are written they are then submitted to the local community planning area group, if approved, the application is submitted to the city Planning Commission, and, finally, to the City Council for final approval. The result is a rigorous three-stage process that all proposed developments must pass but with the addition of a PIL specific impact statement.

\section{Baltimore}


Baltimore's Maritime Industrial Districts (MIDs) are designed to protect and maintain deep water frontage for the Port of Baltimore's industrial uses. MIDs have both much more increased restrictions and additional process requirements compared to the city's other industrial zones.

MIDs are much more restrictive than other industrial districts in the city. MIDs ban all residential uses and even limit multiple institutional uses such as hospitals and certain kinds of schools. Additionally, MIDs do not allow for certain kinds of open space uses like parks and forbids nearly all commercial uses that do not directly support maritime industrial customers. MIDs even prohibit some industrial uses in favor of prioritizing maritime uses explicitly.

Similarly to San Diego, Baltimore also has multiple criteria proposed developments in MIDs must meet in order to be approved (City of Baltimore 2017, 123):

1. The proposed rezoning conforms with the goals of the city's master plan

2. The proposed development would not limit access into or out of the district

3. The development would not encourage or cause the loss of deepwater assets in the district

4. Would not negatively impact adjacent industrial users who must now contend with non-industrial neighbors

5. Would not reduce or impede future economic development and growth of maritime industry within the district

6. Would have an appropriately sized buffer to separate industrial from non-industrial users

7. Adhere to federal rules regarding homeland security and port safety

8. The Maryland Port Administration and adjacent property owners must be notified of the proposed change and the Director of 
Planning must receive an opinion from the Port Administration at

least 30 days before the re-zoning hearing

Baltimore's MIDs are arguably the most restrictive industrial policies in the country banning nearly all non-maritime related uses and requiring both city and state reviews in addition to adhering to federal Homeland Security rules.

Jacksonville

Jacksonville depends upon more stringent use rules as its primary policy lever. The city has two protective zones- the industrial sanctuary overlay zone and the area of situational compatibility zone. The industrial sanctuary overlay zone is the more stringent of the two, but both have more stringent requirements for non-industrial uses than the city’s standard industrial zones.

The city's primary zoning tool for these zones is not the outright banning of incompatible uses, such as in Baltimore or Chicago, but through large buffer requirements for proposed non-industrial uses. For example, residential zones in the industrial sanctuary overlay zone, depending on their density, are required to have either a 300-foot buffer (for low density residential development) or a 200 foot buffer for multifamily. Additionally, proposed commercial developments are subject to buffers of 50 and 100 feet for standard commercial areas and commercial-office mixed areas. The area of situational compatibility zone also has buffer requirements but less extreme ones of 100 and 50 feet for single family and multifamily developments. 
Beyond the more stringent buffer rules for non-industrial uses, the industrial sanctuary overlay zone allows for more liberal industrial uses than those delineated in other industrial districts in the city.

San Francisco

San Francisco's Production, Distribution, and Repair (PDR) zones were created in order to address the gaps in the city's traditional manufacturing zones. PDRs have much more stringent use restrictions than the city's traditional manufacturing zones, including an outright ban on residential uses except for homeless shelters given a conditional use exemption. Additionally, PDR zones place additional restrictions on proposed commercial developments.

The city also requires additional review for proposed redevelopment of PDR properties to include non-PDR uses. Those uses include office and institutional uses, excluding hospitals. But in order to qualify for those conditional uses the site must meet minimal size requirements and the developers need to submit a plan for actually supporting PDR uses within the building

Portland

Portland has six “employment” zones, of which three, are specifically industrial oriented: General Industrial 1, General Industrial 2, and Heavy Industrial. While the industrial zones are largely self-explanatory, the other three employment zones also allow for industrial businesses. The three industrial zones make up the greater "industrial sanctuary" for the 
city. The industrial sanctuary zones have more stringent use restrictions as well as additional policy support for supporting freight movement such as requiring wider streets to accommodate truck traffic.

In terms of its use restrictions, Portland's industrial sanctuary primarily restricts new retail and office development (residential uses are generally not allowed in industrial zones already).The city also forbids most major institutional uses ranging from hospitals and schools to jails in the industrial sanctuary. Though, recently the restrictions on office development were loosened to allow for greater industrial office/support employment.

While the industrial sanctuary rules heavily circumscribe non-industrial uses, the sanctuary also loosens development restrictions for industrial users with no height or FAR restrictions for industrial redevelopment.

Finally, the industrial sanctuary zones are also all city-designated "Freight Districts”. Such districts have additional requirements on street capacity to allow for easier truck movements through the districts.

Boston

Boston's industrial sanctuary rules are largely dictated by Massachusetts state land-use law. Specifically, the city has waterfront manufacturing (WM) and marine economy reserve (MER) districts designated to support maritime industries. These waterfront districts largely overlap with Massachusetts Designated Port Areas (DPA). The state has 10 DPAs that were designated by the 1978 Coastal Zone Management Act. This act is designed to preserve the state's shoreline for "public use" of which marine-dependent 
industry is included. DPAs are a recognition that existing environmental regulations and priorities limit the potential to create new, large maritime industrial areas on sensitive shore or wetland areas and thus seeks to protect existing maritime industrial space.

The combination of DPA process rules and Boston's additional restrictions protect existing maritime uses in the city. DPAs are managed at district level covering a wide variety of uses that are all connected to supporting maritime industrial uses. As such, individual parcels are not eligible to either be removed or added to DPAs, only significant portions or entire DPAs can be transitioned. Cities wishing to remove or add areas to their DPAs must take part in an extensive three-part review for the the state along with an additional maritime industrial suitability analysis in order to determine whether the proposed area can be removed from the DPA.

In addition to the state process, Boston's own rules limit retail and restaurant developments within WM districts to no more than 2,500 square feet, generally disallows residential uses and conditionally allows some institutional uses such as museums, daycare facilities, or correctional institutions.

San Jose

San Jose's Framework for Employment Lands instituted a no-net loss employment lands policy creating a new set of requirements developers must meet if they wish to redevelop industrial parcels (City of San Jose 2007). While the policy references all employment lands, including some commercially zoned land, industrially zoned parcels are given additional consideration under the no loss rule. In order for a proposed re-zoning of 
industrial employment land to be approved the city offers four ideal characteristics of an offset site:

1. The site is adjacent to viable heavy or light industrial land

2. The site is currently zoned heavy or light industrial

3. The site currently contains legal industrial businesses

4. The site is at least five acres

In addition to the recommended site features potential developers are also required to contact potentially impacted property owners of the proposed change and to go through the process of a General Plan amendment. The city makes decisions on General Plan Amendments four times a year. Amendment applications must include a full Environmental Impact Review, are presented at community meetings for public discussion, verbally presented to the Planning Commission who will then forward their recommendations to the City Council where a final decision is made.

New York

New York’s “Industrial Business Zones” (IBZs), passed under Mayor Bloomberg, are primarily an industrial attraction and support tool, but the mayor's office reserves the right to deny individual applications seeking to convert parcels to non-industrial uses. Aside from the unilateral power to reject individual applications IBZs are primarily tools for reshaping New York’s production landscape through offering a series of subsidies for city businesses to relocate into the IBZs.

Each IBZ is managed by a community and workforce development organization that offers specific programming and policy support for businesses within the IBZ and prospective 
businesses looking to move into the IBZ. These organizations work with industrial users to take advantage of series of tax supports from the city including, but not limited to: an IBZ business relocation credit that offers $\$ 1,000$ per employee up to $\$ 100,000$; a relocation tax credit for firms looking to move into the city or from certain areas of Manhattan; and jobs training tax credits for innovative industries. Individual IBZ organizations also offer their own individual job training and industrial support programs.

In addition to their supportive subsidies IBZs do have some increased use restrictions. Specifically, hotels will now require a special permit to locate in IBZs and there is an ongoing public comment period weighing increasing restrictions on their construction. Additionally, the city is debating whether to limit the expansion of self-storage facilities and is currently taking public comments on the issue.

IBZs are still evolving as a policy tool but are the most comprehensive in terms of supportive industrial policy while now moving towards harder regulatory approaches to prevent encroachment of non-industrial uses.

Seattle

Seattle's most recent comprehensive plan re-states the city's commitment to protecting industrial land in line with King County’s regulations regarding Manufacturing/Industrial Centers (MICs). MICs are industrial areas designated by the county to accommodate industrial growth. The City of Seattle has two MICs within its borders and follows the rules set forth by the county. MICs protect industrial land through greater restrictions on uses including greater restrictions on potential commercial and residential development as 
well as greater restrictions on institutional uses such as primary and secondary schools. In addition to the county restrictions, the city’s most recent draft of their comprehensive plan proposes policies and language to further discourage residential conversion and to loosen building height restrictions of industrial buildings in MICs.

\section{Minneapolis}

Minneapolis primarily uses a new stringent redevelopment process to protect its industrial within their newly formed industrial employment districts. The districts are a new overlay designation in the latest comprehensive plan that offers language that the city should prioritize industrial uses/users in the districts as well as steer new industrial development into them.

Converting industrial parcels to non-industrial uses in employment districts now activates a comprehensive plan amendment process where public input is required and the city weighs the question of conversion specifically against the current supply of industrial land and future industrial employment impact. If the City Council approves the amendment, then the city must propose the change to the Metropolitan Council who have the final decision.

Use versus Process- Complementary Approaches

ILPs exhibit incredible variation in the shape of their policies and implementation procedures. Taking the, admittedly, broad simple typology to classify them there are an 
immense number of ways these cities have decided to implement these polices. That variation rests upon the mixture of dependence on increased use restrictions, more burdensome process rules and additional review from higher levels of government.

The most extreme example of new restrictions is Baltimore's MIZOD district, arguably the strongest protective policy of all the sample cities. Passed in 2004 as a direct response to waterfront mixed-use development, Baltimore city, along with industry groups and the state port administration designed the MIZOD policy. The MIZOD district expressly forbids all uses that are directly marine-related including other industrial uses lacking a direct marine or marine support use. Unlike other cities, Baltimore also expressly bans new institutional uses, such as schools/universities, hospitals or correctional facilities. These rules also extend to banning parks and disregarding certain landscaping requirements seen in similar policies.

Most other cities are not nearly as extreme as Baltimore, but a common feature of many of these policies is the explicit exclusion of residential redevelopment. The worry over residential incursion is a classic complaint of industrial users and makes sense as a baseline protection in zones. While residential construction is generally discouraged in industrial zones, many cities still allow residential construction as a conditional use and this can lead to the gradual conversion of industrial districts parcel by parcel.

Less common, though, are restrictions on commercial redevelopment. Four of the citiesBaltimore, Jacksonville, Portland and San Francisco- limit or ban commercial redevelopment in industrial areas. While less common, commercial restrictions are present in cities that also ban or severely restrict residential conversion of industrial spaces. 
Commercial restriction is more partial, though, than residential restrictions. In Portland, for instance, industrial office space and new "industrial” uses, such as software engineering, are allowed in traditional industrial protection areas thanks to new “Employment Opportunity Subarea” overlay zones (Bureau of Planning and Sustainability 2014) .

Beyond creating new traditional zones or comprehensive plan overlays, Jacksonville takes a unique approach compared to the other cities. Jacksonville has two zones- the industrial sanctuary overlay zone and area of situational compatibility zone. The industrial sanctuary is the more stringent zone, but both zones use buffers instead of outright bans in order to discourage residential encroachment. For example, single family residential plots in the industrial sanctuary zone require a 300 foot buffer and a 200 foot buffer for multifamily developments.

Process and Review

The second strategy cities use to protect industrial lands involves making zoning changes more burdensome by adding additional reviews. These process oriented strategies encompass a variety of approaches but fall into roughly three categories: additional city review; regional/state review; and, impact statements. Additionally, cities with significant process requirements make use of more than one of the process strategies.

The most common process requirement is a required city review of proposed industrial land conversions. This means that applications for conversions are reviewed not only by staff planners but by a city’s planning commission or city council. This is most often 
triggered by making conversion proposals revisions to the city's comprehensive plan. Four- Baltimore, Minneapolis, San Diego and San Jose- of the six cities that require city review treat re-zonings of industrial land as comprehensive plan amendments. As such, the process for converting a particular plot or area of a district is no longer a simple rezoning or variance request to a planning office but requires a fleshed-out review. Additionally, because these areas are linked to city comprehensive plans it often precludes the creeping conversion of areas through the sum of individual re-zonings.

Beyond city review, some cities also require review at a different scale of governmenteither the regional or state level. This "scale jumping" serves the same purpose as any other form of additional review but is notable in that it explicitly involves non-local decision makers and criteria in what are normally entirely local affairs. Minneapolis and Portland are the lone examples of cities using the regional planning system to protect industrial land. Minneapolis, one of the few areas of the country with a regional government, has a regional comprehensive plan that is made up of the comprehensive plans of member cities. Thus, requests for comprehensive plan amendments require approval by city and regional officials. Formally, proposals must submit a request to Minneapolis's Department of Planning and Community Development and then they will submit the request to the city's Planning Commission and Council for approval. Only after both approve the amendment change is the request forwarded to the Metropolitan Council (Elliott and Mogush 2017). Portland is required to maintain minimum levels of employment lands in order to meet regional and state land-use planning regulations, but conversion decisions are decided by the city alone. 
While Minneapolis has an involved process, Baltimore requires not only city but also state approval for converting parcels in its Maritime Industrial District. In Baltimore, proposals for rezoning must go through the city and the Maryland Port Administration (City of Baltimore 2017, 125). Additionally, the order of the reviews is flipped. The city must inform the Port Administration, as well as adjacent property owners, before the rezoning hearing and the planning director must get the opinion of the Port Administration at least 30 days before the planning commission hearing. In this instance, the Port has the option of first refusal before the city can weigh in.

The state of Massachusetts also requires state review for Designated Port Areas (DPA). Boston holds a DPA within its borders that effectively protects marine industrial land for future uses. DPAs are the result of the Coastal Zone Management Act of 1978. The state, in reviewing redevelopment applications from cities, judges sites on four criteria: the area has not been proposed for de-designation in the last five years; there has not been active industrial use within the proposed area in the last five years; another municipality has not requested that the area be excluded from review; and, finally, the proposed area is not fully enclosed by an existing DPA (Office of Coastal Zone Management 2015, pp 8). If the proposed meets any of the four criteria, then the state will deny the request for de-designation.

New York's Industrial Business Zones (IBZ) offer the most idiosyncratic process in that land conversion decisions in the Zones are made by the Mayor. Beyond that, IBZs are the most peculiar of the listed policies in that they are primarily subsidy vehicles with some added protective policy against hotels, but protection is dependent upon the Mayor's 
office. The primary policy tool of IBZs are tax rebates. The primary rebate is a re-location rebate that businesses can receive for relocating from non-protected manufacturing zones to IBZs. Rebates equal $\$ 1,000$ per employee up to $\$ 100,000$. IBZs also have community development and workforce organizations that manage independent zones that offer business support services to members.

Finally, most cities require industrial impact estimates as part of the required packet developers must offer in their applications. Now, the requirements for what constitute appropriate job impacts vary from simple notification requirements for neighboring plots to economic estimates of job impacts of new development. For example, Baltimore does not require explicit quantitative projected impacts on jobs, but of the 7 overall criteria used to determine whether a parcel will be rezoned in a MIZOD 3 relate directly to the impact on maritime industrial use. First, it must be clear that all deep water assets will be preserved. Second, maritime industrial uses within the MIZOD will be free of intrusion by non-maritime industrial uses. And, third, that any proposed redevelopment positively contributes to maritime industrial economic development within the district.

\section{Geographic Coverage}

A final feature of variation among these policies is their spatial extent. Beyond differences in policy implementation, these policies cover wildly different areas ranging from technically covering all industrial lands in Portland to protecting only deep water frontage in Baltimore. 
Baltimore

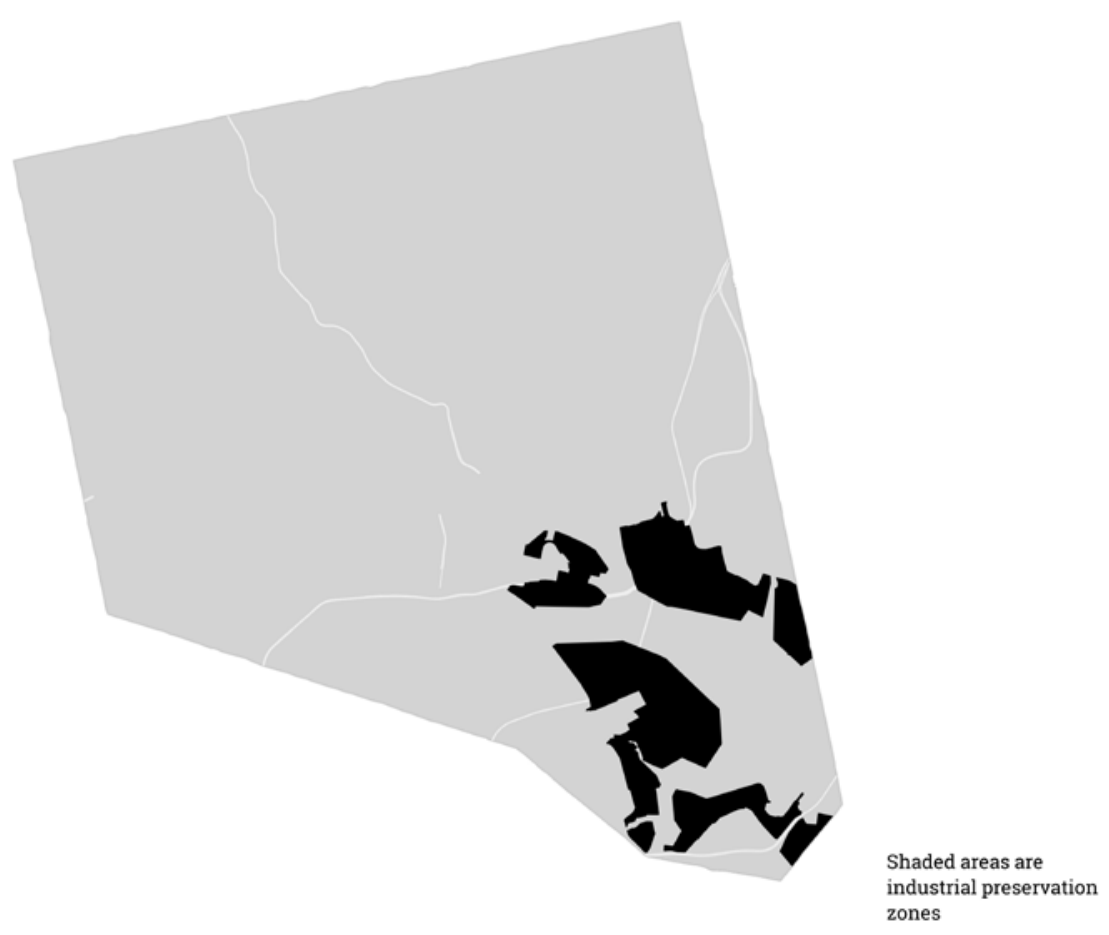

Figure 3: MIZOD Coverage in Baltimore

Baltimore's MIZOD zones are isolated to harbor deep water frontage. Baltimore is an illustrative example because its geographically circumscribed area reflects the strategic importance of the land and also allows for its rather draconian rules without threatening development in other industrial areas of the city. Portland, on the other hand, has its industrial sanctuary rules cover all relevant industrial zones for the city. Portland then uses an additional set of overlays to highlight areas of greater or lesser protection. 
Portland

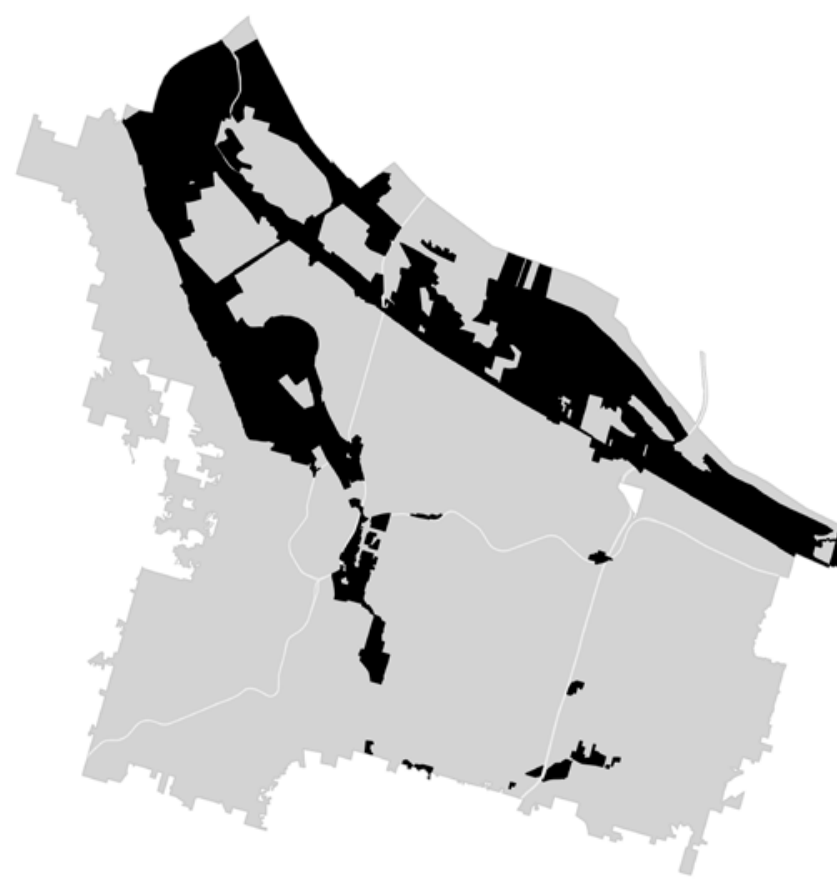

Shaded areas are industrial preservation zones

Figure 4: Portland Industrial Sanctuary Coverage

Discussion and Conclusion

This piece introduces a novel set of emerging land use policies in the US. While there are some older policies in place, principally, Chicago, Portland and Boston, the majority of industrial land protection policies were passed after the year 2000. These policies set themselves apart by rejecting the traditional language of industrial land use as a nuisance to be avoided and through embracing the idea that industrial land and work are necessary to maintain a functioning, and more equitable, city economy.

One question that remains with respect to these policies is the timing. The kind of development pressure that would precipitate a policy response seems self-evident in a city 
like San Francisco that has seen tremendous growth for decades now and has a famously restrictive housing market. But general population growth only explains so much when you examine a city like Baltimore that is still slightly losing population, but also passed the most restrictive of protective policies. In Baltimore's case, it was the specific development pressure on a strategically important set of lands that spurred the greater business community to action. This kind of reaction to specific development threats follows Chicago's experience where neighborhood and labor groups worked with the Washington administration to limit the conversion of industrial areas proximal to the Loop (Rast 2001). Also crucially, these policies were generally passed before at the beginning of the Great Recession before US manufacturing employment, in particular, lost another sizable share. The lack of protective policies arising post-Great Recession may, in part, be reflective of weakened urban industrial interests or reflective of indifferent city governments that have now enjoyed an extended employment and development boom.

Recognizing the contingent nature of the adoption of these policies and their variation, I still argue that these policies represent a coherent set of novel policies. One commonality among these policies is the dramatic discursive shift of the policy language. ILP policy language largely rejects the "nuisance" characterization of industrial land in rather emphatic fashion.

While these policies generally reference the importance of industrial land to economic development, the actual passage of the policies seem to be more related to the growing realization that the affected cities face immediate and critical shortages of usable industrial land. This is doubly so for port cities that face growing pressure to convert industrial 
waterfronts to residential and commercial playgrounds. Jacksonville’s zoning code, for example, offers not only strict code language but some background information and declaration of policy statements. The code includes findings from the city council that include the importance of the topic by recognizing that (City of Jacksonville 2017):

“...the loss of industrial lands combined with residential intrusion into established industrial areas has created a need to protect existing strategically located industrial lands...”

In a 2010 report on the impact of the MIZOD overlay, Baltimore explicitly cites the growing demand waterfront industrial properties for redevelopment and the threat of PUDs as the prime motivation for passing the overlay in 2004 (Lemke 2010, pg. 1). As such, even in the anodyne language of zoning codes there are differences in how these codes are framed. Going back to Baltimore, the statement of intent for the cities General Industrial-2 zone says, “The I2 General Industrial District is intended to provide for a wide variety of general manufacturing...uses (City of Baltimore 2017, pg. 200).” The discursive shift is evident when compared to the intent statement for the MIZOD,“...[MIZOD] is intended to ensure the preservation of deep water frontage...for maritime industrial uses...where maritime shipping and maritime industrial uses can be conducted without the intrusion of non-industrial uses...(City of Baltimore 2017, pg. 200).” This language shift is a dramatic reframing of the place industrial lands have in land use as strategic assets.

Jacksonville, Baltimore, and, to an extent San Diego, also represent special cases because they are port/logistics centers. Baltimore and Jacksonville have active maritime industrial activities and San Diego Prime Industrial Lands are designed to protect, in part, vital industrial lands on the Mexican border for shipping purposes. The movement of goods is 
a specific area where the place-based nature of certain industries remains consistent over time. It is possible to produce many goods in the exurbs of a region where once it was in the central city, but a combination of unique geography, topography and historical investment make it prohibitively expensive, if not impossible, to create new deep water ports in major urban areas.

Beyond traditional industrial location factors (access to deep water harbors in port cities) and immediate shortages of industrial land in fast growing cities, fiscal concerns also motivate at least one city, San Jose, to preserve its industrial land. In San Jose's case, industrial and commercial land offer greater property tax returns than residential development and the inability of the city to extend services to new residential developments spurred the adoption of the no-net-loss industrial land policy.

In terms of strategies, the most surprising may be the fairly common review by "higher" forms of government in order to protect industrial land. These scale jumping strategies make clever use of existing planning, or planning-related, institutions. Ports play a particularly interesting role as independent public, or quasi-public, agencies that are generally much more insulated from popular control and controversy.

This piece fills a current gap in the current land use and economic development literature on industrial land's role in urban labor markets by identifying the cities that are actually engaged in protecting industrial land. These policies show that a handful of large cities are aware of industrial land shortages and are willing to act on it. Additionally, cities are paying attention to other cities. In multiple policy documents, city researchers note what 
other have cities done and set the terms of policy design and adoption (Bujold, Martin, and Spector 2006; Puget Sound Regional Council 2015).

Cities use a variety of strategies to protect industrial lands that can be roughly categorized into two categories- use and process protections. The use protections offer straightforward listed restrictions on development, and the process-oriented restrictions highlight multiple avenues cities use to discourage redevelopment applications. These strategies include the use of industrial impact statements and additional review by local, regional and state authorities. This additional set of reviews brings in institutions, such as Port authorities, that generally do not have a heavy hand in local planning issues and extend the number of institutions responsible for local land use decisions.

These policies signal a growing realization of impending industrial land shortages in cities that must be addressed. While cities with growing populations and economies place additional pressure on industrial districts for conversion, cities should also recognize that demand for industrial areas by industrial users is also growing. The growth of on-demand delivery services such as Amazon Prime have made urban warehouse space much more valuable in the last few years. Additionally, many cities are no longer losing manufacturing or industrial jobs at catastrophic rates and are actually seeing growing demand for manufacturing ready space, especially from small manufacturers and “makers”. Concurrently, Seattle is experimenting with multistory warehousing space (Solomon 2018). Common on the Pacific Rim, multistory warehouse and manufacturing space allow for the production of many goods in dense urban areas on scarce land. As centrally located industrial land comes back into favor for industrial users, multistory 
production and distribution buildings can help solve some of the cost issues that currently face industrial land developers. In short, current demand for urban land is not isolated to only commercial and residential space and cities should prepare now to take advantage of the boom in warehouse demand, in particular, but also space for smaller manufacturers that depend heavily on agglomeration economies to survive. Cities can encourage this kind of development by loosening FAR restrictions and encourage greater industrial use density in traditionally single level warehouse or industrial districts.

This is piece is a start, but further research is necessary. On the institutional question, the role of ports in land use planning should be re-examined to see how active they are or are not over contemporary fights of water-adjacent parcels, especially as cities seek to reclaim their waterfronts for residential and commercial issues. Boston's waterfront protection policy is based in the 1978 Coastal Zone Management Act, an act that requires further research to see what other influence it has on land use planning decisions and exploration on the different ways states have implemented it.

There are also ongoing questions as to the effect of these policies on greater planning practice and organization. Managing industrial land as an asset can potentially bridge traditional divides between economic development and land use planning and birth new institutional forms or practices. Comparing the organizational structures and practices of protective versus non-protective cities could be one way to explore the effect of novel policies on greater policy making structures. Finally, these policies, though relatively new, have been present long enough that the question of their effectiveness can be properly 
evaluated. Researchers should seek to measure what effects, if any, these policies have on growing, or protecting, industrial employment.

\section{References}

Bujold, Mary, Grant Martin, and Mark Spector. 2006. "Industrial Land Use Study and Employment Policy Plan.” Minneapolis: City of Minneapolis.

Bureau of Planning and Sustainability. 2014. "Portland’s Central Eastside.” Portland, OR.

City of Baltimore. 2017. “Article 32-Zoning.”

http://ca.baltimorecity.gov/codes/Art\%2032\%20\%20Zoning.pdf.

City of Chicago. 1988. "PMD, Planned Manufacturing Districts."

City of Jacksonville. 2017. “Zoning Code.”

City of San Jose. 2007. "Approved Framework for Preservation of Employment Lands for the City of San Jose.” City of San Jose.

Curran, Winifred. 2004. "Gentrification and the Nature of Work: Exploring the Links in Williamsburg, Brooklyn.” Environment and Planning A 36 (7): 1243-58. doi:10.1068/a36240.

- 2007. "'From the Frying Pan to the Oven': Gentrification and the Experience of Industrial Displacement in Williamsburg, Brooklyn.” Urban Studies 44 (8): 1427-40. doi:10.1080/00420980701373438.

_ 2010. "In Defense of Old Industrial Spaces: Manufacturing, Creativity and Innovation in Williamsburg, Brooklyn.” International Journal of Urban and Regional Research 34 (4): 871-85. doi:10.1111/j.1468-2427.2010.00915.x.

Elliott, Beth M, and Paul Mogush. 2017. "Maclolm Yards Comprehensive Plan Amendment Application.” Minneapolis: Department of Community Planning and Economic Development.

Fainstein, Norman I., and Susan S. Fainstein. 1987. "Economic Restructuring and the Politics of Land Use Planning in New York City.” Journal of the American Planning Association 53 (2): 237-48. doi:10.1080/01944368708976658.

Harvey, David. 1989. "From Managerialism to Entrepreneurialism: The Transformation in Urban Governance in Late Capitalism.” Geografiska Annaler. Series B, Human Geography 71 (1): 3-17. doi:10.2307/490503.

Jonas, A. E.G, D. Gibbs, and A. While. 2011. "The New Urban Politics as a Politics of Carbon Control.” Urban Studies 48 (12): 2537-54. 
Leigh, Nancey Green, and Nathanael Z. Hoelzel. 2012. "Smart Growth’s Blind Side: Sustainable Cities Need Productive Urban Industrial Land.” Journal of the American Planning Association 78 (1): 87-103. doi:10.1080/01944363.2011.645274.

Leigh, Nancey, Nathanael Z. Hoelzel, Benjamin Kraft, and C. Scott Dempwolf. 2014. Sustainable Urban Industrial Development. Planning Advisory Service 577. APA Planning Advisory Service.

Lemke, Jill M. 2010. “Maritime Induustrial Zoning Overlay District (MIZOD), Summary and Evaluation 2009-2010.” Baltimore, MD: Department of Planning.

Lester, Thomas W., Nikhil Kaza, and Sarah Kirk. 2013. "Making Room for Manufacturing: Understanding Industrial Land Conversion in Cities.” Journal of the American Planning Association 79 (4): 295-313. doi:10.1080/01944363.2014.915369.

Office of Coastal Zone Management. 2015. “Boundary Review of the Chelsea Creek Designated Port Area, Chelsea, MA.” Executive Office of Energy and Environmental Affairs.

Puget Sound Regional Council. 2015. "Industrial Lands Analysis for the Central Puget Sound Region.” Seattle, WA: Puget Sound Regional Council.

Rast, Joel. 2001. "Manufacturing Industrial Decline: The Politics of Economic Change in Chicago, 19551998.” J Journal of Urban Affairs 23 (2): 175-90.

doi:10.1111/0735-2166.00082.

Solomon, Mark. 2018. "Prologis Has Built the Nation’s First Multi-Level Warehouse. Will the Tenants Come?” FreightWaves. http://www.freightwaves.com/news/smartcapacity/prologis-builds-first-multilevel-dc.

Transportation Research Board, and National Cooperative Freight Research Program. 2012. Preserving and Protecting Freight Infrastructure and Routes. NCFRP 16.

Washington, D.C.: National Academies Press. doi:10.17226/14650.

Wolf-Powers, Laura. 2005. “Up-Zoning New York City’s Mixed-Use Neighborhoods Property-Led Economic Development and the Anatomy of a Planning Dilemma." Journal of Planning Education and Research 24 (4): 379-93. doi:10.1177/0739456X04270125. 
Planners and Industrial Land: Ongoing Dilemmas and Contradictions

Introduction

Industrial land is a growing concern for economic development planners in cities across the country. The combination of population growth, economic restructuring and long time institutional features of planning create an environment where industrial land reserves in many large cities are dwindling to crisis levels. This state places economic development and land-use planners in a bind. Over the past 40-50 years cities have enthusiastically converted their industrial lands to non-industrial uses for a variety of reasons including deindustrialization/economic restructuring, the political pressure of development interests and planners' own understanding of the economic future of their cities not including industrial work (Rast 2001; Wolf-Powers 2005; Curran 2007; Hum 2014). Of particular note is the role that planners, and their own thoughts and biases regarding industrial work and lands, play on exacerbating industrial land conversion.

But, recently, a handful of large cities in the United States have rejected the traditional approaches to managing industrial land and instead have embraced industrial land preservation. These policies could have a dramatic effect on local labor markets as well as planning practice.

The question of industrial land preservation, and greater industrial preservation policy, is not isolated to technical planning debates but reflects ongoing political fights in working class neighborhoods across the country. Tarry Hum (2014) opens her book on Sunset Park with a community protest of Mayor Bloomberg’s proposed rezonings of Sunset Park's 
industrial waterfront. Community and industrial advocates fought hard against the revisioning of Sunset Park as a creative industrial district for fear of bot residential and economic displacement. Similarly, the Baltimore Industrial Group and other industrial advocates pushed the city to adopt a special marine industrial overlay designation in direct response to new mixed-use redevelopment on precious harbor land (Lemke 2010). In both cases, community and industry advocates challenged the city's notion of what productive, competitive and attractive city of the future looks like. In doing so, they pushed for policies that explicitly link alternative visions of urban labor markets.

In multiple cases, it seems that the passage of such policies are passed in spite of city priorities as represented through its plans. In multiple cities, including, but not limited to, Chicago, New York and Baltimore, industrial retention policies are proposed as a response to cities prioritizing commercial or residential redevelopment at the expense of industrial jobs (Rast 2001; WolfPowers 2005; Lemke 2010). Wolf-Powers (2005), in particular, points to the importance of individual planner perception as an important aspect of how decisions regarding redevelopment are important.

Industrial land policy, then, holds a fascinating position in current planning issues as it sits at the middle of conflicting views of what future cities should be and is also reflective of how planners currently understand their cities. The combination of economic restructuring, continued urban population growth and political resistance has given way to a new set of industrial land policies that signal the potential rise of a set of novel economic development and land-use strategies. Cities are using a very traditional tool (zoning and land-use codes) in a novel way to explicitly protect, and support, industrial users. These policies are an interesting hybrid of land-use and economic development 
policies, two fields traditionally separated in city and regional governmental and planning structures. Additionally, these policies are a rejection of the conventional land-use wisdom that generally de-values centrally located industrial land.

In order to gain a better understanding of the role new industrial land policies play in the potential transformation of planning practice, this paper will cover two overlapping questions. First, I will explore the historical separation of economic development and landuse/comprehensive planning and show how the recent concern over industrial land can act as a potential bridge between these two specializations that can help to mutually improve practice. Second, I present results from a survey I administered to planners from 18 of the largest cities in the country exploring the contexts and attitudes of planners working on industrial land policy. The survey covers questions of how planners value industrial land, greater economic development strategies and the political contexts surrounding development decisions they must navigate.

Industrial land policy matters because it has the potential to change individual planning practices as well as transform existing institutional features of many planning departments that prevent the proper integration of economic development and land-use concerns. Additionally, gaining a better understanding of how planners perceive the varied contexts they operate in with respect to industrial land provides us with a better understanding of how practice actually operates and potential ways to improve.

\section{Background}


The background section will cover three sections. The first section explores the history of economic development planning and its separation from land-use/comprehensive planning. This history helps to explain why economic development planning stands semiindependently of the other planning subdisciplines in many cities. The second section reviews the literature on the role that planners, and planning, play in the conversion of industrial lands to non-industrial uses. A combination of institutional pressure, greater political economic context and even personal bias all play a role in how planners treat the question of industrial land conversion. The last section covers a set of recent studies that highlight the economic value of industrial land and offer evidence for preserving such lands in major cities.

The Gulf between Economic Development and Land-Use

Industrial land preservation policies offer a bridge between economic development and land-use/comprehensive planning that is normally missing. But there is the larger question as to why such a gap exists at all.

Economic development, as a practice, has always had an uneasy relationship with other planning specializations because it has existed as a semi-separate practice since the inception of the country. Eisinger (1988) offers the long history of economic development policy in the US going back to colonial periods and the funding of essential transportation infrastructure as a principle economic development activity undertaken by states. In a very real sense, economic development planning has existed as a formal practice before "planning” emerged as a formal field. As such, economic development planning has 
developed both within and without local planning institutions, often operating at the state level creating a distinction between state and local development planning in addition to distinctions between economic development and land-use/comprehensive planning.

One area of sharp historical divide between economic development planners and policymakers from more traditional land-use or comprehensive planning is the rise of public-private partnerships and a new breed of redevelopment agencies in the 1970s and 1980s. Harvey's (1989) article on the rise of entrepreneurial approaches to city management situates this turn on a combination of the hard economic restructuring forced by mass de-industrialization and recession in the 1970s and the federal government's abandonment of city support and funding policy programs like Model Cities. That combination of economic restructuring and federal austerity forced cities to fend themselves and incentivized them to maximize their fiscal situations through massive redevelopment schemes. Sagalyn (2007) offers additional detail of this shift. In particular, Charles Schultze, chairman of Jimmy Carter's Council of Economic Advisers, was instrumental in creating the Urban Development Action Grants (UDAG) program. UDAG was designed to force public officials to compete for federal grant moneys based on their ability to form partnerships with private actors. This legislation started a wave of publicprivate partnerships that subsequently reshaped many cities across the country.

This entrepreneurial turn fundamentally transformed the way cities planned and managed their built environments. One dramatic change was the rise of a new set of redevelopment authorities that were tasked with leading these new public-deals (Sagalyn 2007, 10). The responses by cities were mixed with some combining redevelopment agencies with 
existing planning agencies while others remained separate. But a common feature is the rise of a particular set of development professionals that were not necessarily tied to planning were now, in effect, taking over. Even an advocate of public-private partnerships like Sagalyn highlights the risks cities take in not being properly prepared for such arrangements both financial, political and public.

Fainstein and Fainstein (1987) give an early reaction to these policies and institutional changes by noting a series of shifts: first, the shift to publicprivate partnerships act as a way of shielding development decisions from public scrutiny; second, ceding planning priorities to private developers reinforces the city's relative indifference to comprehensive planning; the loss of federal funds and the transformation of existing funds from more general block grants fundamentally shifted the priorities and institutional structures within New York, most dramatically the change of the Public Development Corporation from an industrial support organization to real-estate developer; and, finally, a strong, oppositional local neighborhood movement suspicious of development proposals by the city because the city largely abandoned social planning and support (N. I. Fainstein and Fainstein 1987, 244-46).

While economic development has always played a more independent role with respect to the other planning sub-disciplines, the passage of UDAG and the rise of public-private partnerships helped to cement the separation of economic development and landuse/comprehensive planning in many cities. The result is that a lot of development in cities today is done through such partnerships or redevelopment agencies that have unclear connection to greater planning priorities as they focus on completing financially successful 
projects. This is not meant to give a final word on public-private partnerships but to note that they represent a particular kind of institutional fracture that separates economic development professionals and planners from planning departments in many cities and encourage the project-based work as opposed to more comprehensive planning efforts.

Planning and Threatened Industrial Lands

There is a growing realization among cities, regions and planning researchers that the availability of viable industrial lands are reaching crisis proportions. The reasons for this crisis are multifaceted but can be subdivided into two larger areas: economic and fiscal concerns; and inadequate or counterproductive planning processes. Additionally, when examining planning practices it is important to identify both internal and external pressures on planners that shape their decisions.

Economic and Fiscal Imperatives

A major driver of industrial land conversion to non-industrial uses concern claims of greater economic or fiscal concerns. Succinctly, the logic is that centrally located industrial lands in growing urban centers are inefficient uses of lands that could be converted to higher economic value uses such as commercial or residential space (Chapple 2014, Rast (2001), Lester and Hartley (2014), Transportation Research Board and National Cooperative Freight Research Program (2012)).

Cities face decades long structural constraints that have forced them to act in an entrepreneurial fashion to chase evermore mobile capital (Harvey 1989). In the service of 
such entrepreneurial strategies to fill funding gaps the underlying logic of industrial land conversion is straightforward- commercial and residential uses are generally worth significantly more in terms of property values compared to industrial uses. Cities, therefore, have an incentive to convert now-valued industrial lands to non-industrial uses. Beyond these more structural constraints and incentives, though, there are an array of realestate and development actors who desire to redevelop centrally located industrial lands who also act upon planners (Rast 2001).

Recently, cities in Europe and the US have seen a new set of political coalitions who make claims not only about fiscal strength or economic development, but sustainability also (Jonas, Gibbs, and While 2011). These calls for sustainability act as a new attack on industrial users as they can be framed as not only inefficient but environmentally harmful as well as outdated. Under such regimes, de-carbonization and sustainability are part of a set of strategies cities use to remain competitive and the conversion of industrial lands and a forced de-industrialization of cities is seen as a good, and logical, step. Absent a political counterweight, then, structural pressures and a new set of development coalitions framing their development in the rhetoric of sustainability lead planners towards approving industrial land conversions.

Planning Out Industry

While structural and greater political factors place strong external pressures on planners to convert industrial lands there are also a variety of internal features of planning that encourage the conversion of industrial land to non-industrial uses. In a 2012 review of 
freight planning resources, the Transportation Research Board identified a series of institutional issues that threatened urban freight infrastructure in the US:

- The federal government has a scattered approach to freight planning with responsibility spread over multiple agencies;

- Local and regional governments primarily responsible for land use did not include freight related matters in comprehensive plans nor did they have freight-specific zoning regulations;

- local authorities lacked basic freight information that would allow them to informatively plan for freight users in the first place;

- freight stakeholders typically did not participate in local or regional planning projects;

- Local jurisdictions have financial incentive to rezone freight areas for more intensive uses (Transportation Research Board and National Cooperative Freight Research Program 2012, 28-29).

While it may not seem immediately apparent, freight infrastructure in cities exists primarily on industrial lands so the conversion of such lands effects not only local manufacturers but regional transportation firms also that need space to collect and move goods efficiently. Additionally, the regional nature of freight means that one city that converts too much of its freight-oriented industrial land could have significant negative effects for the region as a whole. Beyond the more structural weaknesses surrounding freight, existing planning practice shows additional biases against other types of industrial users. Leigh and Hoelzel (2012) reviewed the industrial policies of fourteen major cities and ten "Smart Growth" publications practicing planners reference to help set land-use and economic development policies and found a general bias against industrial land within policy. More specifically, Leigh and Hoelzel found that cities generally did not take industrial land availability into account in their local industrial planning issues and that Smart Growth policy guides either entirely omitted questions about industrial land or generally framed industrial land in a negative fashion and generally recommended 
conversion. Beyond the indifference of Smart Growth policy guidance to industrial land, the underlying perceptions and expectations of planners can also bias them against industrial users. Wolf-Powers (2005) highlights how the personal expectations of planners for their cities, in this case New York, lead them towards particular development conditions. In what she calls “passive support for de-industrialization” (2005, 380), WolfPowers connects land-use decisions to planners allegiance to larger political coalitions dedicated to industrial land conversion and growth as well as to a planner-specific view of the future city economy built primarily on financial sources and tourism. This is not to pain planners as villains, or even dupes of development interests, but actors on their own facing a series of difficult, if not impossible, contexts to navigate and manage.

The value of Industrial Land And an Emerging Set of Policies

The Economic Importance of Industrial Land

There is a growing body of research in economic development that challenges the conventional view of centrally located industrial land being inherently inefficient or obsolete. These studies encompass direct analyses of the role of industrial land in regional business dynamics to exploring the role physical redevelopment plays on local economic restructuring. 
Chapple (2014) shows how industrially zoned land in the Bay Area plays an essential role in the region's business dynamics. Specifically, buildings within larger industrially zoned areas are more likely to seed new businesses and are more likely to have existing successful businesses grow in place. This study points towards the availability of plentiful industrial land as a fundamental aspect of local business dynamics, particularly for growing businesses. For cityregions that have dedicated industrial retention and business support policies the availability of affordable space for businesses to expand should be taken into consideration.

Following a similar vein, Curran’s (2004, Curran (2010)) work in Williamsburg, Brooklyn highlights how the discourses of gentrification privileging flexibility and innovation are used as weapons to encourage the conversion of industrial spaces to commercial or residential lofts. By tracking the historical development of Williamsburg and interviews with industrial tenants, Currant challenges the conventional wisdom concerning these industrial districts by highlighting that the districts are healthy in terms of vacancy and that the primary pressures on industrial tenants were not the forces of global competition but landlords strategically raising rents in the hope they leave.

Lester and Hartley (2014) examine the role of industrial conversion on local labor market change by looking at the changing labor market of gentrifying neighborhoods in 20 large US cities. They find that gentrifying census tracts experience faster job growth than nongentrifying tracts using a differencein-difference approach. Worryingly, though, gentrifying tracts tended to lose goods producing jobs at a greater rate than non-gentrifying tracts. This result means the gentrification accelerates local de-industrialization. The 
physical redevelopment of a neighborhood that we would expect to see due to gentrification also has real industrial consequences. This does not mean that only gentrifying tracts face the loss of blue collar jobs, but that gentrifying tracts are liable to exacerbate such options. Again, the availability of affordable industrial space is linked to both employment and establishment growth.

Meltzer and Ghorbani (Meltzer and Ghorbani 2017) follow Lester and Hartley’s

(2014) work by estimating the effect of gentrification on the employment impacts on incumbent residents. They find that the employment effects of gentrification are highly localized resulting in significant job losses for residents who work in the same census tract. Additionally, those losses are concentrated in low and moderate wage goods producing and service jobs. Fortunately, those losses are generally made up by job growth at longer distances (in this case 1 and 2 mile buffers). But just as in Lester and Hartley, they find that the physical redevelopment of tracts through gentrification has a dramatic effect on local industrial structure.

While there are clear structural and practical limitations on planners' regarding industrial land and redevelopment, we are seeing the emergence of a set of industrial land protective policies (Green 2018). While there are a new set of cities protecting their industrial lands the policy is not entirely novel. Both Chicago and Portland have longstanding industrial land protection policies explicitly designed to protect industrial parcels and users from encroaching residential and commercial conversions. Chicago’s Planned Manufacturing Districts originated from working class neighborhoods in concert with the progressive administration of Harold Washington opposing downtown-oriented developers seeking to 
convert central industrial districts to residential and commercial complexes (Rast 2001). Portland's Central Eastside protection was pushed largely by industrial users over many years defending the district's importance and taking advantage of new state land-use guidelines in the early 1980s to secure protection (Jenni Minner 2007).

These protective policies are put in place to staunch the exit of industrial jobs by moderating rent increases through banning or limiting industrial land conversion. Such policies have clear trade-offs including, but not limited to: preserving dying districts that are victim to greater exogenous forces as opposed to conversion; potentially limiting overall job growth in areas attractive to development; or potentially adding increased pressure to non-protected industrial districts.

\section{Overlapping Dilemmas}

Industrial land shortages are a growing concern for cities across the country. There are positive effects of maintaining industrial land supply on city business dynamics, local area employment and regional freight networks. Beyond those economic benefits having sufficient supplies of industrial land allows cities to hold and expand their own industrial facilities and add flexibility to their own operations. But even recognizing these benefits many barriers and questions regarding industrial land management in our cities remain.

A major set of barriers to proper industrial land management are assumptions regarding de-industrialization and the proper placement of existing industry: first, there is a belief in a generalized de-industrialization narrative, basically that the US does not actually produce physical goods anymore and industry, particularly, manufacturing has gone and will never 
return; and second, that even if the US still produces things production does not belong in cities.

Beyond these more general assumptions regarding the role of industry in the country as a whole, and, specifically in cities, the question of what planners believe also matters. Curran (2004) and Wolf-Powers (2005) illustrate in their pieces the importance of individual planner attitudes towards industrial work as an important component to how they make decisions. So for cities that suffer from such shortages are planners aware of them and, if so, do they even care?

Realizing that maintaining industrial land for industrial users is not only a good policy for protecting jobs but for encouraging business growth and development, cities are now passing industrial land protective policies. But while these policies are adopted in a handful of cities and research reiterates the importance of industrial land for multiple reasons, it is unclear, still, how planners value, or not, industrial land and whether or not there is a difference between planners in cities that are actively protecting their land from those that are not.

In order to better understand how planners value industrial land and whether planners in cities with protective policies are different the next sections will relay the results of a survey of I administered to planners involved with industrial land decisions in the US's fifty largest cities.

Findings 
In the following section I present findings from a survey I administered to planners in order to examine how planners view industrial land and industrial work and the institutional contexts of planning for industrial land.

$\underline{\text { Methods }}$

I designed a Qualtrix survey for planners that work directly on issues regarding industrial land development from the fifty largest cities in the US based on their 2012 population.

I employed a hybrid recruitment strategy. First, I searched city planning and economic development websites for people who are responsible for industrial land matters. This included traditional land-use planners, economic development planners focusing on industrial policy or, in the case of Philadelphia, an industrial land real-estate expert. If I could not identify a specific individual I sent inquiries to the general planning and economic development departments, asking them if they had anyone whose responsibilities included industrial land policy areas. If the cities responded affirmatively I would contact that named person. The ultimate goal was to get 50 individual planners, one for each city, who could answer questions about their cities' industrial land policies.

Out of the fifty largest cities in the US by population in 2012, 29 individuals responded to the survey, and 19 completed it for a 56\% response rate and 38\% completion rate. I present final results from 18 responses, as the 19th response was from a regional government where I already had a respondent from the region's major city. This results in a final survey completion rate of $36 \%$. 
The survey is organized into roughly three parts: the first covers the background and current position of respondents and their perception of their cities' orientation towards industrial land planning; the second goes into further detail about specific city industrial land policy and planning; and the third explores the political economic context surrounding industrial land planning decisions. The first sets of questions ask for basic information regarding position/title, basic responsibilities and background questions regarding city planning policy. Those background questions include queries on whether the the city has a comprehensive plan and its state, whether or not the comprehensive plan covers industrial land issues and the general policy orientation of the comprehensive plan towards industrial land issues. The second set of questions go into more detail about individual planner perception of the state of industrial land in their cities. Has the city performed an industrial land inventory, what is the estimated supply of industrial land in the city, and whether or not the city has a larger urban manufacturing strategy. The final questions cover the institutional and political contexts of planners' work. These questions cover basic organizational structure and responsibilities for implementing industrial land policy as well as economic development and urban manufacturing strategies. I also ask questions about whether planners receive political pressure to convert industrial lands and whether there are external constituencies that advocate on behalf of industrial land preservation. Finally, I ask a series of questions asking the planners their perception of the value of manufacturing/industrial work in their cities and their opinions on the future viability of such work.

In addition to analyzing the survey results I also performed some "ground truthing" by reviewing some of the answers against existing city documents specifically their 
comprehensive plans. I did this primarily as a validity check, but also to get a better understanding of how planners understand their cities' own policies in relation to their policy goals. Where possible, I reviewed the respondents' cities comprehensive plans to see whether they mentioned industrial land in systematic ways as I ask in the survey. In addition to double checking comprehensive plans, I also used earlier work examining the features of industrial land policy in the nation’s largest cities (Green 2018).

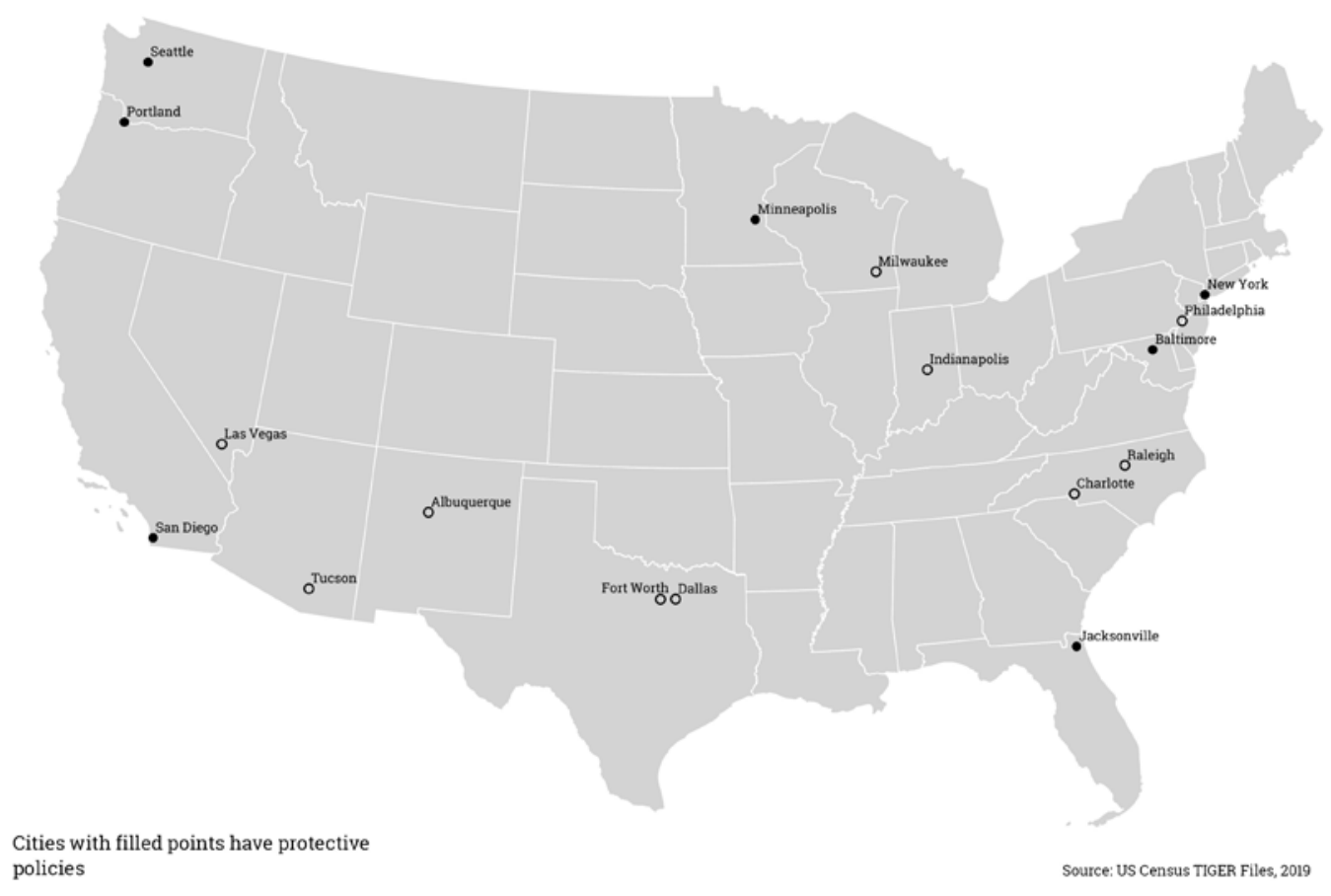

Figure 1: Survey Respondent Cities 


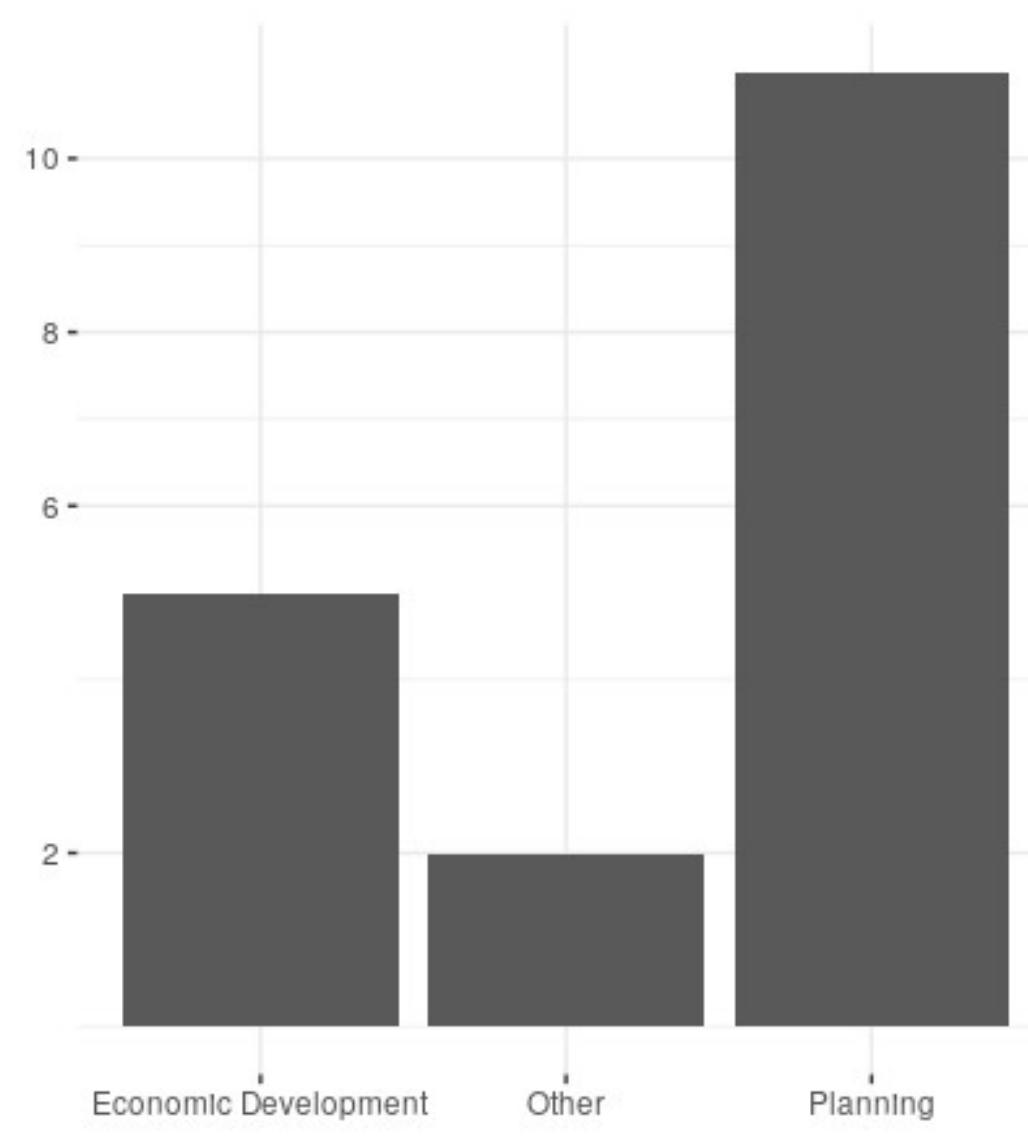

Figure 2: Respondents are Primarily from Planning Departments

\section{$\underline{\text { Survey Results }}$}

All respondents were senior level planners, administrators or department heads. Most work in traditional "planning" departments dealing with long range/comprehensive planning, a little more than a quarter work in separate economic development departments or redevelopment agencies with the remaining coming from a mix of other offices ranging from an industrial real-estate office to a city-wide sustainability program. This initial variation already points towards some of the unique aspects of industrial land policy 
compared to greater land-use regulation. Of the overall sample, 8 out of the 18 respondent cities have a protective land-use policy as identified in Green (2018).

Are cities planning for industrial land?

In order to gauge a city's basic interest in industrial land management I asked the planners whether there were any sections in the current or proposed comprehensive plans for their cities on industrial land.

Seventeen of the eighteen respondents answered their cities currently have comprehensive plans, but the age of specific plan and plan chapters vary from relatively recent revisions made in 2017 to chapters still in effect from the 1980s.

Fifteen respondents answered their cities have a current comprehensive plan they are following. Of the 15 respondents with an existing comprehensive plan 12 responded that their comprehensive plans had a section that explicitly covered questions concerning industrial land management. In terms of how cities value, or devalue, industrial land of the 12 respondents who said their city comprehensive plans contained sections explicitly half of the respondents claimed their city's comprehensive plan sought to proactively preserve or expand existing industrial lands.

While respondents generally report that their cities are actively planning for industrial land most respondents do not believe their cities face immediate industrial land shortages. I asked respondents to estimate the supply of developable industrial land for their cities.

A majority of respondents responded that their cities current supplies of developable land can last 11-15 years or higher. Six respondents reported their cities face immediate 
shortages of industrial land of either 1-5 or 6-10 years of developable land. As the table shows, the planners in protective cities generally estimated their cities industrial land lasting less than 10 years.

Generally, cities report their comprehensive plans cover industrial land management, but another signal of industrial land policy importance is whether or not cities are actually tracking their industrial lands. One way to measure this is to see whether cities have performed an industrial land inventory. Dempwolf (2010) tracked the rise of industrial land-use studies/inventories throughout the early 2000s as cities started to review their industrial land-use policies. Not all cities that performed such studies passed protective industrial land policies, but commissioning a report, and in some case, performing regular monitoring, gives a signal that cities take industrial land management seriously. The vast majority of respondents reported their cities had performed such inventories. 


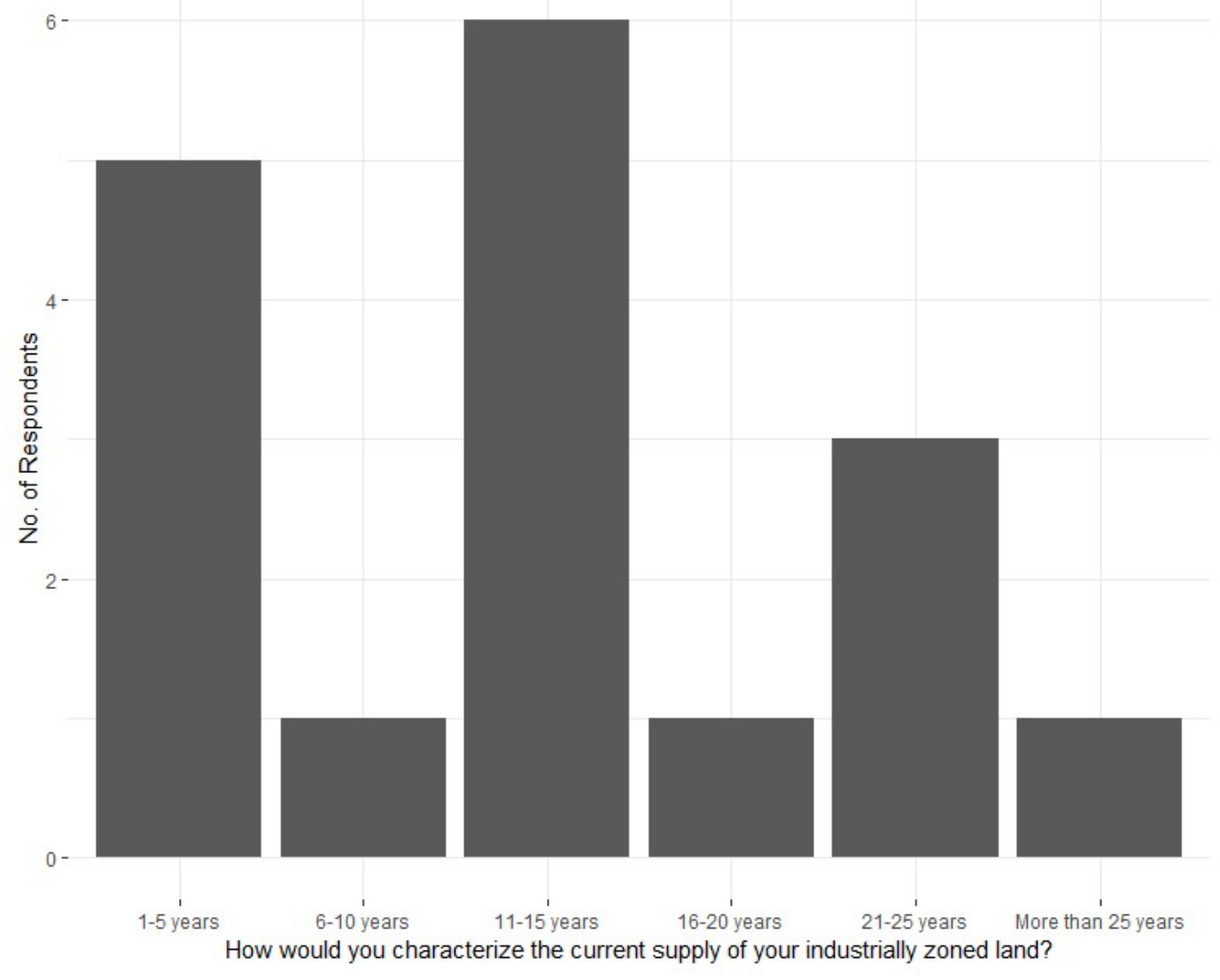

Figure 3: Planners believe their cities have adequate industrial land supplies

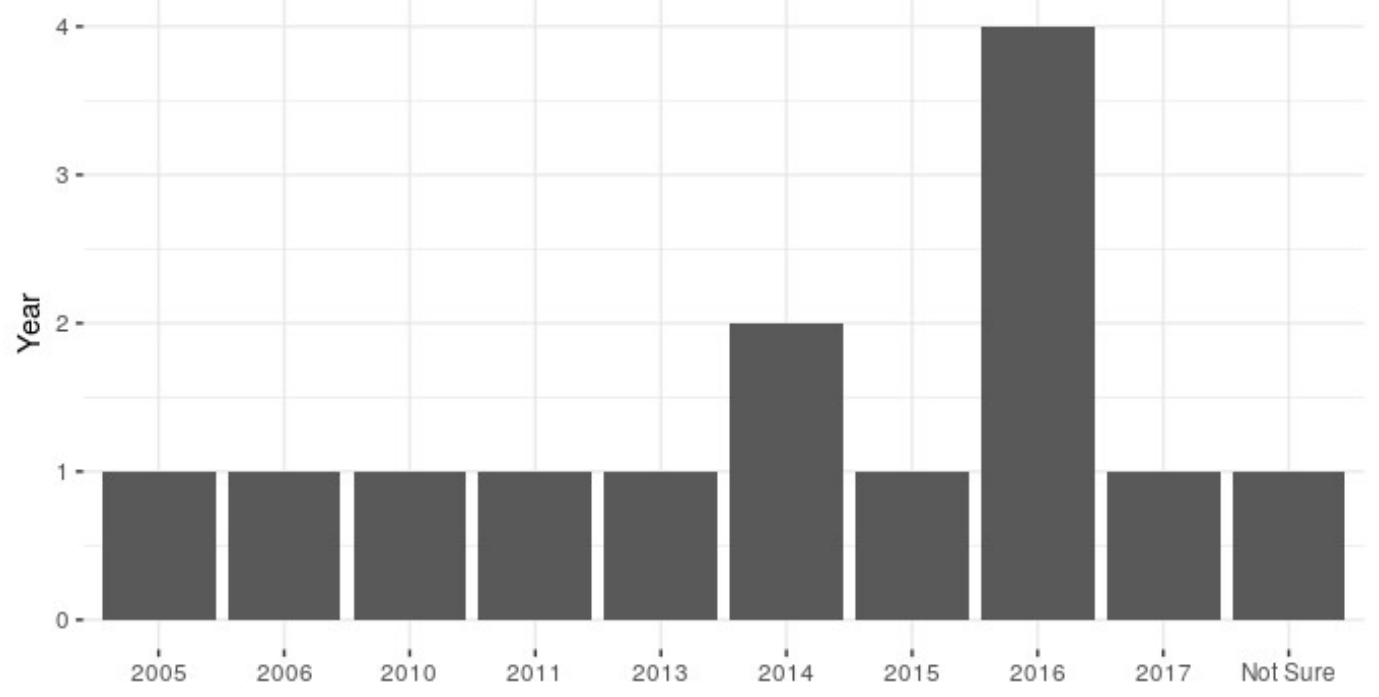

Figure 4: Respondents reported their cities performed inventories primarily since 2010 
Table 1: A Majority of respondents report their cities have industrial land inventories

\begin{tabular}{ll}
\hline Has your city conducted an industrial land inventory? & $\mathrm{N}$ \\
\hline No & 4 \\
Yes & 14 \\
Total & 18 \\
\hline
\end{tabular}

For those respondents that reported their cities have industrial land inventories the distribution of when those studies were completed is relatively new with most respondents reporting inventories being performed since 2010 with a handful performed 2005/2006.

\section{City Strategies}

This section of questions explore what the respondents currently know of their cities greater economic development strategies and plans regarding urban manufacturing and industrial work. To start, I asked respondents whether their cities currently had an urban manufacturing strategy. The answers were nearly split evenly with 9 respondents answering no and 8 answering yes. Next 


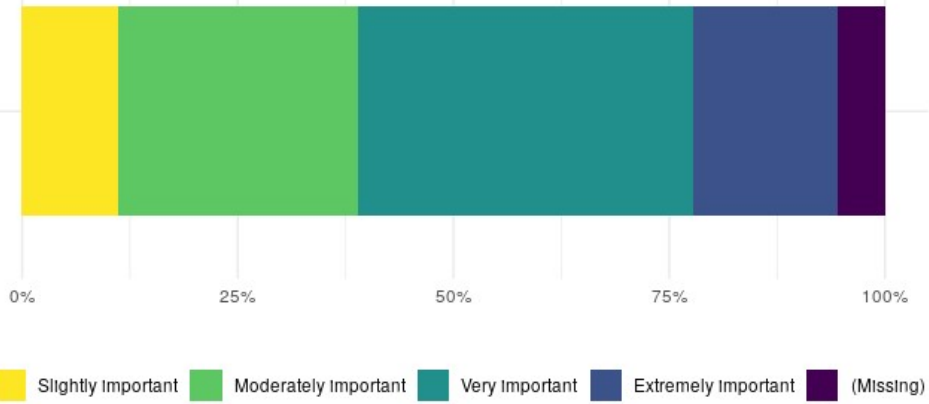

Figure 5: Urban manufacturing is an important part of cities' economic development strategies

I asked respondents how important urban manufacturing was to their cities' overall economic development strategies. A majority of respondents reported that urban manufacturing was very important or extremely important to their cities respective economic development strategies.

Urban manufacturing is an important part of city economic development strategies, according to the respondents, but where does industrial land preservation fit as a policy? I asked the respondents to rank the importance of a set of policies to their cities urban manufacturing strategies.

Industrial land is seen as a moderately important area for economic development strategies, but it falls well short of other areas of policy concern for the respondents. This makes intuitive sense given the novelty of industrial land protection policies and the prominence of more traditional industrial attraction and retention policies. Additionally, as the estimated land supply question responses show the respondents generally perceive their cities to have adequate supplies of industrial land lowering the importance of industrial land policy. 
Next I asked the respondents to give their opinion on how their coworkers and colleagues value industrial land and related economic development issues concerning urban industrial work more generally.

The respondents report that officials in their cities believe that having adequate supplies of industrial land and industrial land preservation are important goals. Additionally, the respondents generally rejected the idea that industrial land preservation is harmful because it does not allow land to develop into a higher use. In a follow up question, I asked whether respondents felt their colleagues thought industrial land preservation was a waste of resources and 2/3 (11 of 18)

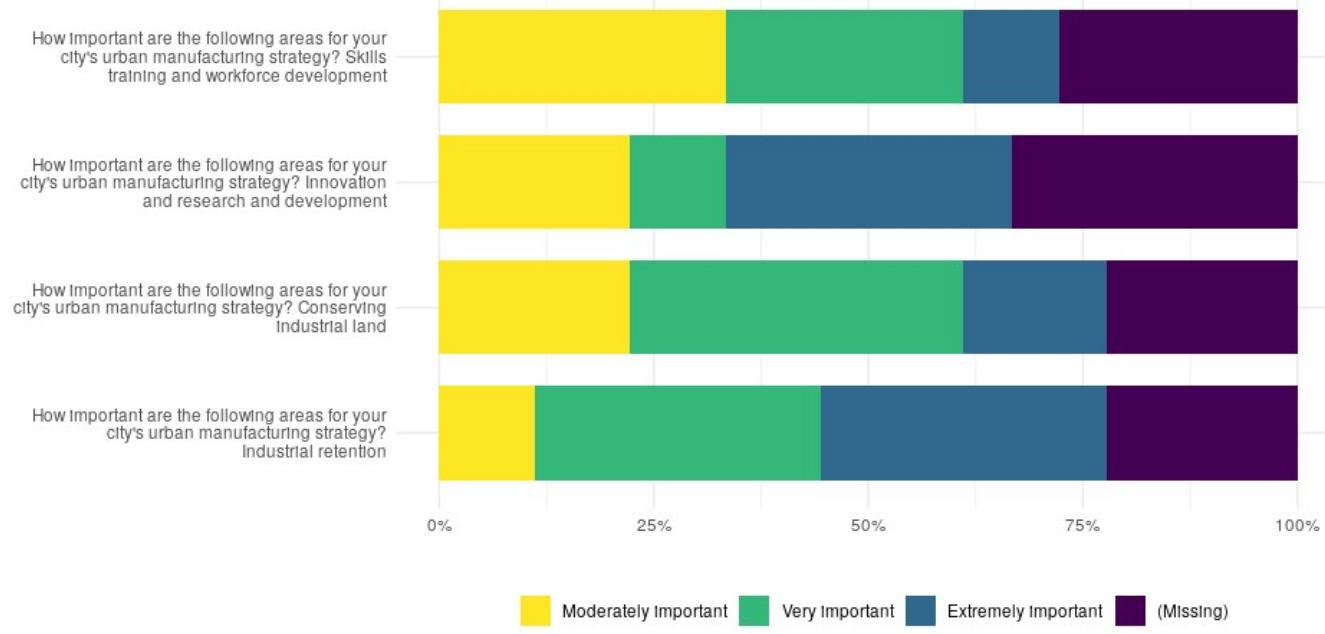

Figure 6: Respondents report industrial land preservation matters for urban manufacturing strategies 


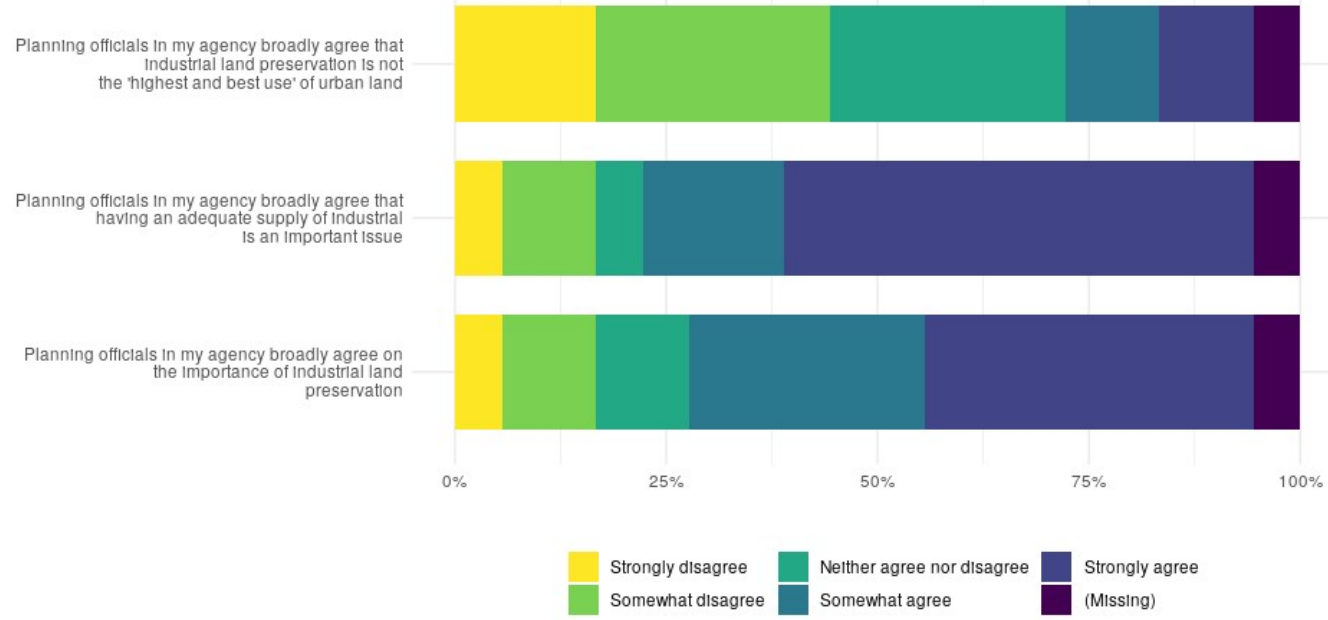

Figure 7: Respondents largely agree that planning officials think industrial land preservation is important

Planning officlals in my agency think that manufacturing jobs are golng away

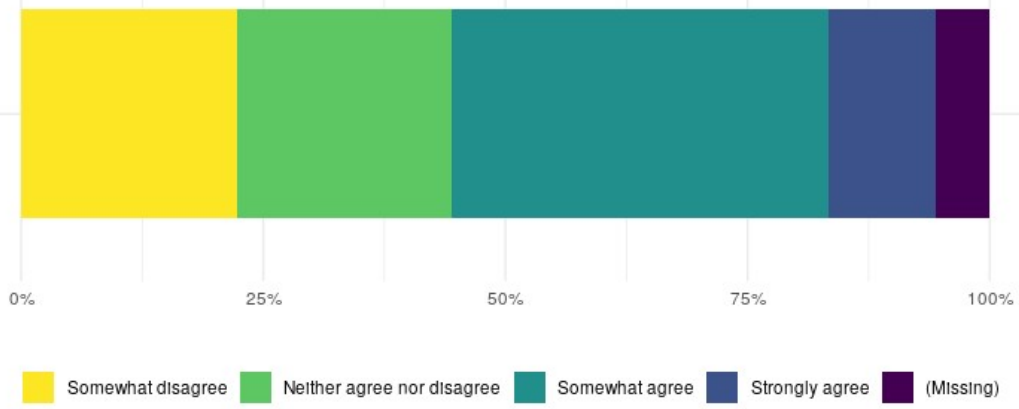

Figure 8: Respondents report planning officials in their city think manufacturing will continue to lose jobs

responded that they disagreed. While respondents report a consensus on the importance of industrial land, the respondents also report that planning officials in their cities are relatively pessimistic about the prospect of manufacturing jobs in their cities.

Though respondents report that officials in their cities are relatively pessimistic on the future viability of manufacturing jobs they do report that officials believe industrial and manufacturing jobs are important to their cities’ economies in a variety of areas. I asked 
the respondents to share their level of agreement to a series of questions about urban/industrial employment's role in their cities.

Most respondents agreed their cities were heavily dependent upon manufacturing/industrial jobs in the past, but were much more ambiguous on the viability of such jobs moving into the future. Regardless of the future viability of such jobs, respondents also largely agreed that manufacturing/industrial jobs are an important source of traded goods as well as important for alleviating income inequality in their cities. Though it should be noted that the question regarding traded goods is more evenly split.

The ambiguity as to the nature of manufacturing/industrial jobs extends also to whether the respondents believe such jobs in their cities are innovative or sustainable. It is nearly an even split among respondents that manufacturing/industrial jobs are innovative with more in agreement that such jobs are sustainable.

When asked directly, though, whether manufacturing/industrial jobs would be an important part of their economies going forward the respondents overwhelmingly strongly agreed (13 of 18 respondents). 


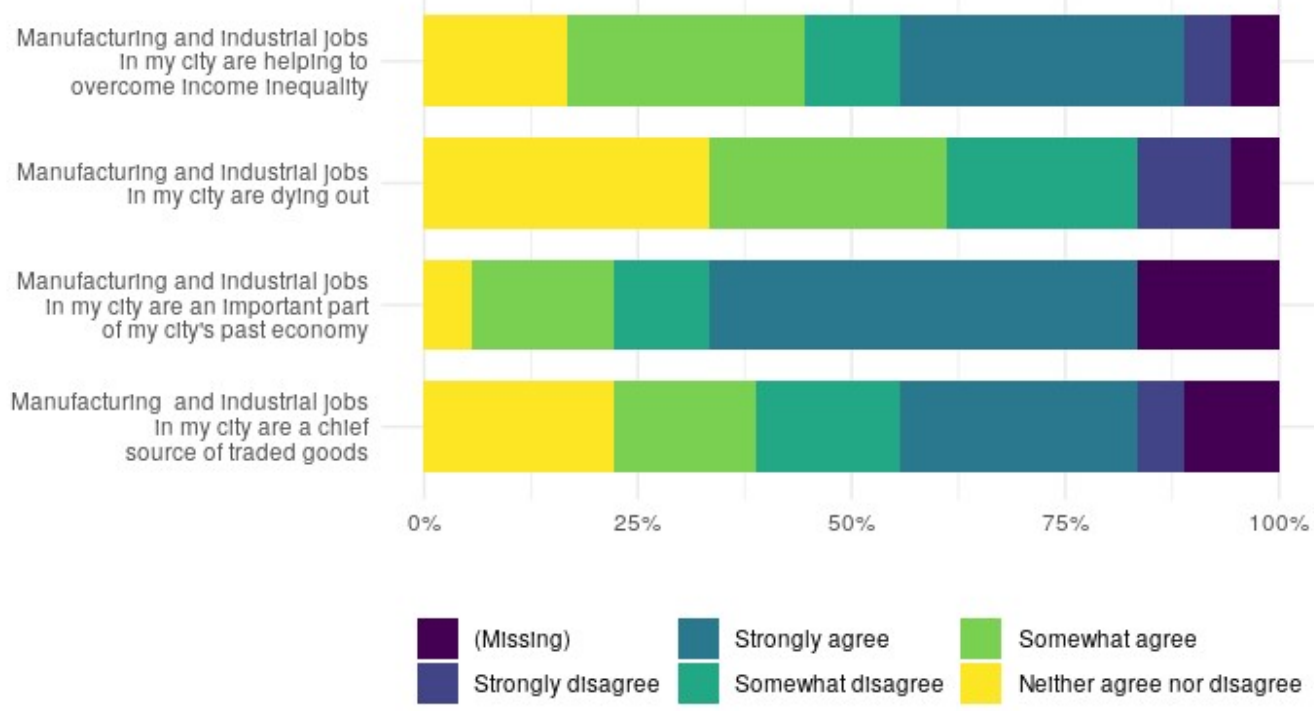

Figure 9: Respondents see urban/industrial employment as key source of traded goods and helps alleviate income inequality

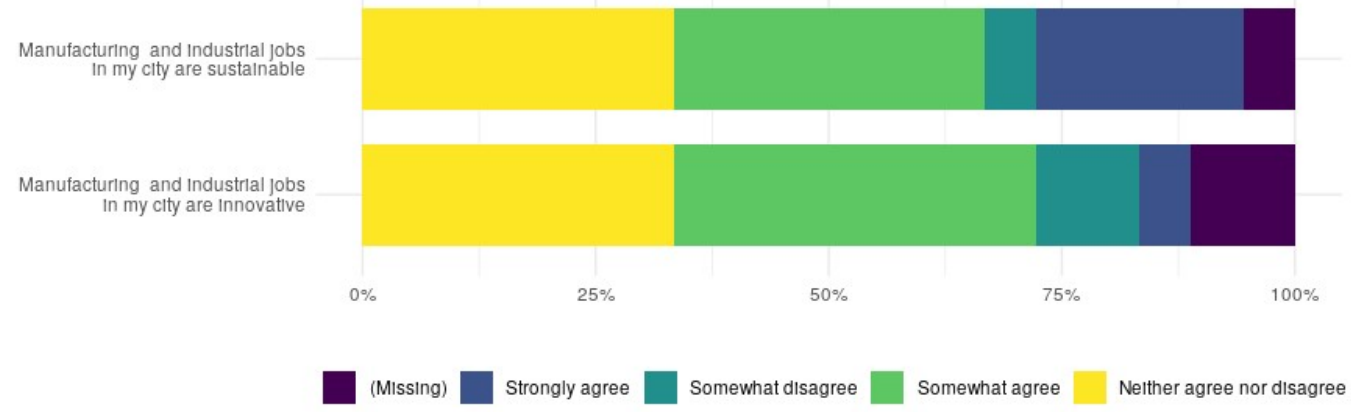

Figure 10: Respondents largely agree that manufacturing/industrial jobs are sustainable 


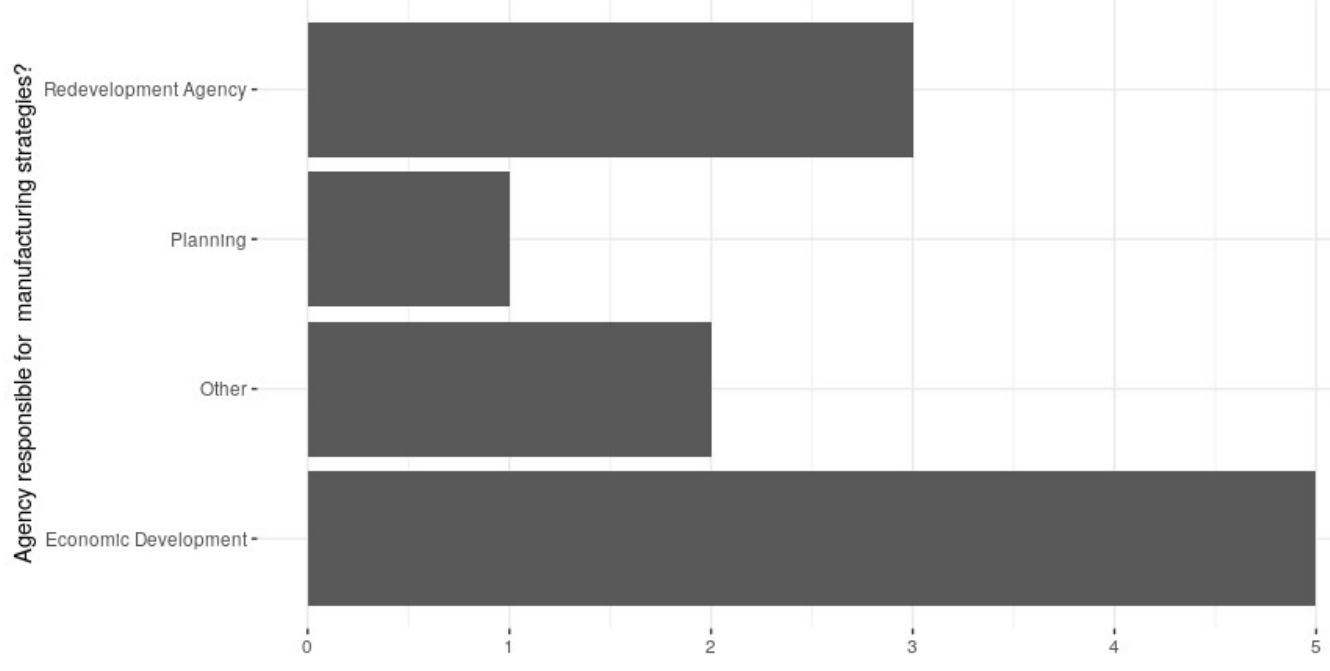

Figure 11: Economic Development and Redevelopment Agencies are responsible for urban manufacturing

Institutional Features

The final set of questions cover the institutional and political contexts planing officials face regarding industrial land. The first questions pertain to implementation of manufacturing or industrial strategies followed by a series of questions of the political pressure planning officials may face regarding industrial land development decisions.

In order to understand what barriers that may exist in the implementation of urban manufacturing/industrial strategies I asked respondents if their home departments were responsible for manufacturing/industrial policy implementation. The majority of respondents (11 of 18) reported that their home agencies were not responsible for implementation of urban manufacturing strategies. When asked which agencies were responsible economic development and redevelopment agencies were most frequently mentioned compared to planning departments. 
In addition to the organizational split on implementation, I also asked respondents whether they perceived any tensions between current and long-range planning regarding industrial land. Nearly 2/3 (11 of 17) of respondents strongly disagreed with that.

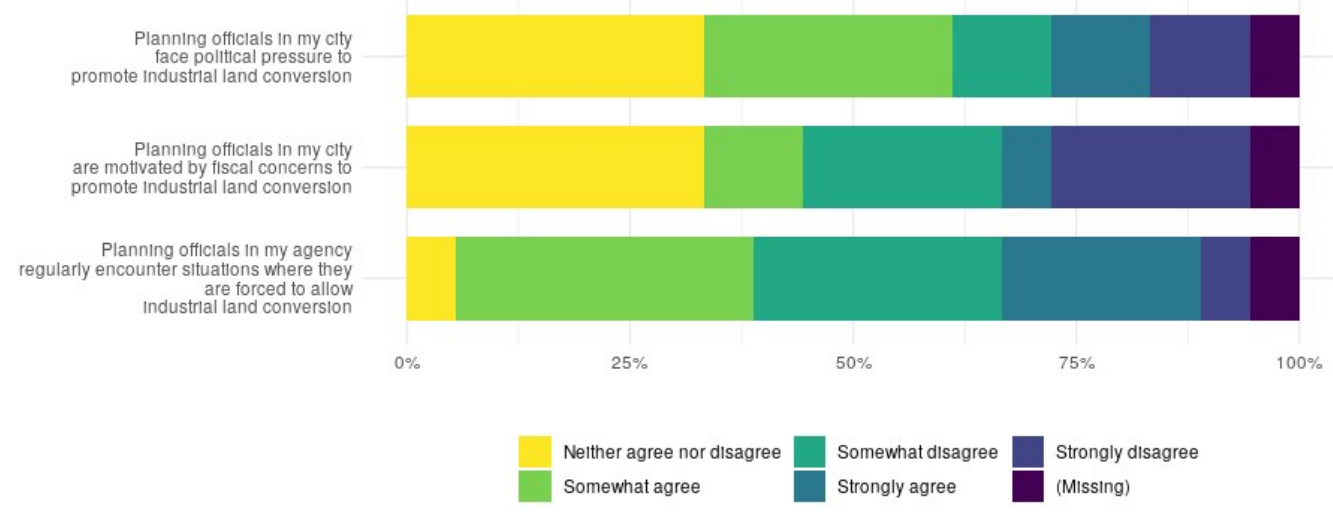

Figure 12: Respondents report planners face political pressure to convert

While the respondents may not largely be responsible for urban manufacturing/industrial strategies, many are still responsible for land-use decisions. I asked a series of questions about the institutional/political context around industrial land conversion decisions. Specifically, I asked whether the respondents thought planning officials in their cities were first, responsible for industrial land conversion decisions, second, were officials motivated by fiscal concerns when making such decisions, and lastly, whether they believed planning officials face political pressure to convert industrial lands to non-industrial uses.

Respondents reported that planning officials in their cities are often responsible for making decisions regarding industrial land and were not generally motivated by fiscal concerns when making such decisions. Though there was a sizable proportion of answers that neither agreed nor disagreed, a plurality of respondents did report they thought planning officials in their cities received political pressure to convert industrial lands to non- 
industrial uses. Interestingly, when I asked about the presence of community or business stakeholder groups, nearly half of respondents agreed that their cities had community groups supportive of industrial land preservation. The same could not be said for business stakeholder groups where most of the respondents could not definitely answer one way or the other.

The survey responses presented above explore respondents' understanding of their cities' planning policy contexts, their economic development policy priorities and political/institutional features of planning practice with respect to questions of industrial land development. Overall, respondents reported that their cities are aware of industrial land supply issues and see such issues as of moderate importance compared to other economic development strategies.

There are strong community stakeholders pushing the clty to promote Industrlal land preservation

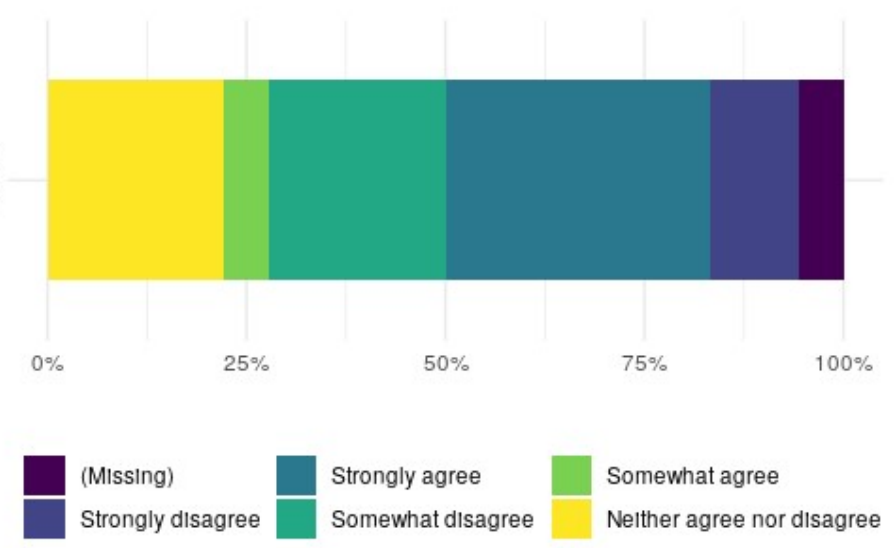

Figure 13: Some community groups are organized to protect industrial land

Additionally, respondents gave supporting evidence to the idea of a more fractured planning system when looking at what agencies are responsible for urban manufacturing strategies as well as the diversity of offices the respondents themselves occupy. Industrial 
land remains in a bit of an uncertain space with respect to who has ultimate responsibilityland-use or economic development. Finally, respondents reported that planners in their office receive political pressure to convert industrial lands to non-industrial uses.

\section{Discussion}

Survey respondents were asked a series of questions in three broad areas: first, the basic planning policy context of their respective cities; the strategies their cities are employing regarding manufacturing and industrial employment; and, finally, the institutional contexts respondents operate within.

The following section offers additional discussion on these areas. The first section explores in more depth how respondent cities are actually planning for industrial land and potential conflicts. Respondents report their cities are planning for industrial land, but is this reflected in their comprehensive plans? Similarly, questions regarding the potentially fragmented nature of industrial land planning speaks to the traditional split between landuse and economic development planning.

The second section presents a more detailed comparison of a select set of survey responses between cities with and without industrial land protection policies. If having an industrial land protection policy plays some kind of shaping role in a city’s approach to planning, then it may be possible to identify differences in responses based on the presence or absence of industrial land policies. 


\section{$\underline{\text { Cities Are Planning for Industrial Land }}$}

According to the survey respondents, cities are planning for industrial land. A large proportion of respondents reported their cities included a section on industrial land in their comprehensive plans or planned on doing so. But in reviewing these comprehensive plans it is clear there is some variability as to what management of industrial land means in practice. For example, Tucson responded that they have a section dealing explicitly with industrial land management, but in the city's economic section of its current comprehensive plan industrial land is mentioned only in relation to expanding industrial land uses around Davis-Monthan Air Force Base (City of Tucson 2013). The management of industrial land is not explicitly mentioned, though industrial land is generally considered within greater policy. A similar approach is seen in Dallas's comprehensive plan where industrial land on the south side of the city is mentioned as an area of increased investment opportunity, but the management of industrial land is not explored in any great detail (City of Dallas 2006). These orientations differ markedly from a city like Seattle where its policies concerning “manufacturing/industrial centers” include an array of policies explicitly oriented around industrial land use for the city, and, recently the city released its first monitoring report including explicit monitoring of development and employment trends in the city's two manufacturing/industrial centers (Office of Planning and Community Development 2018).

More positively, though, respondents report their cities are actively monitoring industrial lands, that such monitoring is relatively recent, and that their cities have urban manufacturing strategies. Industrial land, then, may not be a major priority of planners in 
the respondent cities, but it is, at least, an issue. But there is evidence from the respondents that while industrial land is thought about it is still a relatively minor issue compared to more traditional concerns of economic development strategy such as industrial attraction and research and development.

Respondents do offer some evidence of a variety of planning systems where industrial land management is not monitored or managed by land-use planners. Industrial land policy is split among traditional land-use planning agencies and economic development/redevelopment agencies. As Wolf-Powers (2005) and Fainstein and Fainstein (1987) note in their pieces, this kind of institutional fragmentation can lead to sub-optimal planning outcomes, and depending on which agency is actually responsible for industrial land policy, can shield agencies from public criticism. This is not to say that economic development agencies should not be doing land-use planning, but managing industrial land without clear evidence of working with land-use planners and city land-use priorities can lead to confusing or contradictory policies.

In addition to evidence of a more fragmented industrial land management system, respondents reported they do not believe their colleagues find industrial land inherently inefficient or harmful, but a plurality did report that they believed planners receive political pressure to convert industrial lands. Planners, of course, operate in political spaces and the built environment, with its attendant conflicts, is an inherently political battleground, but it is still illuminating to hear that respondents believe there is external pressure on planners for these decisions. 
Beyond these political conflicts, respondents' opinions on the viability of urban manufacturing/industrial work should lend urban industrial advocates some muted confidence. Respondents were generally supportive of urban industrial/manufacturing work as valuable, especially with respect to alleviating existing income inequality, but there is wariness over the long term viability of such work. While respondents do not seem to harbor any particular bias against industrial work, the consistent belief in the impending death of urban industrial labor can influence planners to set policies against such work. Such ideas can be exacerbated by the institutional fragmentation of industrial land management. It is not difficult to imagine a scenario where an economic development agency charged with supporting industrial users finds their policies at odds with greater land-use priorities on intensifying land uses, more generally, and focusing on preparing space for different industries, such as Eds and Meds.

Are protective cities different?

The overall results of the survey offer a relatively wide breadth of respondent understanding of their cities approaches to industrial land management and economic development planning. Over the past decade and a half, a select set of cities have passed industrial land preservation policies (Green 2018). Of the surveyed cities, seven have passed some form of industrial land preservation policy: Seattle, San Diego, Portland, Baltimore, San Francisco, Jacksonville and New York. These cities are regionally and economically diverse and yet have passed a similar set of policies within the past two decades. The next section presents a selection of the survey results cross tabbed by these 
protective cities versus non-protective cities in order to see if there are substantive differences in planning regimes or practices between the two types. I present a sample of the introductory questions and policy-specific questions to highlight the difference, or lack thereof, between groups.

A natural starting point would be to examine whether cities with protective policies are planning for industrial land more than non-protective cities. The table presents the contingency table of the question of whether cities' current comprehensive plans have sections dealing with industrial land. There is not a noticeable difference between the two groups.

Table 2: Respondents in both types of cities are planning for industrial land

\begin{tabular}{lll}
\hline A comp plan section on industrial land & Non-Protective & Protective \\
\hline No & 3 & 1 \\
Yes & 7 & 5 \\
Total & 10 & 6 \\
\hline
\end{tabular}

There is not a noticeable difference in planning for industrial land among respondents but that does not mean that protective cities do not face different industrial land supply constraints. The table presents the contingency table of the estimated industrial land supply question for protective and non-protective cities. Protective cities largely responded that their cities face immediate industrial land shortages compared to non-protective cities. This makes sense when looking at cities like Baltimore, Seattle or New York that have had particular growth pressures on their industrial lands. 
Table 3: Industrial Land Supply Contingency Table

\begin{tabular}{lrr}
\hline Current supply of your industrial land? & Non-Protective & Protective \\
\hline $1-5$ years & 1 & 3 \\
6-10 years & 1 & 0 \\
$11-15$ years & 3 & 3 \\
$16-20$ years & 1 & 0 \\
$21-25$ years & 2 & 1 \\
More than 25 years & 1 & 0 \\
Total & 9 & 7 \\
\hline
\end{tabular}

Soliciting an industrial land inventory is a signal that a city is concerned about the suitability and availability of developable industrial land. Even without a clear signal of an immediate shortage, cities that are being more strategic about industrial land resources could still create such reports. Cities with protective policies, then, may be more likely to have commissioned such reports. A larger proportion of protective respondents reported having an industrial land inventory, but a large proportion of non-protective cities had inventories also. This is another positive signal that industrial land seems to be a growing concern among planners.

Table 4: Land Inventory and Protective Policy Contingency Table

\begin{tabular}{lll}
\hline Industrial Policy & No & Yes \\
\hline Non-Protective & 3 & 7 \\
Protective & 1 & 6 \\
Total & 4 & 13 \\
\hline
\end{tabular}

An additional interesting observation is that half of the respondents for protective cities responded that their cities do not have greater urban manufacturing strategies. The lack of a greater reported manufacturing strategy is curious given the fact the respondents work 
in cities that are proactively seeking to protect their industrial lands. But this should be taken as a signal that the presence of a particular policy may not necessarily be a signal of a greater strategy.

Table 5: Greater industrial/manufacturing strategies are found in about half of cities

\begin{tabular}{lrr}
\hline Urban Manufacturing Strategy & Non-Protective & Protective \\
\hline No & 6 & 3 \\
Yes & 4 & 3 \\
Total & 10 & 6 \\
\hline
\end{tabular}

Overlapping Dilemmas

Planners face a series of overlapping dilemmas with respect to industrial land management. Earlier in the piece I noted the external and internal pressures planners face to convert industrial land. Survey responses offer additional support to the idea that planners face political pressure to convert industrial lands to non-industrial uses as well as political pressure to preserve industrial land either from community or business groups. Beyond those external pressures, though, planners also must battle their own perceptions and understanding of the current state of their cities' economies as well as the future state of those economies. And, of course, those future visions encompass planners' own conceptions of efficiency and desirability.

These internal and external pressures and contradictions are also exacerbated by institutional fragmentation and unclear policy directives. Even when planners reported their cities were planning for industrial land a review of comprehensive plans show either no actual industrial land policy or an incredibly underdeveloped policy. With respect to 
fragmentation, industrial land issues are split between economic development, redevelopment and land-use agencies, depending on the city, and it is unclear to what extent those agencies work strategically with each other on industrial development questions. Lacking greater strategies, even protective cities may still see continued industrial land conversion and the loss of industrial jobs without consistent monitoring and strategic planning.

\section{Limitations}

While suggestive, this study has multiple limitations. The first, in terms of external validity, is that the sample size is small. Even with a relatively robust response rate for my target population, this survey cannot give us truly generalizable conclusions regarding the thoughts of all planners. This is a weakness inherent to the design, but I believe these descriptive results are still interesting, offer some insight into how industrial land planners understand their city policies and can help to seed valuable additional research questions. Furthermore, I recognize any limitations in the ultimate survey design that may have discouraged potential respondents from completing the survey in full. In terms of internal validity, I sought to eliminate some of the more obvious threats but recognize some remain. A major validity challenge is the legitimacy of the respondents. I reviewed city staffing websites, made email inquiries and also made calls to departments to identify those who have direct responsibility over industrial land issues. I remain confident that the respondents are appropriate, but I realize that there may be multiple people in any given city who do similar work that may have different views. 
Additional limitation related to sample size are that I targeted large cities. Specifically, I targeted the fifty largest by population in the US in 2012. This clearly excludes small and medium sized cities, and while smaller cities must worry about industrial land issues, the particular forms of growth pressure and legacy industries that are reflected in this survey are specific to larger cities. This approach also excludes potential regional strategies to industrial land management. But there are very few regional governments with strong land-use decision making power and cities that do exist in such systems like Portland, Seattle and Minneapolis are represented in the survey respondents.

\section{Conclusion}

There is a growing realization in cities across the country that they face potential shortages of industrially zoned land. Critical urban scholars highlight a series of institutional and structural changes in cities that have contributed to these shortfalls. They include, but are not limited to: the abandonment of cities by the federal government in the 1970s and 80s forcing them to take on more entrepreneurial roles in order to support their tax bases; traumatic economic restructuring that decimated urban industrial employment; the dominance of development-oriented regimes seeking to profit from the transformation and conversion of industrial districts; land-use and economic development planning practices that eschew more comprehensive and strategic approaches in favor of piecemeal development approaches; and the pessimism of practicing planners with respect to the future viability of industrial work in their cities. But even within these structural constraints a handful of large American cities have taken a proactive approach in 
protecting their industrial lands challenging the conventional wisdom of how cities generally manage their land. In order to better understand what these new policies mean for practicing planners, the fragmented nature of economic development versus land-use planning and institutional change connected to industrial land policies I sent a survey to planners responsible for industrial land use policy in their cities.

The point of this is to gain a better understanding of how planners understand industrial land's importance to their respective cities and how planning for industrial land is encouraged or inhibited by institutional and structural features. Wolf-Powers (2005) in examining how planners approach industrial land conversion questions finds the combination of piecemeal planning approaches and planner perception of the future economy played major roles in their decisions to convert or not convert land. This paper seeks to explore across multiple cities how planners actually value industrial land and whether there are systematic differences between planners in protective versus nonprotective cities.

First, planners seem to be paying attention to the question of industrial lands. Even in cities without explicit industrial land preservation policies respondents reported that their cities either mentioned industrial lands in their comprehensive plans or commissioned some form of industrial land inventory. Even taking into account the relatively shallow way some cities approach industrial land in their comprehensive plans there are signals that the issue matters.

Second, survey respondents do offer evidence that their planning systems are fragmented concerning economic development and land-use. A plurality of respondents answered that 
the responsibility of industrial land or greater urban manufacturing/industrial strategies were not under the purview of their departments even though they are responsible for the proper management of industrial land. This does not imply there is no communication or collaboration, in fact in some cities like San Diego the requirement of the economic development office to release biannual reports on the supply of industrial land should help better inform land-use planning done in more traditional planning offices. But the historic separation of economic development and land-use remains in respondent cities.

Industrial land management's growing presence in city concerns seems to have already dramatically altered the way some cities do their planning. It is yet unclear whether these nascent institutional changes can help to bridge the historic gaps between economic development and land-use planning or the tensions between short term, entrepreneurial strategies as opposed to longer term more comprehensive approaches. But it is clear that this relatively obscure topic, industrial land management, has a growing salience to cities and planning practice and does hold potential for real changes to current practice. Researcher concerned with changing practice, the links between economic development and land-use or even policy implementation would be well served to examine industrial land.

\section{References}


Chapple, Karen. 2014. "The Highest and Best Use? Urban Industrial Land and Job Creation.” Economic Development Quarterly, August, 0891242413517134.

doi:10.1177/0891242413517134.

City of Dallas. 2006. “forwardDallas! - Economic Element.” Dallas, TX: Strategic Planning Division.

City of Tucson. 2013. “Chapter3-the Economic Environment.” Tucson, AZ: Planning \& Development Services.

Curran, Winifred. 2004. "Gentrification and the Nature of Work: Exploring the Links in Williamsburg, Brooklyn.” Environment and Planning A 36 (7): 1243-58. doi:10.1068/a36240.

- 2007. "'From the Frying Pan to the Oven': Gentrification and the Experience of Industrial Displacement in Williamsburg, Brooklyn.” Urban Studies 44 (8): 1427-40. doi:10.1080/00420980701373438.

—. 2010. "In Defense of Old Industrial Spaces: Manufacturing, Creativity and Innovation in Williamsburg, Brooklyn.” International Journal of Urban and Regional Research 34 (4): 871-85. doi:10.1111/j.1468-2427.2010.00915.x.

Dempwolf, C. Scott. 2010. “An Evaluation of Recent Industrial Land Use Studies: Do Theory and History Make Better Practice.” Retrieved August 28: 2010.

Eisinger, Peter K. 1988. The Rise of the Entrepreneurial State: State and Local Economic Development Policy in the United States. Univ of Wisconsin Press.

Fainstein, Norman I., and Susan S. Fainstein. 1987. "Economic Restructuring and the Politics of Land Use Planning in New York City.” Journal of the American Planning Association 53 (2): 237-48. doi:10.1080/01944368708976658.

Green, Jamaal. 2018. “Zoning for Jobs- Industrial Land Preservation in the Nation's Largest Cities.” Open Science Framework, February. doi:10.17605/OSF.IO/UD345.

Harvey, David. 1989. "From Managerialism to Entrepreneurialism: The Transformation in Urban Governance in Late Capitalism.” Geografiska Annaler. Series B, Human

Hum, Tarry. 2014. Making a Global Immigrant Neighborhood: Brooklyn’s Sunset Park. Philadelphia: Temple University Press.

Jenni Minner. 2007. “The Central Eastside Industrial District: Contested Visions of Revitalization."

Jonas, A. E.G, D. Gibbs, and A. While. 2011. "The New Urban Politics as a Politics of Carbon Control.” Urban Studies 48 (12): 2537-54.

Leigh, Nancey Green, and Nathanael Z. Hoelzel. 2012. “Smart Growth’s Blind Side: Sustainable Cities Need Productive Urban Industrial Land.” Journal of the American Planning Association 78 (1): 87-103. doi:10.1080/01944363.2011.645274.

Lemke, Jill M. 2010. “Maritime Industrial Zoning Overlay District (MIZOD), Summary and Evaluation 2009-2010.” Baltimore, MD: Department of Planning. 
Lester, T. William, and Daniel A. Hartley. 2014. "The Long Term Employment Impacts of Gentrification in the 1990s.” Regional Science and Urban Economics 45 (March): 80-89. doi:10.1016/j.regsciurbeco.2014.01.003.

Meltzer, Rachel, and Pooya Ghorbani. 2017. "Does Gentrification Increase Employment Opportunities in Low-Income Neighborhoods?” Regional Science and Urban Economics 66 (September): 52-73. doi:10.1016/j.regsciurbeco.2017.06.002.

Office of Planning and Community Development. 2018. "Seattle 2035, Comprehensive Plan- Urban Village Indicators Monitoring Report.” Seattle, WA: Office of Planning and Community Development.

Rast, Joel. 2001. "Manufacturing Industrial Decline: The Politics of Economic Change in Chicago, 19551998." Journal of Urban Affairs 23 (2): 175-90. doi:10.1111/0735-2166.00082.

Sagalyn, Lynne B. 2007. "Public/Private Development: Lessons from History, Research, and Practice.” Journal of the American Planning Association 73 (1): 7-22. doi:10.1080/01944360708976133.

Transportation Research Board, and National Cooperative Freight Research Program. 2012. Preserving and Protecting Freight Infrastructure and Routes. NCFRP 16. Washington, D.C.: National Academies Press. doi:10.17226/14650.

Wolf-Powers, Laura. 2005. “Up-Zoning New York City’s Mixed-Use Neighborhoods Property-Led Economic Development and the Anatomy of a Planning Dilemma.” Journal of Planning Education and Research 24 (4): 379-93. doi:10.1177/0739456X04270125. 
Keeping Space for Jobs: Evaluating Industrial Land Protection Policies

Introduction

The story of US deindustrialization is well known. From the decentralization of industrial plants from union heavy northern areas to the offshoring of production to Asia, the general narrative of US manufacturing employment is one of traumatic decline that devastates communities and is responsible for growing income inequality (Bluestone and Harrison 1982).These losses are often attributed to growing productivity, skill biased technical change or labor competition from lower cost countries (Weaver and Osterman 2016). But this narrative may overstate possible effects missing alternative explanations such as the role of changing corporate strategy and structure on management decisions (Berger 2014). Urban planners, geographers, and regional economic development scholars are now highlighting another potential major factor in local deindustrialization- local and regional land use management, specifically, the loss of land available for industry.

Recent research has tracked the dramatic loss of industrially zoned land in growing, large US cities. Recent analyses from Leigh and Hoelzel (2012), Chapple (2014), and Lester et al (2014; 2013) have explored how dominant urban policy approaches are oriented towards the conversion of industrial lands to non-industrial uses accelerating local labor market restructuring and deindustrialization. Recognizing these gaps, a select number of large US cities have passed new regulations protecting industrial and 
employment lands. Though cities, and researchers, argue that preserving industrial land will help keep manufacturing and industrial jobs in cities, there is a lack of research on the actual jobs impact of such policies. This is due to a combination of the novelty of these policies (many were passed in the last fifteen years) and the lack of available employment data at fine enough geographies to reasonably estimate employment impact at the intra-city scale.

This study relies on a novel data set of existing industrial preservation policies within 45 large cities in the US and local employment data from the Census's Longitudinal Employment Household Dynamics (LEHD) Origin-Destination Employment statistics data set to answer two research questions: first, what is the state of urban manufacturing and industrial employment within cities today; and, second, what is the causal effect of industrial land preservation policy on manufacturing and industrial employment between 2009 and 2015? I employ a quasi-experimental technique- inverse propensity score weighting- to answer the causal question and find a null effect of industrial land preservation policies for both greater industrial and manufacturing employment.

The next section of the study will review the existing literature on industrial land preservation and labor market restructuring, followed by a description of the study's methodology and data, and final discussion section.

\section{Literature Review}

This section will cover recent work on land-use change and labor market restructuring. First, the predominant land-use policy paradigm in the contemporary United States- Smart 
Growth- is under increased scrutiny for encouraging cities to convert industrial land to non-industrial uses regardless of its current strategic or employment value. This highlights a growing contradiction in many cities across the US as they attempt to balance robust population growth with maintaining existing industrial jobs. Second, the question of industrial land, land-use change, local labor market restructuring, and business growth has come back to the fore for economic development researchers. Succinctly, what are the actual labor market and business effects of converting industrial land?

\section{Blindness and Best Uses}

The predominant land-use policy paradigm in the US today is Smart Growth. While not all major cities necessarily call their plans Smart Growth plans, the general principles of encouraging mixed-use, transitoriented development and densifying existing urban areas are now common place and owe their popularity largely to the spread of Smart Growth principles. Unfortunately, Smart Growth proponents have generally ignored the value of industrial lands. Leigh and Hoelzel (2012) reviewed the industrial policies of 13 cities and 10 major Smart Growth publications from Smart Growth America, the Environmental Protection Agency, and Planning Advisory Service (PAS) guides from the American Planning Association. They found that while cities may be concerned with the loss of industrial land and jobs, the dominant land-use guides cities draw from generally frame industrial lands in a negative light as either obsolete, a fiscal drag, or generally polluted. Leigh and Hoelzel highlight a major contradiction in many cities, especially faster growing cities, where policymakers are aware of the importance industrial land and jobs, and even have policies to support them through small business 
support or worker training, yet their land-use policies work directly against them by encouraging the conversion of industrial land to non-industrial uses.

A common reason given for the conversion of industrial land to non-industrial uses is that land should be given over to its "highest and best use". Thus an industrial district in a growing part of a city should be converted to non-industrial if developers are willing to outbid existing industrial users for the land. This argument is generally supported on efficiency grounds but it utterly devalues the role that industrial land, and users play, in greater urban and regional economic development and business growth. Chapple (2014) offers one challenge to this assertion by estimating the role industrially zoned land plays in regional business dynamics- the creation, growth, and death of firms. Chapple finds that firm creation, and growth of newer firms, are correlated with the availability of industrially zoned land in four Bay Area cities. The theory underlying these results is that available industrial land not only lowers start up costs for new firms, but also allows firms to expand in place. Industrial land will not make ineffective firms viable but industrial land does make already effective firms stronger by offering them flexible space for expansion.

While Chapple (2014) examined the regional business dynamics of industrial land supply, Lester and Hartley (2014) estimated the effect of local neighborhood gentrification on labor markets. They find that local gentrification has moderate positive overall effects on employment growth but it also responsible for dramatic industrial restructuring in neighborhoods replacing prior industrial jobs with lesser paid service jobs. In their findings, Lester and Hartley link the processes of social, and physical, neighborhood change to localized economic restructuring. Lester and Hartley’s work should be seen as 
an extension of Curran's $(2007 ; 2004)$ work examining the local policies and practices that forcibly displace manufacturing firms as part of broader, global patterns in capital accumulation and uneven development. Both sets of studies, though, are unequivocal in stating that industrial employment change, particularly deindustrialization, is not wholly an exogenous phenomenon but one that is intimately tied to local policies and priorities. Curran, in particular, examines how the interplay of deindustrialization, labor disputes, and city real-estate interests combine to weaken the standing of industrial employers in Brooklyn as well as contribute to an overall narrative of industrial decline.

\section{Placing Urban Industry}

A perennial fight in many cities is whether manufacturing or industrial operations belong at all in cities. Opponents of industrial land protection argue that protecting industrial users is inherently inefficient as uses of industrial land are less productive than competing uses that can outbid industrial users for centrally located land (Hills and Schleicher 2010; Louw, Krabben, and Amsterdam 2012). Additionally, opponents of such regulations can point to contemporary industrial location theory that predicts that in the face of falling transportation costs goods producing firms are more likely to decentralize operations as they seek to find the proper equilibrium between individual firm production functions and external spatial transaction costs (Mccann and Sheppard 2003; Glaeser and Kohlhase 2003)

But while neoclassical industrial location theory offers reasons for the continued decentralization of US manufacturing, we see that urban manufacturing persists in many 
places precisely because firms value or require their urban settings. Additionally, such firms are more productive, by definition, precisely because they are able to stay within urban areas and compete in more expensive land markets. Byron and Mistry’s (2011) Brookings report on urban manufacturing highlights the metropolitan centralization of smaller urban manufacturing firms that benefit from from their urban locations including, but not limited to, proximity to customers and suppliers and the ability to draw on the larger skilled labor markets in metropolitan areas. These smaller firms, more dependent upon existing relations with proximal firms and close working relationships with clients, garner their competitive advantages precisely because they are urban. Van Winden at al (2010) expand on this point noting that more advanced manufacturing requiring closer relationships with clients for prototyping and testing reward proximity and encourage agglomeration. In short, aspects of contemporary manufacturing and industrial work have distinct urban biases. The massive single story production facilities for automobiles may never return to American cities, but they do not have to in the face of other manufacturing industries in food processing, semiconductors or autonomous vehicle prototyping and testing.

Urban deindustrialization is still largely understood to be an exogenous phenomenon where global competition, technical change or falling transportation costs are principally responsible for the loss of industrial jobs. But work from critical geographers such as Curran (2004, 2007) and planners such as Leigh and Hoelzel (2012) and Lester and Hartley (2014) point towards local policy as a significant factor in local economic restructuring. In the face of the combination of both external and internal factors, a select group of cities in the US have passed industrial land protection policies 
to keep and grow existing industrial jobs. But, to date, there has not been a study of the efficacy of these policies on a national scale.

In order to understand the effect of local development policy on labor market I am estimating the effect of industrial land preservation policies on the change of manufacturing, and broader industrial, employment at the census tract level between 2009 and 2015.

The Large City Geography of Production

While manufacturing is often the poster child for urban industrial employment and development, the availability of industrial land serves multiple kinds of industrial users allowing analysts to measure the geography of production in multiple ways. For this study, I tracked both manufacturing employment (CNS05 in the LEHD corresponding to the NAICS industry sectors 31-33) and a broader "industrial" employment category that is the sum of agricultural, mining, utilities, manufacturing, wholesale trade, and transportation and warehousing employment.

Urban Manufacturing Is Not Dead, But In Some Cities It Is Dying

From 2004-2015 for the 45 large cities where data is available manufacturing still has a significant presence in city labor markets in both absolute and relative terms but the state of manufacturing across cities is decidedly mixed. Figure 1 shows the broad pattern of the change in manufacturing employment over time in the nation's largest cities. Most 
cities, unfortunately, have lost manufacturing employment compared to their 2004 employment, corresponding to a more general belief that manufacturing is losing in the country and that cities, especially, are inhospitable places. But there are some notable exceptions. Of particular note are Texan energy cities like Houston and Arlington that have had tremendous growth compared to their 2004 baselines (Figure 1). On the other end, manufacturing employment loss does not seem to have any particular major patterns with growing, bustling cities like Seattle losing significant portions of their manufacturing employment compared to its 2004 baseline along with long suffering cities like Baltimore and Detroit.

Cities with the most dramatic manufacturing growth are also those cities with the greatest employment growth showing a pro-cyclical employment effect for manufacturing, but the share of manufacturing in these fastest growing cities is generally falling.

Beyond the growth rates, the absolute number of manufacturing jobs across the largest cities in the country is higher than most would assume. In 2015, there were approximately 1,433,927 primary jobs in manufacturing in the nation's 47 largest cities. Of these 47 cities, 26 had at least 20,000 primary manufacturing jobs, and 7 cities had at least 50,000 primary manufacturing jobs. While these numbers challenge the conventional wisdom of American large cities as devoid of manufacturing these jobs are still a modest share of all jobs in most cities. The average share of manufacturing jobs in these cities in 2015 is only $6.1 \%$, with a median value of $5.3 \%$. 


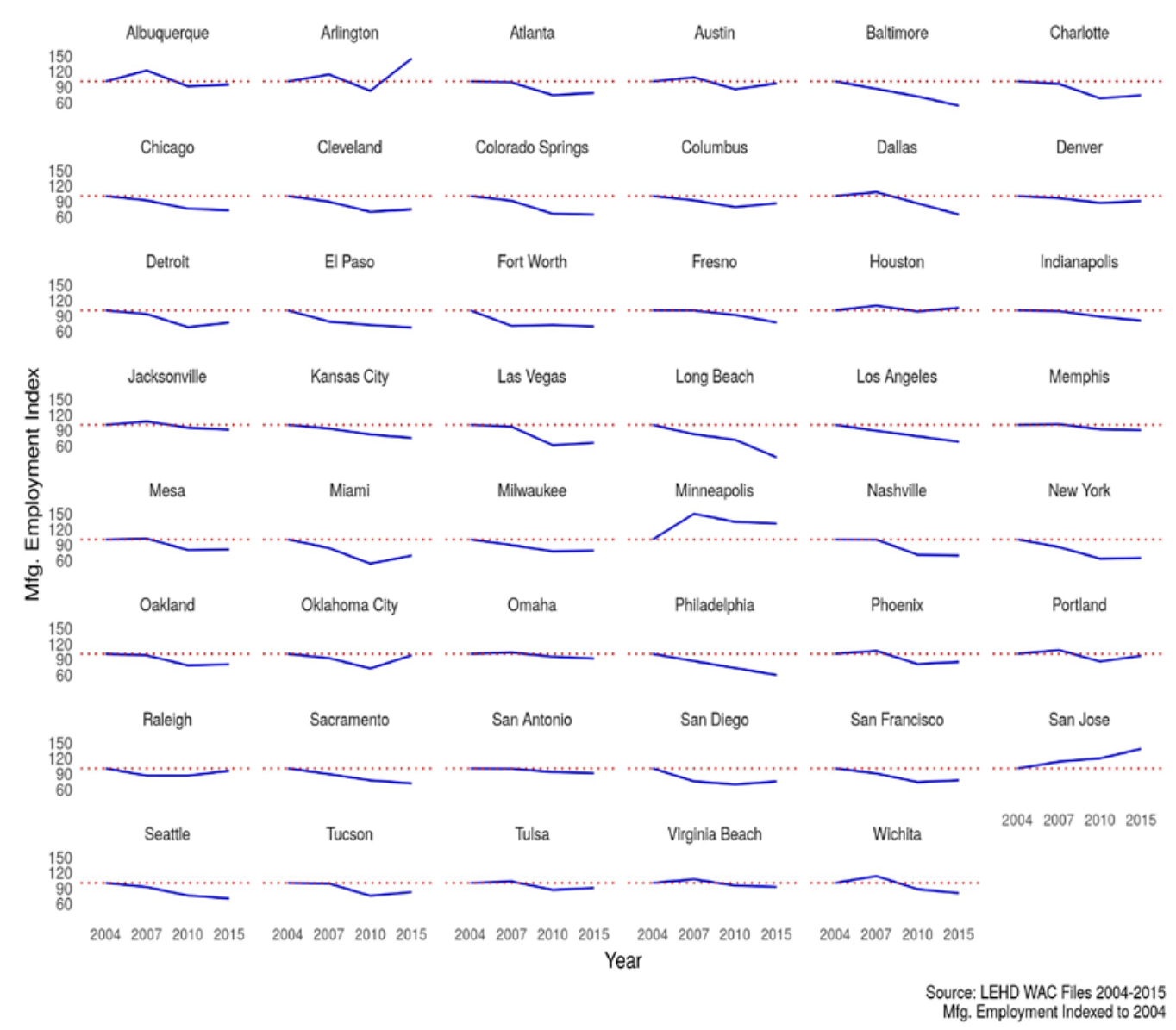

Figure 1: Change in manufacturing employment for the nation’s largest cities

The general patterns of manufacturing employment are decidedly mixed. Most cities have lost manufacturing employment since 2004 due primarily to the extreme shock of the Great Recession. That being said, manufacturing employment has not only recovered but also grown in four cities: Arlington, Houston, Minneapolis and San Jose. These cities all specialize in different areas and have dramatically different absolute and relative amounts of manufacturing employment suggesting that their success is not necessarily tied to one particular industry, region of the country, or land-use regime. 
While manufacturing occupies much of the rhetorical space in debates on urban industrial employment, manufacturers are not the only users of industrial land nor is manufacturing necessarily the primary source of what many would consider to be industrial jobs. Utilities, wholesale distribution businesses and even urban cannabis growers all require access to industrial land, not to mention many of the ostensibly nonindustrial occupations, such as clerks and data analysts, that still often work onsite to support industrial operations. In order to capture these jobs I summed the jobs for agriculture, mining and oil/gas extraction, utilities, manufacturing, wholesale trade, and transportation and warehousing. These industrial categories are admittedly broad but many of their sub-industries and largest occupational groups correspond to what we would normally view as "industrial" jobs.

Similar to manufacturing jobs, the cities with the most dramatic industrial jobs growth belong to cities with robust overall employment growth. Additionally, 21 cities had positive industrial job growth from 2004-2015. But due to the general decline in manufacturing employment, the trend of industrial job growth is lower, or negative, in many cities. For example, Long Beach’s industrial employment falls from 34,458 jobs in 2004 to 


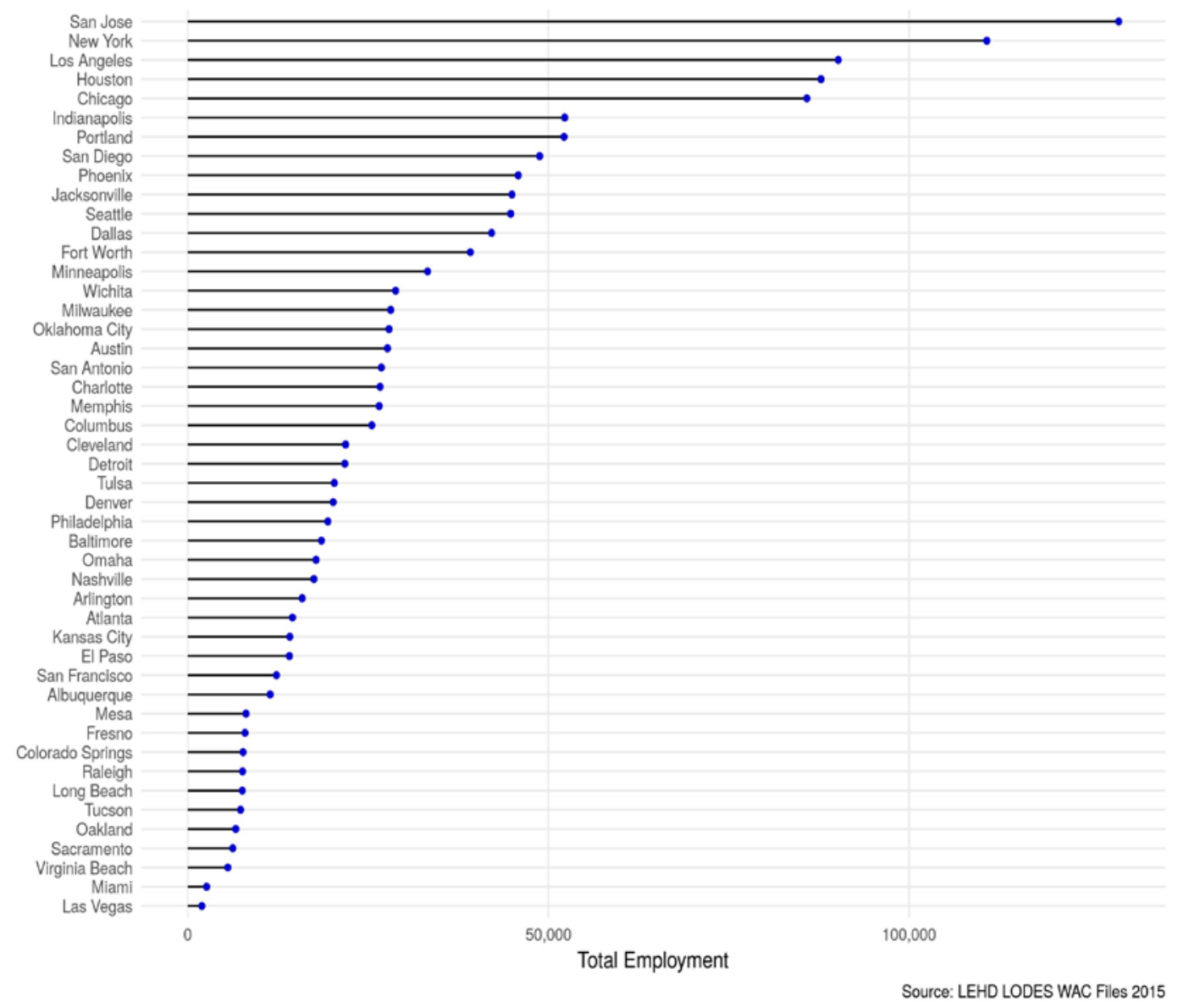

Figure 2: Most Large US Cities had at least 25,000 manufacturing jobs 


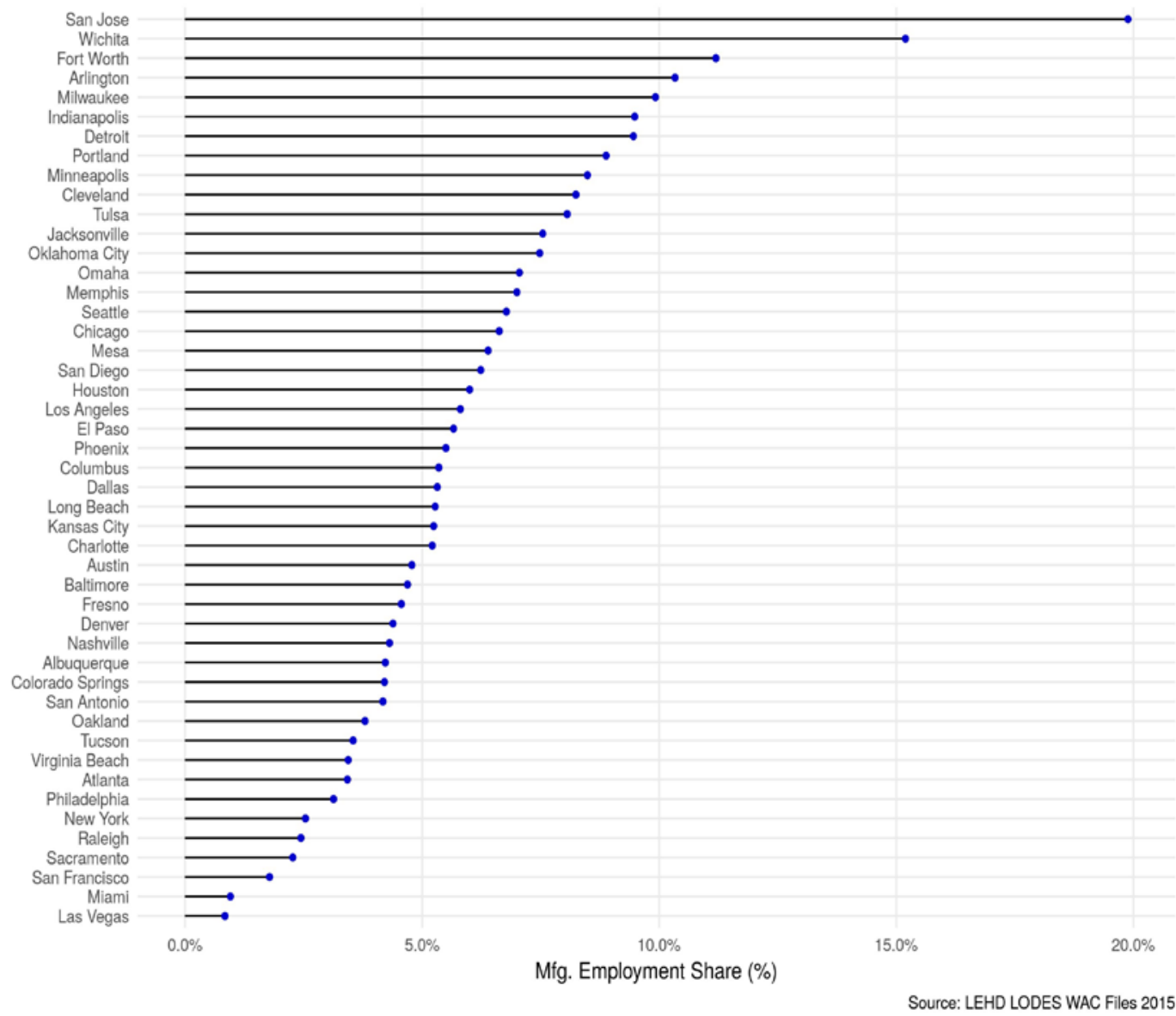

Figure 3: Wichita and San Jose lead large cities in the percentage share of jobs in manufacturing 


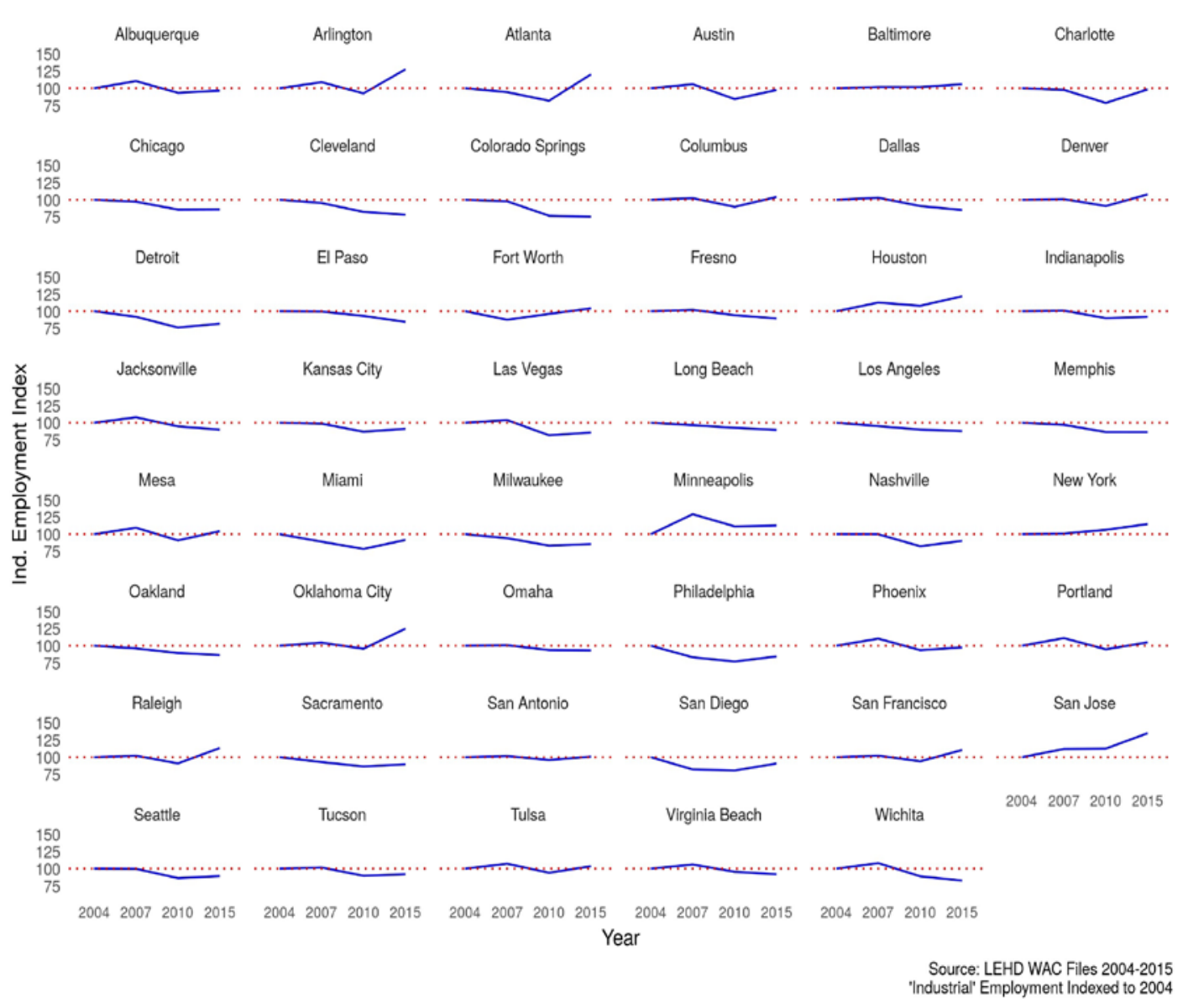

Figure 4: 'Industrial' employment is growing in nearly a quarter of large US cities

30,864 jobs in 2015- a 12\% drop. But excluding manufacturing employment, “industrial” jobs increased from 14,258 to 23,301 jobs, nearly an increase of two-thirds.

Industrial jobs' share of overall employment across the cities generally fell from approximately an average share of $19 \%$ in 2004 to $16 \%$ in 2015 . Twelve cities, though, have $20 \%$ or greater of their total jobs as “industrial” with Forth Worth leading the way with nearly a third of primary jobs coded as industrial in 2015. 
Absolute industrial employment numbers largely follow overall city labor market size with Houston, New York, and Los Angeles leading the country in overall industrial primary jobs, though Fort Worth is also in the top ten cities.

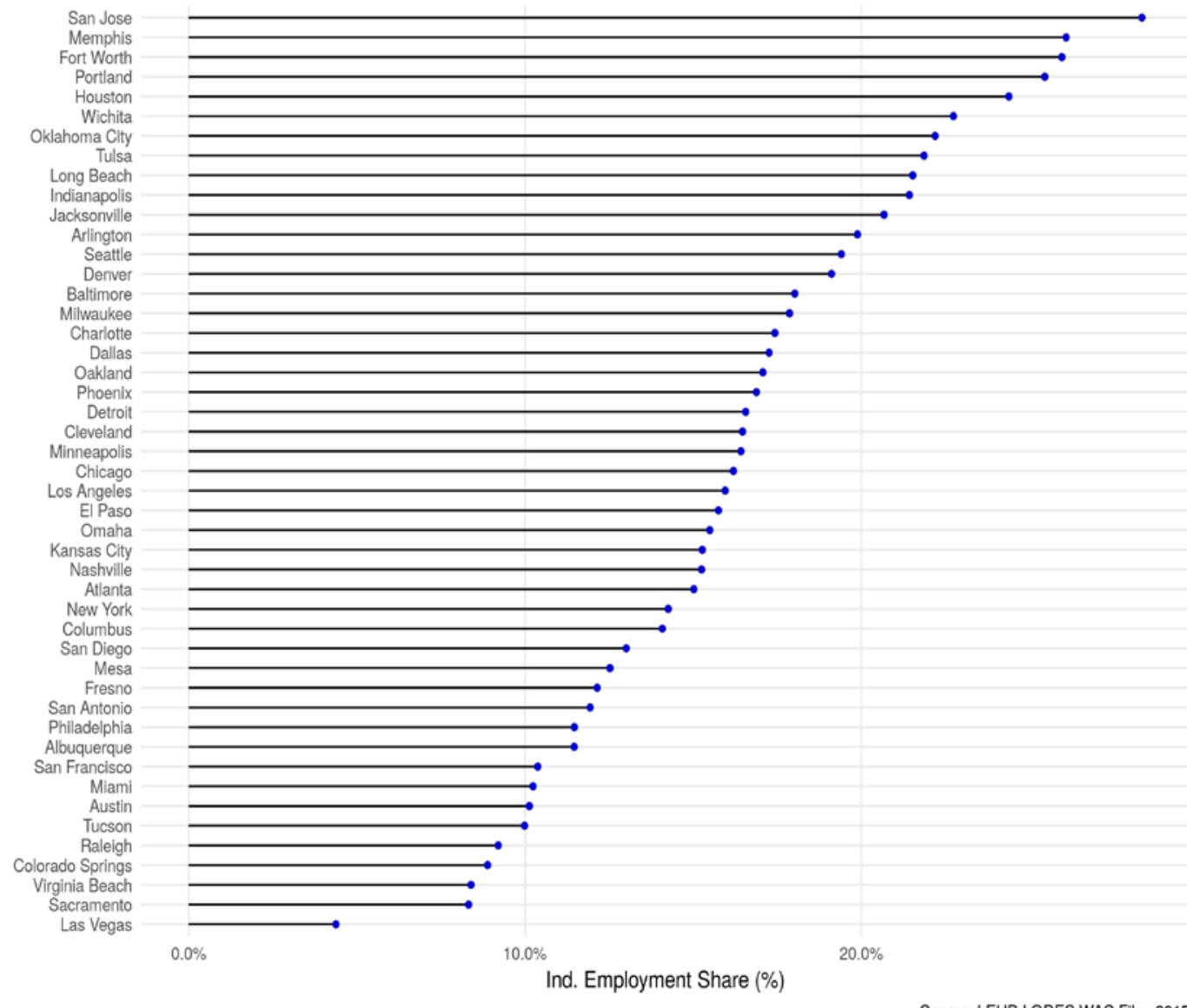

Figure 5: Industrial Job Share of Total Employment, 2015

\section{$\underline{\text { ILP Policies }}$}

I have identified 8 cities in the sample with an industrial land protection (ILP) type policy. I use the list of cities identified as protective in Green (2018). An ILP is a distinct land use classification with some form of additional protection for industrially zoned 
land. Additionally, the language of the ordinance must frame industrial land as an asset as opposed to the more traditional nuisance language found in zoning codes. The archetypal example is Chicago's Planned Manufacturing District ordinances that protect specific industrial corridors and outright ban residential conversion and require additional process steps for proposed re-zonings (see (Green 2018) for an overview). These policies vary in three main ways from one another- temporal, spatial, and regulatory. First, these policies were not passed at the same time. All of the cities included in the model passed their policies in since 2000, but Portland and Chicago (not included here) passed their policies in the late 80s/early 90s. Spatially these policies cover different parts of their respective cities and different shares of overall industrial land. For example, Jacksonville has two policies, one strict policy that covers marineserving land, and a weaker policy that provides an additional buffer surrounding the more strict areas. The result is that a significant portion of the city's available industrial land is covered under one of the two policies. Conversely, Baltimore's policy is restricted to protected port lands only. Finally, each policy has its own rules and restrictions regarding converting land to non-industrial uses. While this variation does not allow a true 1:1 comparison of policies, all of the policies make it harder to convert industrial land to non-industrial uses and so functionally all seek to reach the same goals. 
Table 1: Cities with ILP Policies (excludes Chicago and Portland)

\begin{tabular}{lr}
\hline City & \multicolumn{2}{c}{ Year } \\
& Passed \\
\hline Baltimore & 2004 \\
San Diego & 2008 \\
Jacksonville & 2007 \\
Seattle & 2002 \\
San Jose & 2007 \\
Minneapolis & 2009 \\
San & 2008 \\
Francisco & \\
New York & 2006 \\
\hline
\end{tabular}

Data and Methodology

$\underline{\text { Data }}$

The primary data source for this study is the Workplace Area Characteristic (WAC) file Longitudinal Origin-Destination Employment Series (LODES) data set from the Longitudinal Household Employment Dynamics (LEHD) data set from the US Census Bureau[^1]. The LODES data set combines administrative employment data from state unemployment insurance filings with Census population information to offer a geographically fine (census block level) measure of employment for major industrial categories. In addition to its geographic specificity, most states in the country have LODES data going back to 2002 allowing for a truly longitudinal study of the changes in the geography of jobs.

\section{LEHD}


For this study, I collected LODES WAC data for the years 2004-2015, for 45 of the US's 50 largest cities aggregated to the census tract level for all tracts with at least 189 jobs (this excludes excessively residential tracts that are not relevant to the study). There are 45 cities due to a incomplete data for some states in the LODES data set (Washington DC, Massachusetts). Chicago and Portland were dropped from the model because they passed their protective policies in the late 80s/early 90s. LODES data is normalized to 2010 census geographies allowing for valid comparisons across time and the ability to easily join the data to other census sources. From the LODES I collected agricultural, mining, utilities, manufacturing, wholesale trade, transportation, information, finance and insurance, real estate and rental and leasing and management of companies and enterprises employment for all primary jobs (LEHD job type code “JT01”). I use primary jobs as they are the highest paying job for an individual worker for the year and each primary job is matched to only one worker.

The LEHD LODES data offers immense opportunities for intra-city analysis, but collecting and organizing the data is a complicated endeavor. In order to make it possible to collect the flat files from the LODES I created an R package- lehdr. The LODES dataset comes in a series of compressed csv files based on state, year, job type and segment of the workforce at the census block level. Thus for an analyst attempting to do longitudinal analysis across multiple states they must download potentially dozens of files, load them separately into their software package of choice and manipulate them from there. The lehdr package solves this problem by calling the Census FTP that holds the flat files and downloads them directly. Beyond simply downloading multiple years and states at the same time, lehdr also aggregates LODES data up to the state level 
following the standard census geography hierarchy: block, block group, tract, county and, finally, state. This tool eliminates one of the largest barriers to using LODES data.

\section{Additional Data}

Census tract population data was collected from the Census 2000 SF3 table using the Longitudinal Tract Database (Logan, Xu, and Stults 2014). The Census information collected includes estimates of total, Non-Hispanic White, Non-Hispanic Black, and Hispanic residents. Additionally, I collected the total number of housing units and the total number of owner and renter occupied units. Finally, I calculated total population density $\left(\mathrm{km}^{\wedge} 2\right)$.

Finally, I calculated street network density from the Environmental Protection Agency's Smart Location Database (SLD) (Environmental Protection Agency 2013). The SLD is the most comprehensive national level database of the urban built environment publicly available collected at the block group level. In order to re-calculate the street network density from the block group to the census tract I used the following equation:

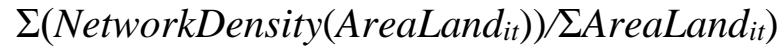

Succinctly, I take the sum of the product of the network density measure and land area of block groups by census tract. That term is divided by the sum of the areas of the block groups by census tract.

Finally, I include dummy variables for whether a tract intersects with what I call an ILP, or Industrial Land Preservation Zone. ILP shapefiles were collected from individual city websites, given upon request by the city, or, in the case of New York City, manually 
created from the affected parcels by extracting IBZ tax lots from city PDFs and joined to the city’s PLUTO tax lot system.

\section{Methodology}

Identification Strategy

In order to measure the impacts of ILP-type policy, I employ a quasi-experimental method- propensity score weighting (Austin 2011b; Rosenbaum and Rubin 1983). Propensity scores are the probability of a unit of observation receiving treatment conditioned on a set of characteristics. For this project I am using the inverse probability method with the goal of estimating the Average Treatment Effect (ATE) which is the average effect of moving the entire population from control to treatment (in this case transitioning block groups to industrial preservation) and Average Treatment Effect on the Treated (ATT). Once the propensity score is estimated and the weights are calculated the weights are used in a weighted regression of the treatment dummy variable regressed on the dependent variable- change in manufacturing and industrial employment between 2009 and 2015. If the dummy variable is significant, then this signals a causal effect of the treatment on your observations.

The ATE is defined as:

$$
A T E=E\left(y_{1}\right)-E\left(y_{0}\right)
$$

This corresponds to the expected value of $y_{1}$ in the treatment minus the value of $y_{0}$ in the untreated group. The point of the propensity score is to calculate a balancing score such 
that the conditional distribution of covariates for treated and untreated groups are the same. This balanced score creates a pseudo-population of units that allow for a direct comparison (Rosenbaum and Rubin 1983). Additionally, using the propensity score, one can calculate the average treatment effect of the treated, or the average effect of the treatment on treated variables (McCaffrey, Ridgeway, and Morral 2004):

$$
A T T=E\left(y_{1} \mid z=1\right)-E\left(y_{0} \mid z=1\right)
$$

The choice of ATE versus ATT is one of personal preference and theoretical appropriateness. I present both in this study in order to be thorough, but the ATT, average treatment effect on the treated, is the more theoretically interesting metric for this study. While the ATE is informative, it is unlikely, let alone preferable, that a city would place ILP type policies on every land-use type in the city. In this case, especially because these policies are explicitly spatial to begin with, that the policy concern is one of the changes in jobs in the areas covered by the policies.

Traditionally, propensity scores are calculated using logistic or probit regression. For this study though, I use a generalized boosted model approach from the R package twang to estimate both ATE and ATT weights (Ridgeway et al. 2017). Generalized boosted models are an unsupervised machine learning approach that can be used to predict assignment. The basic logic behind boosted models is that at each step a classifier is fitted to the training data, if an observation is accurately classified, then it receives a relatively low weight while observations that are incorrectly classified receive a higher weight so the algorithm works on improving predictions for hard to classify units (Hastie, Tibshirani, and Friedman 2009). Finally, the boosted model is combined with regression trees, another unsupervised 
machine learning approach. Tree-based modeling approaches work by taking a set of covariates and splitting on a value of a single covariate and estimating a model. For example, for a model with two covariates, age and sex, a tree-based model may first take the age variable, split it at 18 so you have two models with age older and less than 18 , the algorithm then predicts the outcome variable for the split variable and then the algorithm chooses the model that minimizes the sample mean of the dependent variable (Hastie, Tibshirani, and Friedman 2009; McCaffrey, Ridgeway, and Morral 2004). At each step the tree continues to partition the variables until it reaches the end of the number of splits as set by the analyst. The number of trees is set by the analyst with the general rule of thumb that the greater number of partitions the greater the complexity of the tree. Combining these two approaches, the gradient boosted model approach recursively calculates the probability of a unit receiving treatment across multiple regression trees. An advantage of the GBM approach over logistic or probit regression is the averaging of results over multiple trees moderates the effect of outlier observations on estimated probabilities. Additionally, the stopping method of the approach is based upon the models that give the best balance of covariates between treated and untreated groups. While logit or probit models are the more traditional approaches to weighting, the use of ensemble machine learning methods like GBM are being used in preventive medicine, education and urban studies (Cohen et al. 2009; Gormley, Phillips, and Anderson 2018; Austin 2011a).

In order to calculate weights I estimated the ATE and ATT propensity scores using the twang package on 7,905 census tracts across 45 cities. This sample includes all tracts with at least 189 jobs (the first quartile of employment at the tract level). The package automatically calculates the inverse probability weights. A primary assumption of 
propensity scores is that treatment assignment depends on the values of pre-treatment variables (Rosenbaum and Rubin 1983; Sutton 2014). This is why as stated in the previous section I collected data from the 2000 Census and the 2004 LEHD data, the earliest year available with coverage of all of the cities in the sample. The final propensity score treatment models included the following variables; population density; percent of housing units that are vacant; the percent of renter occupied housing units; the jobs to population ratio for 2004 total employment to 2000 population; the percent of employment in manufacturing; and the share of "FIRE" employment, "FIRE" jobs being the sum of information, finance and insurance, real estate, and the management of companies and enterprises; and the share of jobs in retail trade.

The proper specification for the is a matter of theoretical debate. A central issue is whether the propensity score model should focus on variables that are predictive of an observation receiving treatment or should variables be predictive of the ultimate outcome of interestin this case, manufacturing and industrial employment growth. This is matter of debate, but in practice, analysts include both sets of variables out of a sense caution and desire to avoid omitted variable bias.

The population based variables were included under the assumption that census tracts with less people, more vacant units, a greater proportion of renters or generally less dense would be more likely to receive the treatment than other tracts due to a lack of people to fight said designation or assuming that they had less political power. The jobs variables were included with the assumption that tracts with a greater diversity of industries, particularly FIRE employment, would be less likely to receive treatment than tracts dominated by industrial or manufacturing employment. In addition to predicting the probability of a tract 
receiving treatment, I assume tracts with a greater industrial mix would be less likely to see employment growth in manufacturing or "industrial” employment compared to tracts with less diverse industrial mixes. I also included two built environment variables- street network density and the Euclidean distance to central business district to the tract centroid. The effect of distance from the CBD on the probability of treatment is ambiguous. In cities where ILP type policies were passed thanks to significant external pressure, like Chicago, the proximity to the CBD would be a predictor or protection, but for a city like San Diego it would not. I also hypothesize that distance to CBD has an ambiguous to positive relationship to employment growth.

Network density has ambiguous relationships to the probability of treatment and future employment growth, but do represent part of the underlying physical context that different industries find themselves within.

Table 2: Independent variables for propensity score model

\begin{tabular}{lll}
\hline Variable & Year & Data Source \\
\hline Population Density (sq. km.) & 2000 & Census \\
\% Vacant Units & 2000 & Census \\
\% Renter Occupied Units & 2000 & Census \\
Jobs to Population Ratio & $2000 / 2004$ Census and \\
& & LEHD \\
\% Manufacturing & 2004 & LEHD \\
$\begin{array}{l}\text { Employment } \\
\text { \% Industrial Employment }\end{array}$ & 2004 & LEHD \\
\% FIRE Employment & 2004 & LEHD \\
\% Retail Employment & 2004 & LEHD \\
Road Network Density & 2010 & EPA SLD \\
Distance to City Center (km) & - & Calculated \\
\hline
\end{tabular}


For example, a denser street network would be less convenient for firms that need to move massive amounts of goods in large trucks, but would help firms that depend upon proximity to surrounding firms.

Separate models were estimated for the ATE and ATT weights and separate models were estimated based on the share of employment in manufacturing or industrial employment, respectively. These weights were then applied to a final regression model regressing the change in either manufacturing or industrial employment in a tract from 2009-2015 on a dummy variable for whether or not the tract is in a ILP. Robust standard errors are calculated and clustered at the city level using the estimatr package in R (Blair et al. 2018; R Core Team 2017). The final results are four models: $\Delta$ Manufacturing $2015-2009$ ATT,

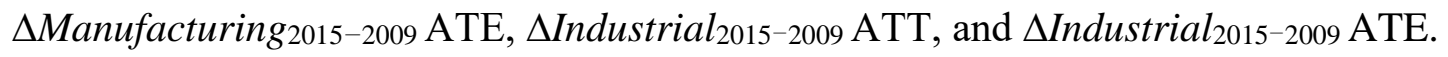

The table shows the mean values for the independent variables that go into the propensity score model. A cursory inspection shows the differences in means between the two groups. Somewhat surprisingly, the differences are not as extreme when comparing built environment features or select population features. The differences truly arise when comparing the employment structure of the census tracts. Tracts under ILPs have much larger jobs to population ratios, greater shares of industrial and manufacturing work and smaller average shares of service employment. Also note that ILP treated tracts are significantly closer to their city centers than non-treated tracts lending credence to the notion that these protective policies are often used to defend especially centrally located industrial districts at greater risk for conversion. These mean values not only illustrate the 
importance of proper identification between the two groups, but also offer some preliminary evidence that there are real systematic differences between treated and nontreated tracts.

Table 3: Mean Values for Independent Variables

\begin{tabular}{lrr}
\hline Variable & Non-ILP & ILP \\
\hline pop2000_density & 5608.6432522 & 3007.9547144 \\
vacant_units_per2000 & 0.0694357 & 0.0701960 \\
rent_occ_units_per2000 & 0.4866763 & 0.5560608 \\
jobs_to_pop_ratio & 13.2999493 & 118.6534374 \\
mfg_share & 0.0745082 & 0.2035632 \\
ind_share & 0.1614641 & 0.44444424 \\
fire_share & 0.1062007 & 0.0784641 \\
retail_share & 0.1512359 & 0.0941538 \\
dist_km & 10.5499749 & 8.5458801 \\
road_network_density & 21.6298218 & 21.5950530 \\
\hline
\end{tabular}

GBM Results

While the ultimate individual variable results are not important, the twang package does allow for the examination for the relative importance of individual variables in the estimation of the propensity score. The relative importance of variables can help one to understand if a particular variable matters for prediction, but the individual influence of any particular variable does not matter when compared to overall predictive accuracy of the model and its success in minimizing the difference between the treated and untreated variables distributions. 
Table 4: Relative Variable Influence for Manufacturing Employment ATE Propensity Score Models

\begin{tabular}{lr}
\hline Variables & \multicolumn{2}{c}{$\begin{array}{l}\text { Relative } \\
\text { Influence }\end{array}$} \\
\hline mfg_share & 43.505586 \\
jobs_to_pop_ratio & 42.704133 \\
retail_share & 3.099245 \\
pop2000_density & 3.093465 \\
vacant_units_per2000 & 3.088667 \\
rent_occ_units_per2000 & 2.890573 \\
road_network_density & 1.618331 \\
fire_share & 0.000000 \\
dist_km & 0.000000 \\
\hline
\end{tabular}

Table 5: Relative Variable Influence for Manufacturing Employment ATT Propensity Score Models

\begin{tabular}{lr}
\hline Variables & \multicolumn{1}{l}{$\begin{array}{l}\text { Relative } \\
\text { Influence }\end{array}$} \\
\hline mfg_share & 24.407914 \\
jobs_to_pop_ratio & 23.039004 \\
pop2000_density & 10.213140 \\
rent_occ_units_per2000 & 9.295684 \\
dist_km & 8.419735 \\
road_network_density & 6.589730 \\
retail_share & 6.407573 \\
fire_share & 5.982151 \\
vacant_units_per2000 & 5.645069 \\
\hline
\end{tabular}


Table 6: Relative Variable Influence for Industrial Employment ATE Propensity Score Models

\begin{tabular}{lr}
\hline Variables & \multicolumn{2}{c}{ Relative } \\
& Influence \\
\hline jobs_to_pop_ratio & 38.629361 \\
ind_share & 4.771463 \\
dist_km & 4.410849 \\
pop2000_density & 3.768066 \\
vacant_units_per2000 & 3.468944 \\
rent_occ_units_per2000 & 3.224995 \\
road_network_density & 2.262845 \\
fire_share & 1.971580 \\
retail_share & \\
\hline
\end{tabular}

Table 7: Relative Variable Influence for Industrial Employment ATT Propensity Score Models

\begin{tabular}{lr}
\hline Variables & \multicolumn{1}{l}{$\begin{array}{l}\text { Relative } \\
\text { Influence }\end{array}$} \\
\hline jobs_to_pop_ratio & 26.294980 \\
ind_share & 25.677660 \\
pop2000_density & 8.596356 \\
rent_occ_units_per2000 & 8.256006 \\
dist_km & 7.182868 \\
road_network_density & 6.848170 \\
vacant_units_per2000 & 6.641657 \\
retail_share & 5.735979 \\
fire_share & 4.766324 \\
\hline
\end{tabular}

Variable Balance

In order to determine whether the propensity scores have properly balanced the distributions of the treated and untreated group it is necessary to run balance tests. Two 
measures are generally recognized as appropriate measures of balance: the standardized mean difference and the Kolmogorov-Smirnov (KS) test. The Kolmogorov-Smirnov test compares the distance between the empirical cumulative distribution functions of each variable for the two treatment groups. The KS test ranges between 0 and 1 with 0 meaning perfect overlap of the two distributions and one perfect separation between the groups. Values closer to 0 show variables are appropriately balanced. The standardized mean difference is the difference in the means of the two covariates divided by the standard deviation of the full treated group. Similar to the K-S test, scores closer to 0 are preferred and scores of less than .25 are generally considered balanced. These two tests are preferred over hypothesis tests, such as t-tests, because, first, balance is an in-sample measure and does not refer to any greater super-population from the sample, and, second, hypothesis tests interpret changes in the balance of covariates as changes in statistical power when this is not the case (Stuart 2010).

The first figure shows a 'Love’ plot of variable balances for the ATE and ATT propensity score models for the manufacturing change models. Unfortunately, for the ATE model, two variables (share of manufacturing employment, share of retail employment) do not meet the recommended threshold for proper balance. While these two variables do show improvement in the balance, the fact that they are also relatively important variables in predicting treatment their excessive difference scores require even more caution. The ATT model shows significantly better balance between the variables with no variable exceeding 0.1 mean standardized difference.

The second Love figure shows the industrial model difference scores. Retail and manufacturing share of employment ATE difference scores also exceed 0.25 in this model. 
But the ATT difference scores are all well within the .25 threshold and most are less than 0.1 meaning the variables are well balanced between the groups.

The two 'Love' plots show substantial improvement in variable balance across all models compared to unadjusted scores but the ATE models for both the manufacturing and industrial scores have multiple variables that do not meet the recommended thresholds found in Stuart (2010). For the sake of completeness, I am presenting both the ATE and ATT models, but readers should note that the ATT models are appropriately specified with respect to variable balance between the treated and untreated groups.

\section{$\underline{\text { Results }}$}

Overall, this study finds a null effect on job growth of ILP designation for both industrial and manufacturing jobs between 2009 and 2015. I estimated four models regressing the dummy variable for whether or not the centroid of a tract fell within an ILP against the change in manufacturing or industrial employment. Both the average treatment effect on the treated (ATT) and average treatment effect (ATE) models are included for completeness. Robust standard errors clustered at the city level are also presented.

\begin{tabular}{|c|c|c|c|c|c|}
\hline & \multicolumn{2}{|c|}{ Mfg. ATT } & Mfg. ATE & Ind. ATT & Ind. ATE \\
\hline \multirow[t]{2}{*}{ (Intercept) } & -34.47 & & -8.40 & 176.44 & 12.37 \\
\hline & {$[-139.28$} & 70.35] & {$[-18.69 ; 1.88]$} & {$[-27.81 ; 380.68]$} & {$[-4.82 ; 29.56]$} \\
\hline \multirow[t]{2}{*}{ ilp_dummy } & -6.96 & & 13.65 & 2.90 & 30.58 \\
\hline & {$[-40.12$} & 26.20] & {$[-154.73 ; 182.03]$} & {$[-41.78 ; 47.58]$} & {$[-119.51 ; 180.67]$} \\
\hline R2 & 0.00 & & 0.00 & 0.00 & 0.00 \\
\hline Adj. $\mathrm{R}^{2}$ & -0.00 & & 0.00 & -0.00 & 0.00 \\
\hline Num. obs. & 7908 & & 7908 & 7908 & 7908 \\
\hline RMSE & 42.42 & & 468.42 & 89.56 & 740.16 \\
\hline
\end{tabular}


Table 8: Effect of ILPs on Manufacturing and Industrial Employment Change, 2009-2015

All models returned non-significant results for the protective policy. The nonsignificance remained consistent across other values, including total job change between 2009 and 2015 and manufacturing and industrial job change between 2005 and 2013, as sensitivity analyses.

\section{Conclusion}

Ultimately, the findings of this article question the effectiveness of industrial lands protection policy on protecting manufacturing or industrial jobs. This study combines a novel dataset of industrial preservation policies with the LEHD LODES and Census 2000 to estimate the effect if ILP policy on manufacturing and industrial job growth.

This paper shows the effects, or lack thereof, of a novel set of land-use policies and their connections to local labor market change at the city level. This paper contributes to a growing literature examining the links between land-use policy and labor market change. Although this particular study finds no effect of ILP policies it offers relevant contributions to the literature. First, to aid in the process of collecting LEHD data, a valuable yet unwieldy data source, I have developed an R package, lehdr, to query LODES files across multiple states and years. Second, I applied a gradient boosting model to the problem of propensity score estimation, a novel methodological addition in the planning and economic development literature. Finally, this paper contributes to the growing number of papers employing quasi-experimental methods in planning research. 
The overall null result requires further exploration. One potentially major limitation is the small sample size of the number of treated units. Though the overall sample size is adequate at 7,908 observations there were only 78 treated census tracts. Given the rarity of the treatment it would be difficult to find meaningful effects even with the covariate adjustments provided by the propensity scores.

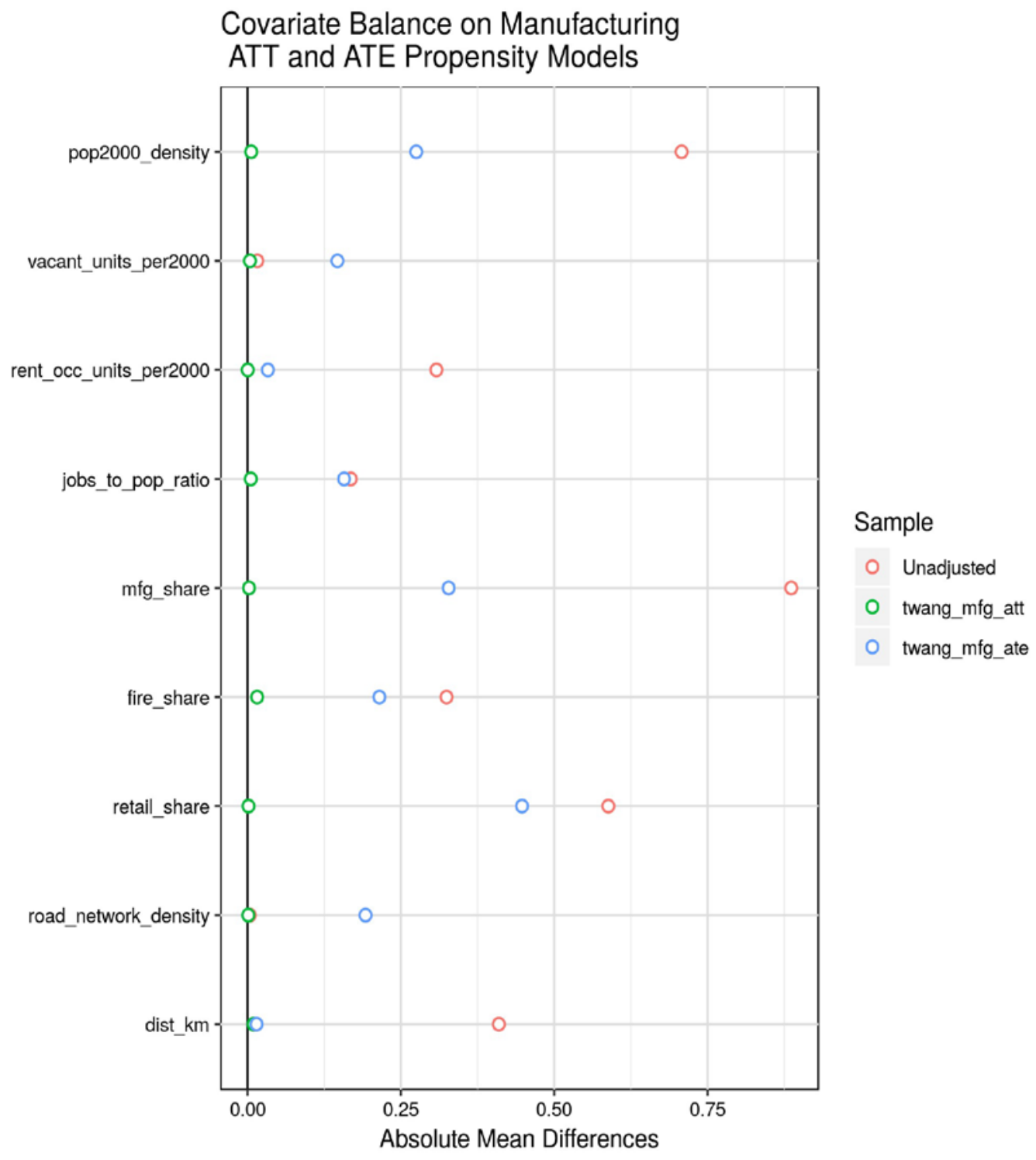

Figure 6: Variable Balance for Manufacturing Models 


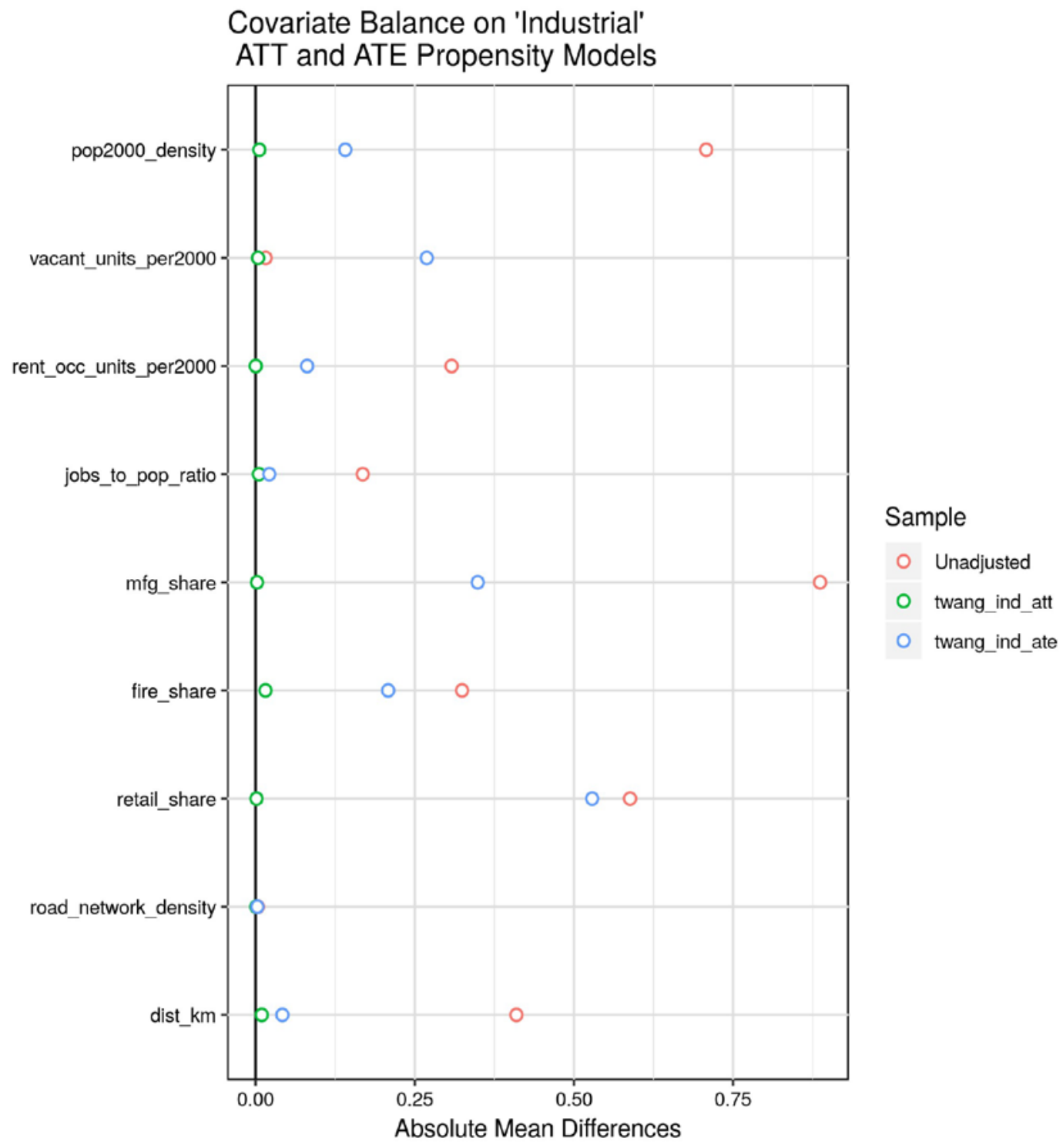

Figure 7: Variable Balance for 'Industrial' Models

Secondly, census tracts are a convenient geography for intra-urban analysis for many issues, but may be an inappropriate geography for local land-use evaluation studies. Census tracts are relatively large geographies within cities that can conceivably cover many distinct types of land-uses. As such, smaller census geographies such as block 
groups may be more appropriate for more accurately capturing more homogeneous, in terms of land-use, units. The lack of certain data provided by the Census Bureau at block group level in addition to a lack of straightforward geographic crosswalks to compare units over time limits the utility of block groups, but these issues can be addressed with the proper attention. Finally, while the LEHD offers unparalleled geographic specificity for employment to the public, being limited to only two-digit NAICS equivalents requires relatively dramatic effects of treatments to be measured. Considering the heterogeneous rise of particular industries such as food processing at the expense of larger industries in primary metals, for instance, real job growth is likely to be washed out using more aggregated units. As such, one next step for this work will be to see if it is possible to gain access to the confidential LEHD files from Census in order to have a better understanding of the range of effects of this policy.

This paper is hardly the final word on the efficacy of these particular policies or hybrid land-use/industrial strategies in urban areas. Given the dual pressures of greater demand for industrial lands and growing urban economic inequality, cities will increasingly consider strategies that marry land-use and labor market priorities. The growth of these policies and strategies offer a rich opportunity for land-use and economic development planning researchers to better reconcile land-use policy and local labor market change. Additionally, results from this paper and similar research should help to inform cities as they move forward with policy experiments to either preserve dwindling industrial land reserves, shore up their local labor markets, or both. 
Supplemental Figures

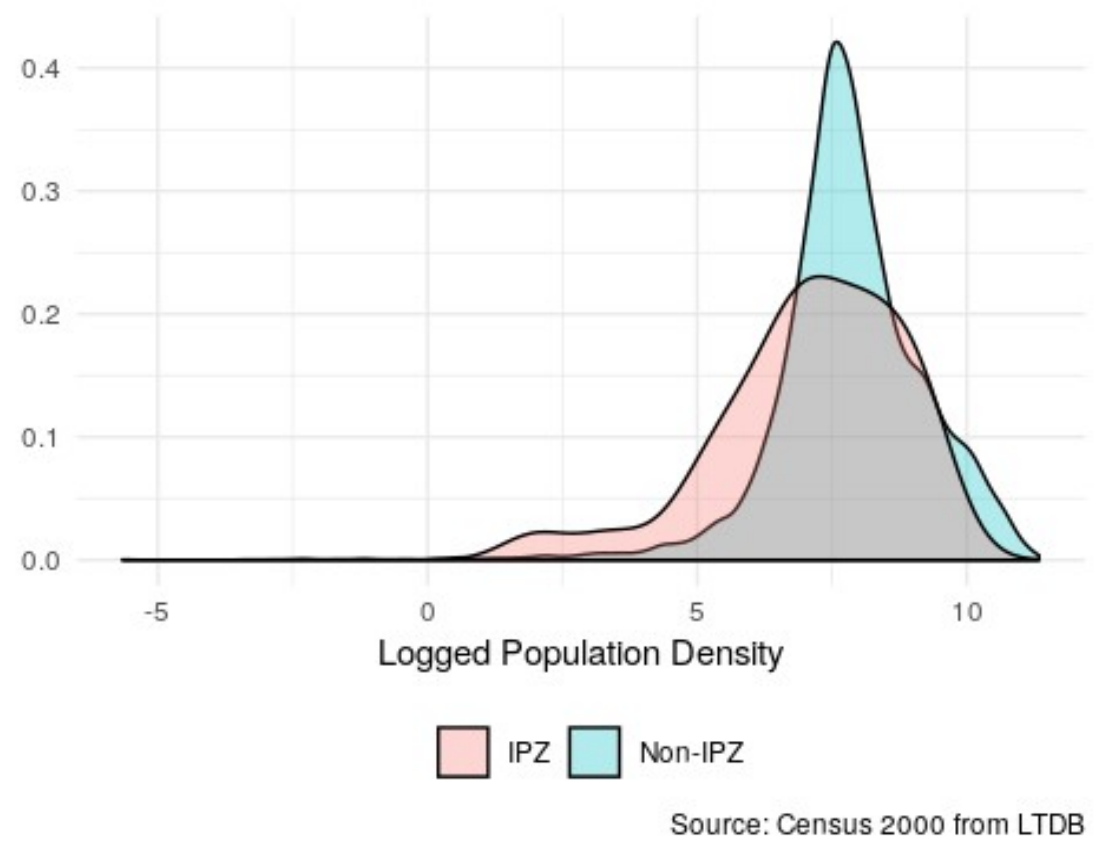

Figure 8: Population Density Distribution

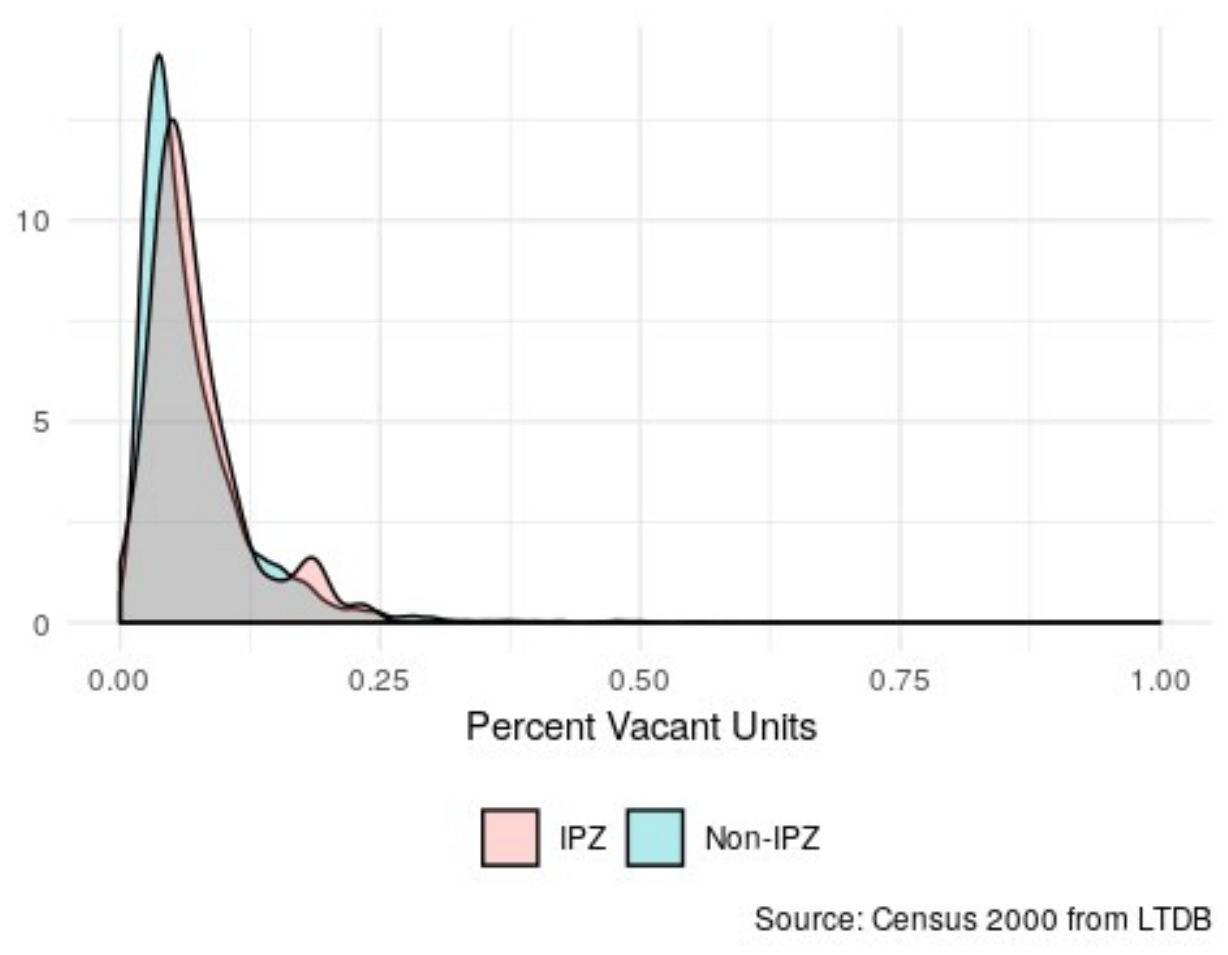

Figure 9: Vacant Units by Protection Policy 


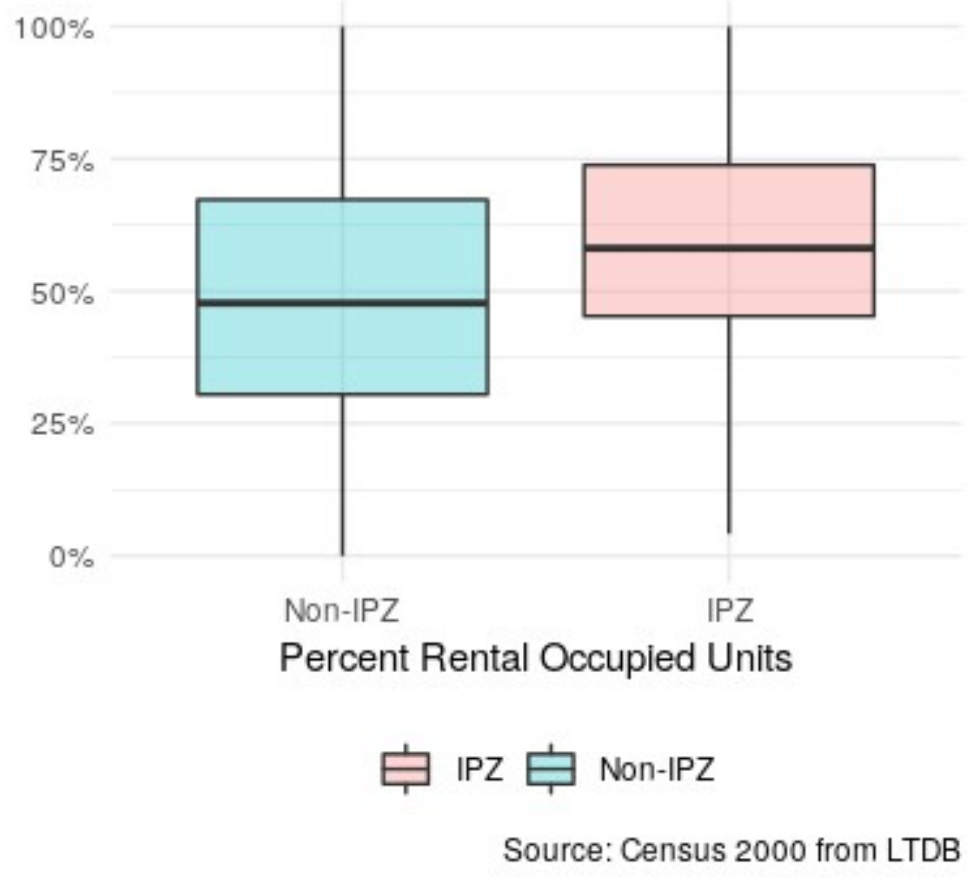

Figure 10: Renter Occupied Units by Protection Policy

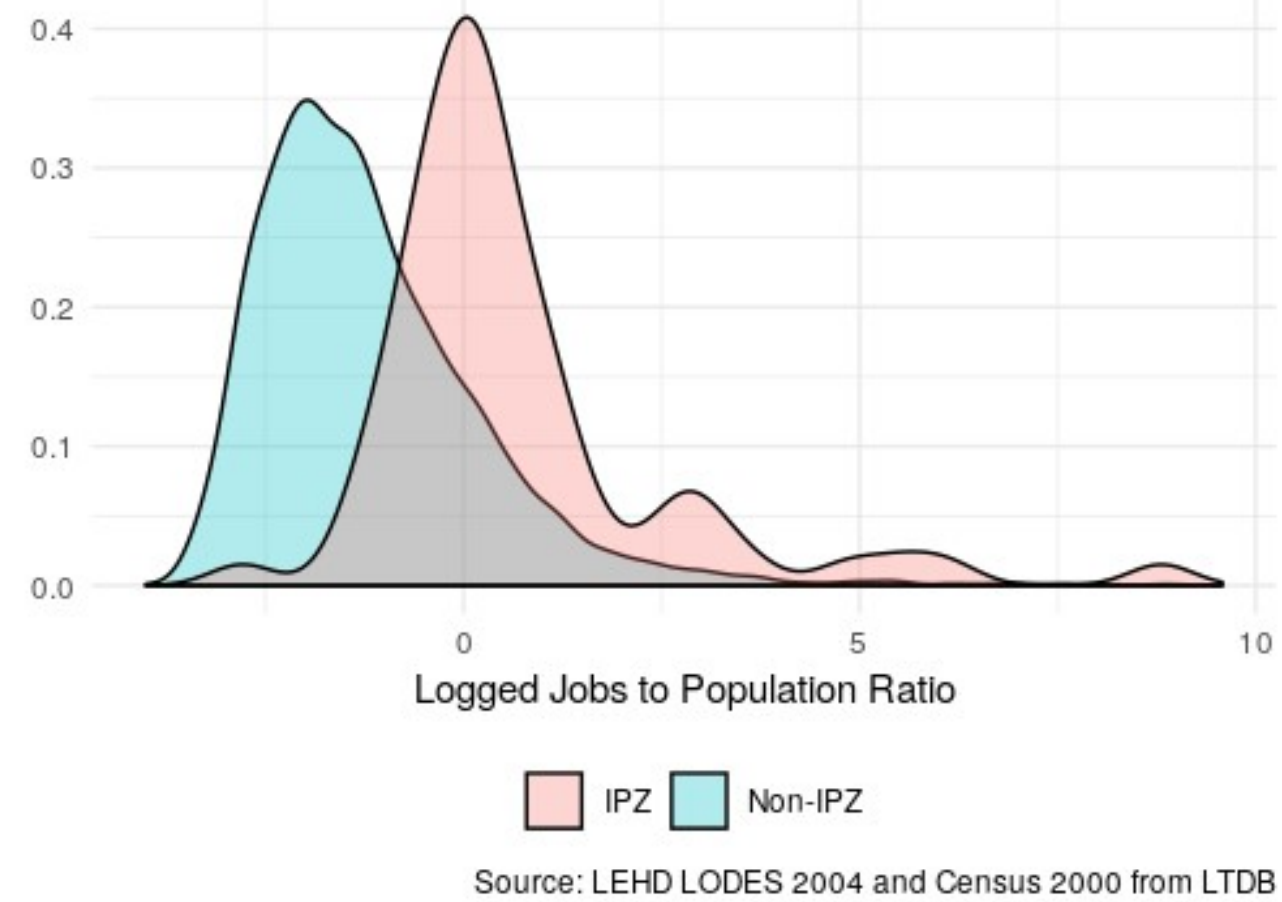

Figure 11: Logged Jobs-to-Population Ration by Protection Policy 


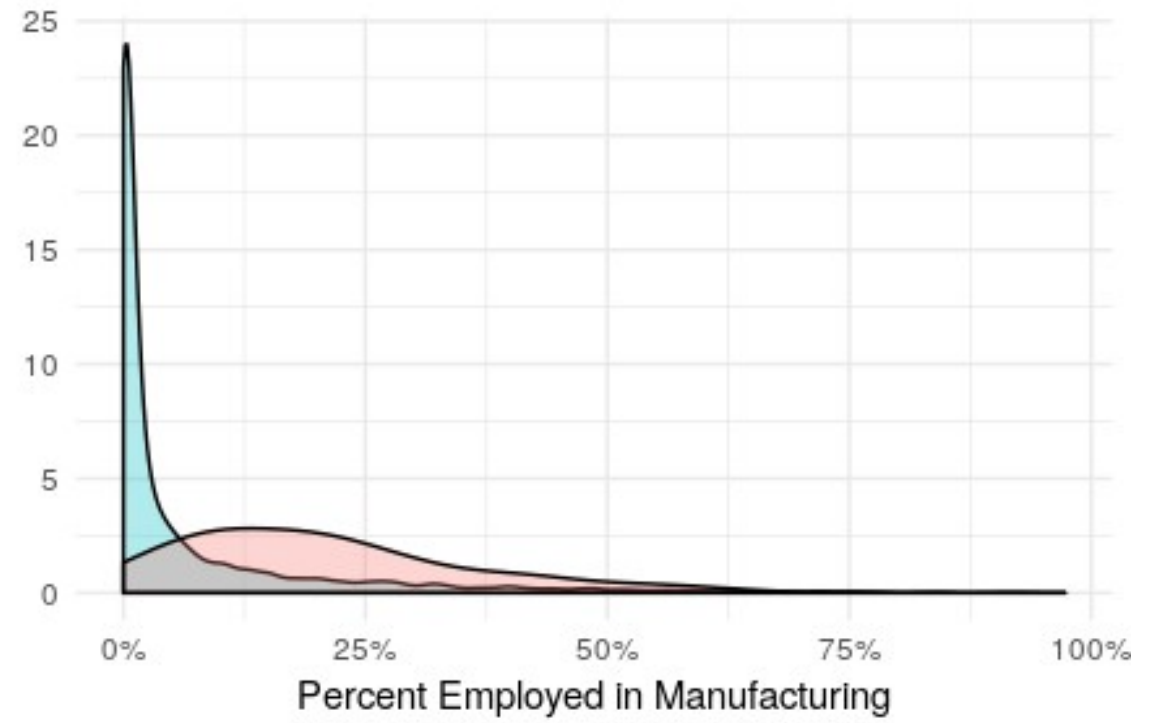

$\square$ IPZ $\square$ Non-IPZ

Source: LEHD LODES 2004

Figure 12: Manufacturing Employment share by Protection Policy

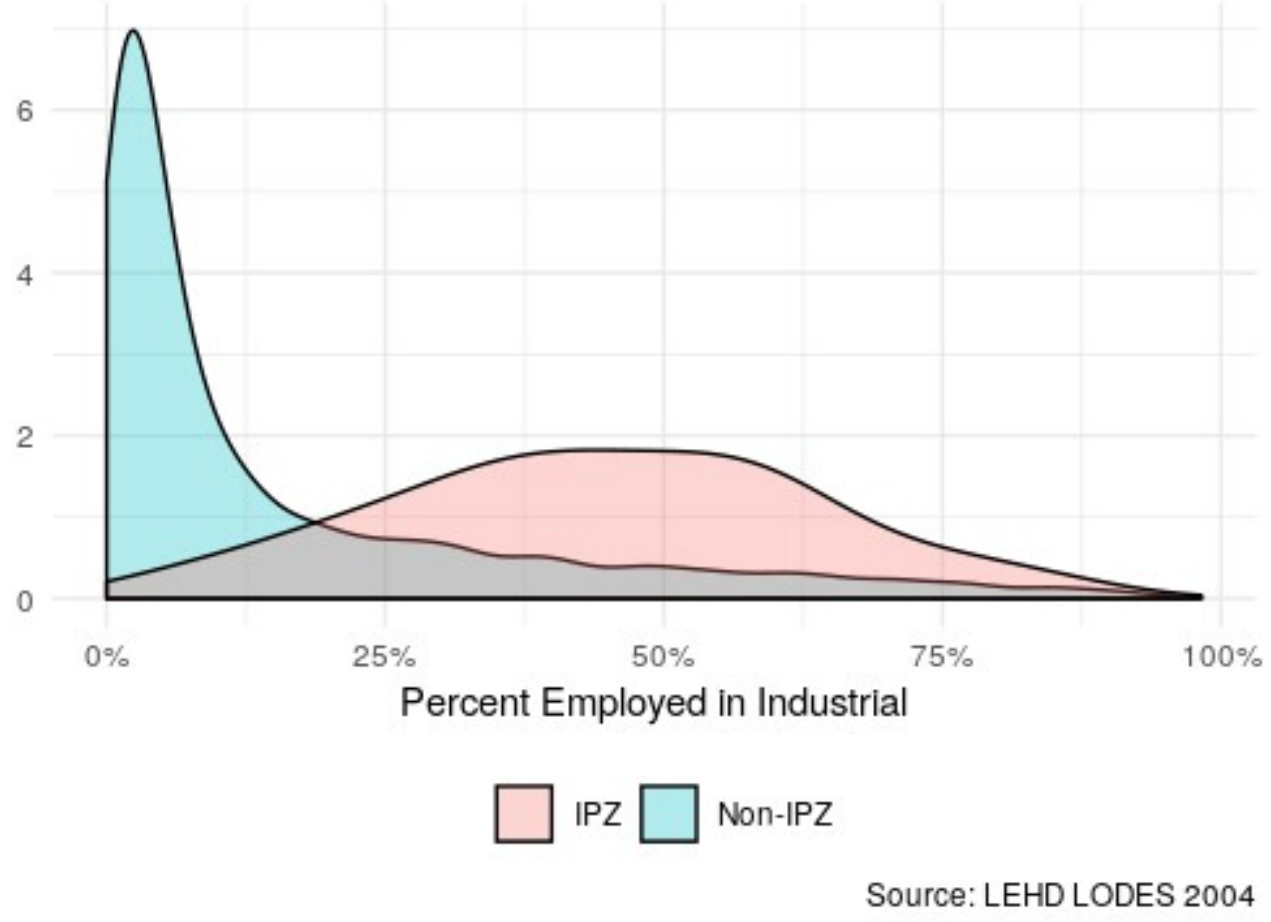

Figure 13: Industrial Employment share by Protection Policy 


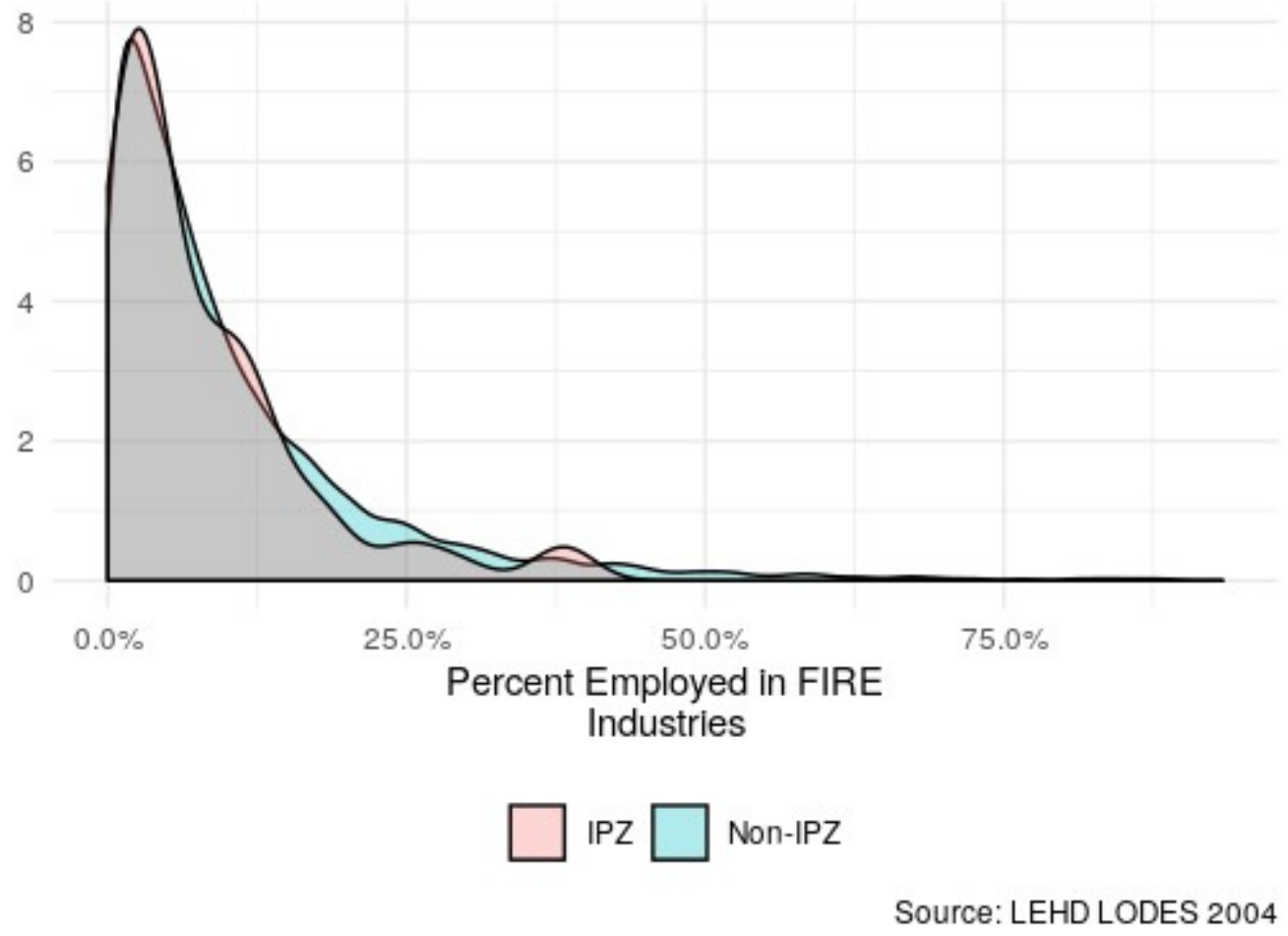

Figure 14: FIRE Employment share by Protection Policy

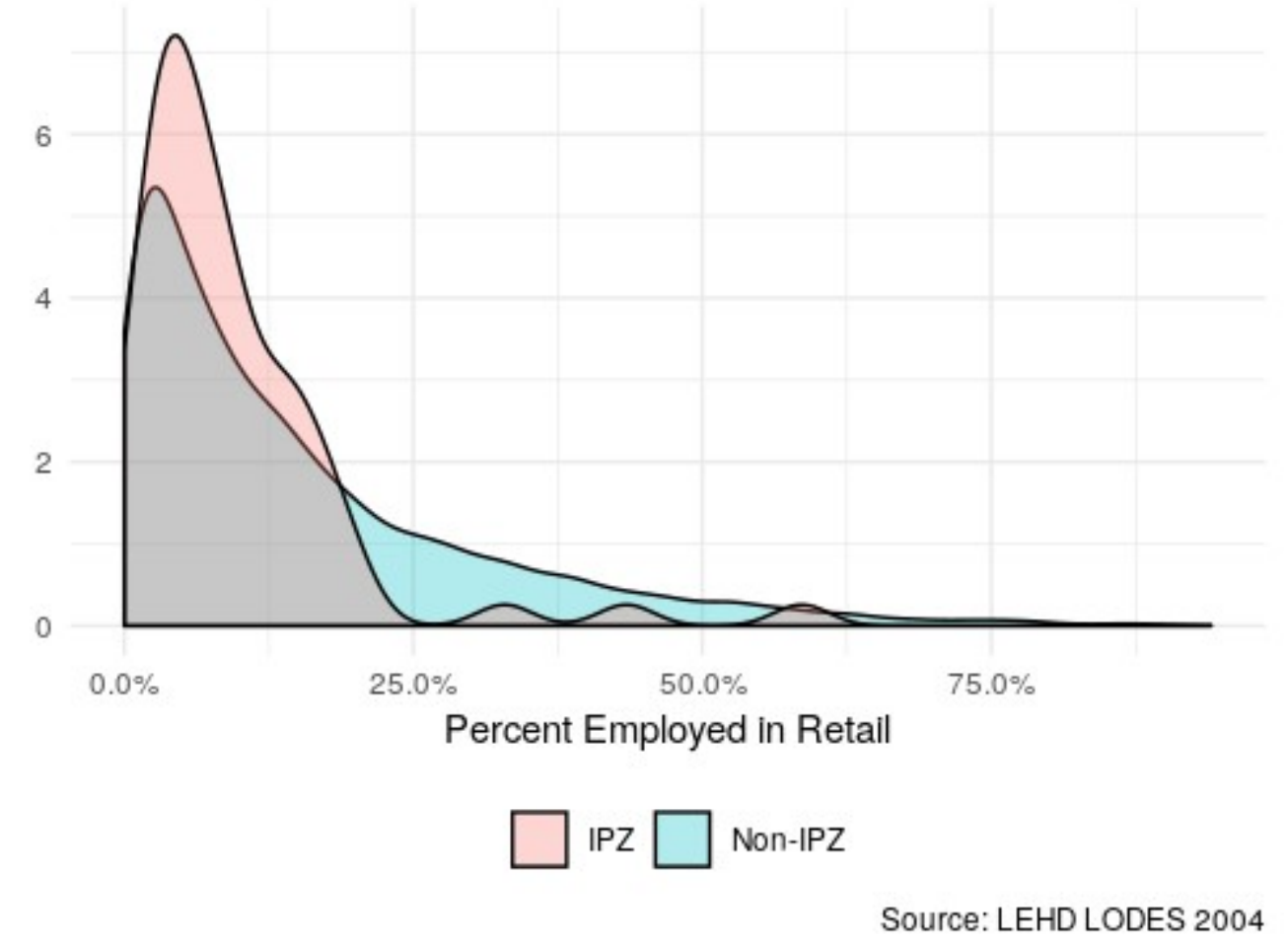

Figure 15: Retail Employment share by Protection Policy 


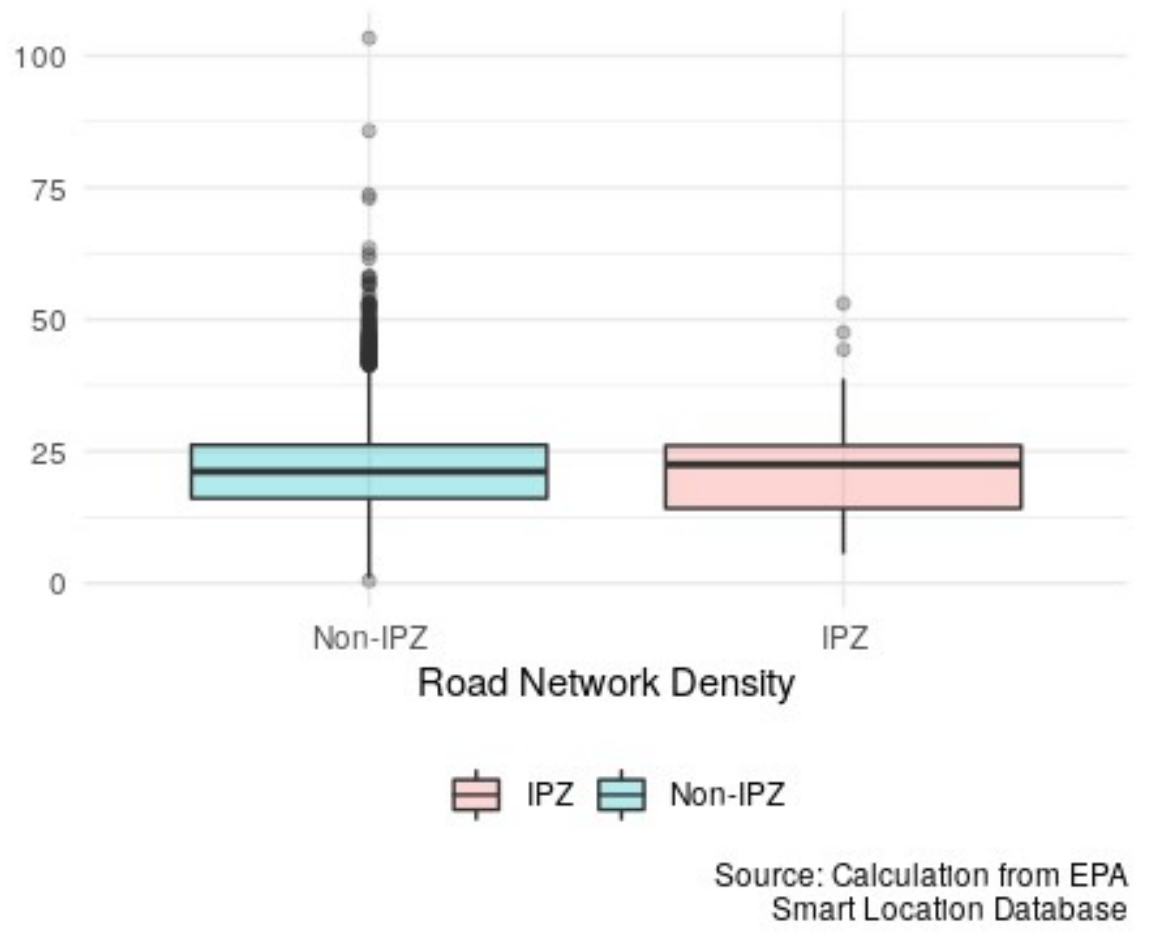

Figure 16: Road Network Density by Protection Policy

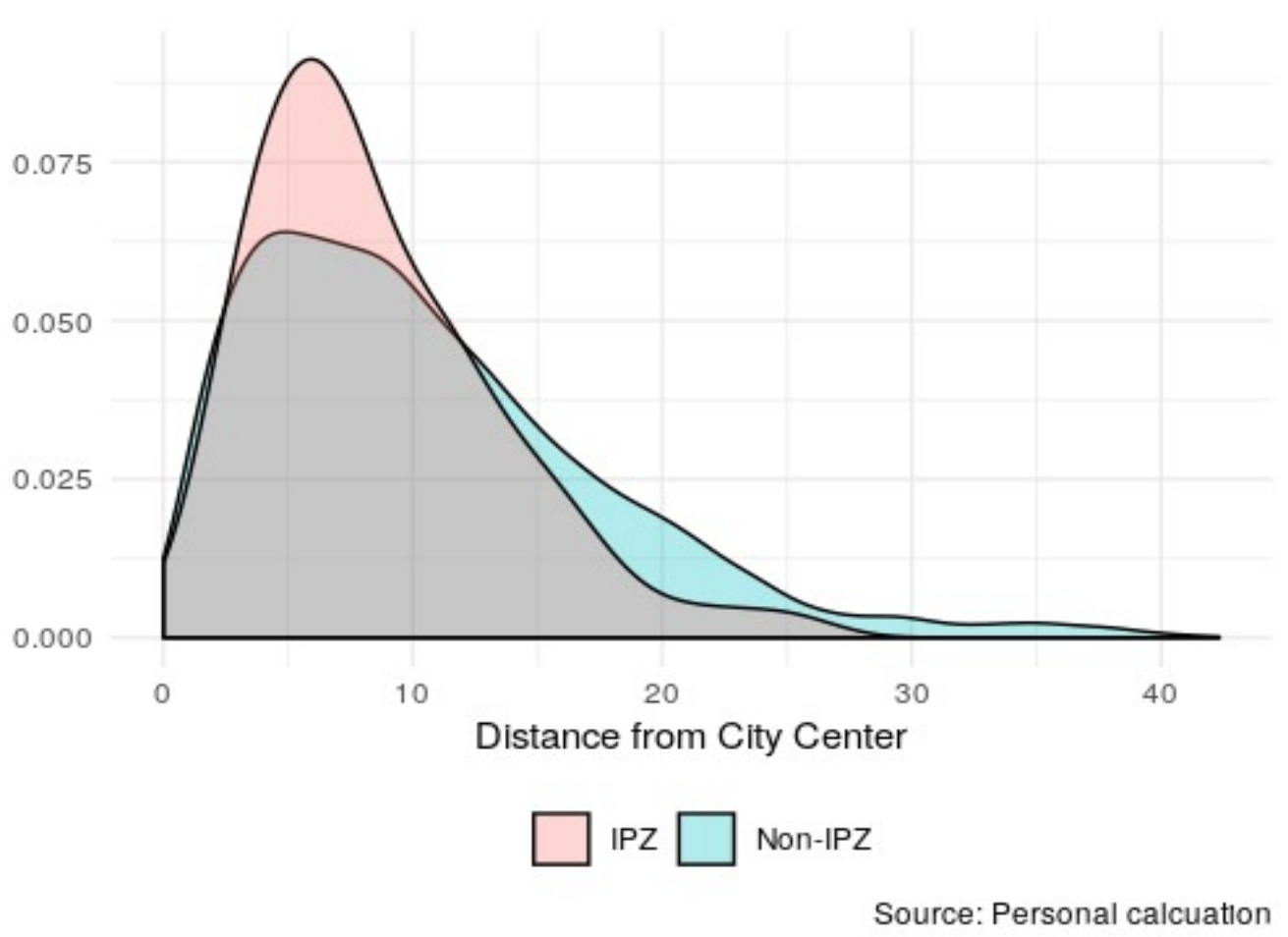

Figure 17: Distance to City Center by Protection Policy 


\section{References}

Austin, Peter C. 2011a. “A Tutorial and Case Study in Propensity Score Analysis: An Application to Estimating the Effect of in-Hospital Smoking Cessation Counseling on Mortality.” Multivariate Behavioral Research 46 (1): 119-51.

doi:10.1080/00273171.2011.540480.

2011b. “An Introduction to Propensity Score Methods for Reducing the Effects of Confounding in Observational Studies.” Multivariate Behavioral Research 46 (3): 399-424. doi:10.1080/00273171.2011.568786.

Berger, Suzanne. 2014. “How Finance Gutted Manufacturing.” Boston Review, April.

Blair, Graeme, Jasper Cooper, Alexander Coppock, Macartan Humphreys, Luke Sonnet, and Neal Fultz. 2018. "Estimatr: Fast Estimators for Design-Based Inference.”

Bluestone, B., and B. Harrison. 1982. The Deindustrialization of America: Plant Closings, Community Abandonment, and the Dismantling of Basic Industry. Basic Books New York.

Byron, Joan, and Nisha Mistry. 2011. “The Federal Role in Supporting Urban Manufacturing.” The Brookings Institution.

http://www.brookings.edu/ /media/Research/Files/Papers/2011/4/urban\%20manufacturi ng\%20mistry\%20byron/

Chapple, Karen. 2014. "The Highest and Best Use? Urban Industrial Land and Job Creation.” Economic Development Quarterly, August, 0891242413517134. doi:10.1177/0891242413517134.

Cohen, Deborah A., Daniela Golinelli, Stephanie Williamson, Amber Sehgal, Terry Marsh, and Thomas L. McKenzie. 2009. "Effects of Park Improvements on Park Use and Physical Activity: Policy and Programming Implications.” American Journal of Preventive Medicine 37 (6): 475-80. doi:10.1016/j.amepre.2009.07.017.

Curran, Winifred. 2004. "Gentrification and the Nature of Work: Exploring the Links in Williamsburg, Brooklyn.” Environment and Planning A 36 (7): 1243-58. doi:10.1068/a36240.

2007. "'From the Frying Pan to the Oven': Gentrification and the Experience of Industrial Displacement in Williamsburg, Brooklyn.” Urban Studies 44 (8): 1427-40. doi:10.1080/00420980701373438.

Environmental Protection Agency. 2013. “EPA Smart Location Database.” Washington DC.

Glaeser, Edward L., and Janet E. Kohlhase. 2003. "Cities, Regions and the Decline of Transport Costs.” Papers in Regional Science 83 (1): 197-228. doi:10.1007/s10110-0030183-X.

Gormley, William T., Deborah Phillips, and Sara Anderson. 2018. “The Effects of Tulsa’s Pre-K Program on Middle School Student Performance.” Journal of Policy Analysis and Management 37 (1): 63-87. doi:10.1002/pam.22023. 
Green, Jamaal. 2018. "Zoning for Jobs- Industrial Land Preservation in the Nation’s Largest Cities.” Open Science Framework, February. doi:10.17605/OSF.IO/UD345.

Hastie, Trevor, Robert Tibshirani, and Jerome Friedman. 2009. The Elements of Statistical Learning: Data Mining, Inference and Prediction. 2nd ed. Springer Series in Statistics. New York, NY: Springer US.

Hills, Roderick M., and David Schleicher. 2010. "The Steep Costs of Using Noncumulative Zoning to Preserve Land for Urban Manufacturing.” The University of Chicago Law Review 77 (1): 249-73. doi:10.2307/40663033.

Leigh, Nancey Green, and Nathanael Z. Hoelzel. 2012. "Smart Growth’s Blind Side: Sustainable Cities Need Productive Urban Industrial Land.” Journal of the American Planning Association 78 (1): 87-103. doi:10.1080/01944363.2011.645274.

Lester, T. Wiliiam, and Daniel Hartley. 2013. "Working Paper, FRB: The Long-Term Employment Impacts of Gentrification in the 1990s." Http://Www.clevelandfed.org/Research/Workpaper/2013/Wp1307.pdf. http://www.clevelandfed.org/research/research_publication.cfmid=35.

Lester, T. William, and Daniel A. Hartley. 2014. "The Long Term Employment Impacts of Gentrification in the 1990s.” Regional Science and Urban Economics 45 (March): 8089. doi:10.1016/j.regsciurbeco.2014.01.003.

Logan, J. R, Zengwang Xu, and Brian J. Stults. 2014. "Interpolating U.S. Decennial Census Tract Data from as Early as 1970 to 2010: A Longitudinal Tract Database.” The Professional Geographer 66 (3): 412-20.

Louw, Erik, Erwin van der Krabben, and Hans van Amsterdam. 2012. "The Spatial Productivity of Industrial Land.” Regional Studies 46 (1): 137-47. doi:10.1080/00343404.2010.530250.

McCaffrey, Daniel F., Greg Ridgeway, and Andrew R. Morral. 2004. "Propensity Score Estimation with Boosted Regression for Evaluating Causal Effects in Observational Studies.” Psychological Methods 9 (4): 403-25. doi:10.1037/1082-989X.9.4.403.

Mccann, Philip, and Stephen Sheppard. 2003. "The Rise, Fall and Rise Again of Industrial Location Theory.” Regional Studies 37 (6-7): 649-63.

doi:10.1080/0034340032000108741.

R Core Team. 2017. "R: A Language and Environment for Statistical Computing." Vienna, Austria: R Foundation for Statistical Computing.

Ridgeway, Greg, Dan McCaffrey, Andrew R. Morral, Beth Ann Griffin, and Lane Burgette. 2017. "Twang: Toolkit for Weighting and Analysis of Nonequivalent Groups."

Rosenbaum, Paul R., and Donald B. Rubin. 1983. "The Central Role of the Propensity Score in Observational Studies for Causal Effects.” Biometrika 70 (1): 41-55. doi:10.1093/biomet/70.1.41.

Stuart, Elizabeth A. 2010. "Matching Methods for Causal Inference: A Review and a Look Forward.” Statistical Science 25 (1): 1-21. doi:10.1214/09-STS313. 
Sutton, Stacey A. 2014. "Are BIDs Good for Business? The Impact of BIDs on Neighborhood Retailers in New York City.” Journal of Planning Education and Research 34 (3): 309-24. doi:10.1177/0739456X14539015.

Van Winden, Willem, Leo Van den Berg, Luis Carvalho, and Erwin Van Tuijl. 2010. Manufacturing in the New Urban Economy. Vol. 42. Taylor \& Francis US.

Weaver, Andrew, and Paul Osterman. 2016. "Skill Demands and Mismatch in U.S. Manufacturing.” ILR Review, July, 0019793916660067. doi:10.1177/0019793916660067. 


\section{Conclusion}

Large cities in the US wrestling with population growth pressures and rising social inequality are experimenting with a variety of policies to address these urgent issues. A handful of these cities have turned to industrial land preservation as one policy to combat income inequality and to protect scarce industrial resources. The three essays in this dissertation explore different attributes of these new policies.

Though industrial land planning is a growing concern in the planning and economic development literature many gaps remain. First, while recent a guide from the American Planning Association (Leigh et al. 2014) offers some examples of protective policies and codes, and researchers have highlighted individual city battles over industrial land (Rast 2001; Curran and Hanson 2005), until now there has not been a wider review of city policies concerning industrial land protection. More critical scholars have highlighted the critical role of planner perception to questions of redevelopment (Wolf-Powers 2005). Specifically, scholars highlight the importance of planner visions of the future in shaping their present decisions. For the case of industrial land and industrial neighborhoods, a generalized pessimism regarding the viability of industrial work long term and a desire to transform cities in more sustainable ways encourage planners to convert industrial districts even if they are healthy. But, to date, there has not been a study that asked planners directly how they view industrial land in their cities and the politics surrounding industrial land conversion. Finally, there is a growing body of quantitative modeling work that is estimating the business impact of industrial lands (Chapple 2014) as well as the local jobs impact of local land use redevelopment (Lester and Hartley 2014). These studies offer 
compelling evidence that industrial land is important for greater regional business dynamics and that the conversion of industrial lands causes local job quality to fall even in the face of overall greater job growth. But these studies do not address questions regarding industrial land preservations effectiveness as a policy.

These three gaps- a lack of a more comprehensive review of industrial land preservation policy; a greater examination of planner perception regarding industrial land use in cities; and an evaluation of the effectiveness of industrial land preservation policies- are what the essays in this dissertation are meant to answer.

In order to address the first gap I reviewed the zoning codes and comprehensive plans of the 50 largest cities in the US to identify places that are actually engaged in protecting industrial land and to map out features of their respective policies. I identified eleven cities that are protecting their industrial land. These cities are geographically diverse and most cities have passed protective policies in the past 15 years. Portland, Chicago and Boston are exceptions here with their policies being passed in the late 80s/early 90s and late 1970s, respectively.

Cities use a variety of strategies and policies to protect their industrial lands. Aside from simply imposing more stringent use requirements through zoning cities also require a variety of impact statements and performance reports. San Diego, for example, requires rezoning applications for Prime Industrial Lands to offer jobs impact statements similar to environmental or traffic impact statements in other areas. For cities with strong comprehensive planning, proposed industrial land conversions trigger a comprehensive plan amendment process. This process requires a generally higher level of review to the 
planning commission or city council, as a whole, and is indicative of a kind of institutional scale jumping strategy cities use to deter industrial land conversion. Such scale jumping ranges from getting the requirements of the city council, or Mayor's office in New York, to confirmation from the state port administration in Maryland.

In my second essay I presented the results of a survey of planners responsible for industrial land development decisions. Respondents reported that their cities generally found industrial land an important issue and were planning for it. Respondents generally felt their cities' current supply of industrial land was sufficient for the medium to long term, but planners in cities with industrial land protective policies nearly all reported immediate industrial land shortages. On the question of more general industrial work, though, respondents exhibited a more pessimistic view of the viability of industrial work going into the future. Politically, respondents reported that planners in their departments receive political pressure to convert industrial lands and that there are a minority of areas with strong community groups advocating for the protection of industrial lands. The survey highlights the overlapping dilemmas and contradictions planners face in trying to do their work regarding industrial land. These dilemmas include both external pressures, such as political pressure to convert and greater urban economic restructuring, and internal pressures, such as institutional fragmentation that separates economic development and land use planning and planners own perceptions regarding a desirable future labor market.

Finally, the third essay attempts to answer the ultimate question of whether industrial land protective policies work. In order to do so I estimate a propensity score weighted model on the change in manufacturing and greater "industrial" jobs between 2009 and 2015 at the 
census tract level for the 45 largest cities in the US. In the process of answering that question I also explored general trends in urban manufacturing and industrial employment from 2004 to 2015. I found that urban manufacturing and industrial employment is still an important component of employment in many cities, though it is decreasing in most, and that the primary contributor to the decline in overall industrial employment is the massive job losses in manufacturing. Excluding manufacturing, though, industrial jobs have grown or remained constant in most cities. My propensity score estimation ultimately returned a null result of these policies on changes in manufacturing or industrial job growth. It is very possible that these policies have not had a measurable effect on job change in affected census tracts in the time period I measured, but I suspect the smaller sample size of affected tracts (only 78 tracts qualified as protected) and the variation within protective policies are major drivers of the null result. Additional study here with more granular data could provide the necessary statistical power to get a reliable estimate.

In addition to the substantive gaps outlined above this dissertation also offers some novel methodological contributions to the planning and economic development literature. While quasi-experimental methods, such as propensity score modeling or difference-in-difference equations, are more common in planning research, to date, I am not aware of researchers using an ensemble machine learning method in the estimation of propensity scores. The use of machine learning techniques is growing in program evaluation (Abadie and Cattaneo 2018) and this dissertation gives one example of the application such methods to planning policy concerns. Additionally, in order to build out the model I had to create a way to download LEHD LODES files for multiple states across multiple years in a straightforward fashion. The result is the lehdr package, an R package designed to download LODES flat 
files. The package can download multiple states and years of LODES data simultaneously and also can aggregate lodes data for all Census geographies in its standard geographic hierarchy (from blocks to state). The package is already in use in a handful of planning, geography and engineering departments across the country for research and methodological courses that make use of LODES data. I have plans to further refine the package with my co-authors, Professors Liming Wang and Dillon Mahmoudi, and submit it to CRAN to make it an official R package. A major barrier to the use of LODES data in urban research has been the difficulty in collecting and organizing the data. This package fills an essential research gap and with the LODES data getting updated data starting the summer of 2019 my package can be an essential part of LODES data research moving forward.

Ultimately, I found a null effect of these protective policies on job change in one of my chapters, but I still believe there may be a place for such policies in our cities. As I covered in the introduction, the hollowing out of middle skill jobs in the labor market leaves cityregions with a diminished tool set for combating income and social inequality. This is doubly the case in cities with hostile state governments that actively work to further constrain the policy options of urban areas. Absent the ability to directly regulate the labor market city-regions must look towards workforce development and, the focus of this dissertation, industrial policy. Industrial land preservation is only one small policy that should be part of a greater suite of industrial retention policies for industrial users including worker training support, capital upgrading and innovative small business financing options. One area cities and city-regions can work on directly, though, is workforce development and training. Specifically, city-regions should make better use of their local training 
institutions, particularly community colleges, to upgrade the skills of workers. Making community college free or much less expensive, expanding class options to evenings and weekends and offering services like free childcare would all make community college more accessible to workers as well as more competitive when compared against expensive forprofit college options. Linking improved community college offerings with industrial partnerships for industrial users can help guarantee a consistent supply of trained workers for what are good jobs. A combination of these workforce, land use and small business support policies can help make our cities hospitable for industrial users and workers.

Beyond the main results of these essays, multiple avenues for additional research are evident. In particular, my second essay, in trying to garner a greater understanding of practicing planners' perceptions regarding industrial land management brings up greater questions regarding political pressure planners receive on land issues and institutional fissures. The traditional schism between economic development and land-use planning requires further exploration in terms of overall planning processes and, more importantly, implementation and evaluation challenges. Industrial land management, in particular, poses a unique concern because the strategy rests easily in both economic development and land-use policy terrains. As such, there is plenty of opportunity for misunderstanding or conflicting strategies, but also, the complementary nature of industrial land management offers a logical bridge between economic development land-use policy. These contradictions can potentially be managed through comprehensive planning processes that should require true integration across these areas, but evidence from my second essay shows that there still may be contradictions or tensions between how planners perceive 
what their cities are doing and what the plans actually say. Exploring these tensions would add a much richer understanding of practice that is sorely needed in planning research.

One additional area of research concerns greater theoretical questions concerning urban form, economic growth and labor market change. Studies of "post-industrial" cities often assume a form of generalized de-industrialization and frames the conversion of industrial lands as a response to exogenous losses in employment. Additionally, such studies add a normative bent to such conclusions by framing industrial work as either outdated/obsolete or, more recently, environmentally unsustainable. This frame ignores the real empirical evidence that industrial work is still present in many cities, makes up a non-trivial proportion of employment and, finally, is actually growing largely due to the same technological and consumption changes that characterize the "post-industrial". The rise of e-commerce, in particular, has inverted the industrial location strategies of logistical companies. No longer are central hubs connected by airports necessary to be most competitive, but centrally located distribution facilities that minimize distance and time to delivery are now in high demand. These kinds of technological changes that many assume would obliterate the importance of proximity and agglomeration have actually reinforced the importance of proximity and urbanity. In light of this, the way we theorize the evolution of the urban form of cities and the attendant labor market transformations should be updated. We cannot blithely assume that technological advancement will naturally lead to decentralization and planners, geographers and economists should revisit industrial location theories in light of the durability of firms and uses in ostensibly "post-industrial" places. In this sense, cities may still be going through varied of stages of deindustrialization, but they are hardly “post” industrial. 


\section{References}

Abadie, Alberto, and Matias D. Cattaneo. 2018. "Econometric Methods for Program Evaluation.” Annual Review of Economics 10 (1): 465-503. doi:10.1146/annureveconomics-080217-053402.

Chapple, Karen. 2014. "The Highest and Best Use? Urban Industrial Land and Job Creation.” Economic Development Quarterly, August, 0891242413517134. doi:10.1177/0891242413517134.

Curran, Winifred, and Susan Hanson. 2005. "Getting Globalized: Urban Policy and Industrial Displacement in Williamsburg, Brooklyn.” Urban Geography 26 (6): 461-82. doi:10.2747/0272-3638.26.6.461.

Leigh, Nancey, Nathanael Z. Hoelzel, Benjamin Kraft, and C. Scott Dempwolf. 2014. Sustainable Urban Industrial Development. Planning Advisory Service 577. APA Planning Advisory Service.

Lester, T. William, and Daniel A. Hartley. 2014. "The Long Term Employment Impacts of Gentrification in the 1990s.” Regional Science and Urban Economics 45 (March): 8089. doi:10.1016/j.regsciurbeco.2014.01.003.

Rast, Joel. 2001. "Manufacturing Industrial Decline: The Politics of Economic Change in Chicago, 19551998.” Journal of Urban Affairs 23 (2): 175-90. doi:10.1111/07352166.00082.

Wolf-Powers, Laura. 2005. “Up-Zoning New York City’s Mixed-Use Neighborhoods Property-Led Economic Development and the Anatomy of a Planning Dilemma.” Journal of Planning Education and Research 24 (4): 379-93. doi:10.1177/0739456X04270125. 